\title{
A Novel Ruthenium-Fluvastatin Complex Downregulates SNCG Expression to Modulate Breast Carcinoma Cell Proliferation and Apoptosis via Activating the PI3K/Akt/mTOR/VEGF/MMP9 Pathway
}

\author{
Wei Liang $\mathbb{D}$, Junfeng Shi $\mathbb{D}$, Haiyan Xia $\mathbb{D}$, and Xiaowei Wei \\ Department of Oncology, Nanjing First Hospital Nanjing Medical University, Nanjing 210006, China \\ Correspondence should be addressed to Xiaowei Wei; gswxw@njmu.edu.cn
}

Received 19 February 2021; Revised 16 April 2021; Accepted 7 May 2021; Published 7 June 2021

Academic Editor: Peeter Karihtala

Copyright (C) 2021 Wei Liang et al. This is an open access article distributed under the Creative Commons Attribution License, which permits unrestricted use, distribution, and reproduction in any medium, provided the original work is properly cited.

\begin{abstract}
Breast cancer is the most common cause of malignancy and cancer-related morbidity and death worldwide that requests effective and safe chemotherapy. Evaluation of metallodrug-based anticancer agents and statins as chemotherapeutics with fewer side effects is a largely unexplored research field. Synthesis and characterization of the ruthenium-fluvastatin complex were achieved using multiple spectroscopic techniques and thus further examined to evaluate its chemotherapeutic prospects in both MDA-MB-231 and MCF-7 cancer lines and eventually in vivo models of DMBA-induced mammary carcinogenesis in rodents. Our studies indicate that the metal and ligand chelation was materialized by the ligand's functional groups of carbonyl $(=\mathrm{O})$ oxygen and hydroxyl $(-\mathrm{OH})$, and the complex has been observed to be crystalline and able to chelate with CT-DNA. The complex was able to reduce cell proliferation and activate apoptotic events in breast carcinoma cell lines MCF-7 and MDA-MB-231. In addition, the complex was able to modify p53 expressions to interfere with apoptosis in the carcinoma of the breast, stimulated by the intrinsic apoptotic path assisted by Bcl2 and Bax in vivo, yet at the same point, controlling the PI3K/Akt/mTOR/VEGF pathway, as obtained from western blotting, correlates with the MMP9-regulated tumor mechanisms. Our research reveals that ruthenium-fluvastatin chemotherapy may disrupt, rescind, or interrupt breast carcinoma progression by modifying intrinsic apoptosis as well as the antiangiogenic cascade, thereby taking the role of a potential candidate in cancer therapy for the immediate future.
\end{abstract}

\section{Introduction}

Breast cancer in women is the most recurrent cancer in any of the five continents diagnosed worldwide, with an approximate 2.1 million new cases in 2018 [1]. The incidence of breast cancer in the Asian countries is still underneath as compared to that in Europe or America, but Asia's contribution in the worldwide burden of breast cancer is speedily escalating as a result of expressed economic growth and urbanization [2]. The situation in China has been worrying partly because of its fast population growth and socioeconomic progress. As a densely populated country, China accounts for one-fourth of total cancer-related death, and there has been an increasing incidence in cancer prevalence, mortality rate, and emergence among young people [3]. Breast cancer has often been diagnosed as an invasive malignant tumor without curable therapy [4]. Regretfully, the molecular mechanistic pathway underlying breast cancer is still unclear. Hence, a good understanding of the genetic underpinnings of breast cancer has great importance, and the alteration from researchers for further in-depth study was sought.

Current treatment strategies have limitations which lead to clinical resistance and morbidity associated with therapy owing to their adverse effects and limited efficacy on tumors. Novel molecules are therefore urgently required to combat emerging cases of breast cancer with less adverse effects, reduced tumor recurrence, and reduced mortality. An 
interesting approach called drug repurposing in the one hand and drug combination approach in another hand to tackle this problem are progressively being investigated and applied $[5,6]$. By addressing the significance, the global market for drug repurposing almost touched nearly 20.7 billion euro in 2015 and is expected to reach 26.6 billion euro by 2020 [7]. Because of benefits such as reduced toxicity, improved effectiveness, reduced dose at an equivalent or enhanced level of effectiveness, and counter drug resistance, drug combination represents an impressive and progressively used approach which has become a standard for treating cancer [6]. Particularly in cancer, various clinical trials are conducted with a crescent focus on the combination of cytotoxic drugs [8]. The combination of repurposed pharmaceutical agents with other chemotherapeutic agents continues to show impressive outcomes which are beneficial when traditional monotherapy for cancer patients has failed to provide safe and tolerable treatment [9]. To overcome these challenges, our work is oriented towards investigating the effect of drugs like statins that can be repurposed for breast cancer therapy, in combination with chemotherapeutic transition metal like ruthenium.

Statins elicit several effects beyond their lipid-reducing roles defined as the pleiotropic effects [10] often caused by blocking the prenylation of a multitude of intracellular signaling proteins, thus affecting the development of cancer among statin users [11-15]. Statin has been delineated to be associated with a reduced rate of cancer progression and cancer-associated mortality $[16,17]$ from gastrointestinal carcinoma [18], breast carcinoma [19], hepatocellular carcinoma [20], prostate cancer [21], lung adenocarcinoma [22], and pancreatic carcinoma [23]. Fluvastatin is one of the members of the statin family, broadly used as a lipid lowering agent. In addition to its cholesterol-reducing activities, fluvastatin exhibited the anticancer activities by inducing apoptosis in glioma, breast, and hepatocellular carcinoma cell lines [24-26]. Notably, fluvastatin was shown to have a chemoadjuvant effect on experimental pancreatic cancer [27].

Along with platinum-based cancer drugs, several efforts have been made to design compounds based on ruthenium, since these compounds have been reported to have a lower number of side effects due to their alternate modes of action [28]. Ruthenium complexes have in many cases exhibited strong cytotoxicity against platinum-resistant tumor cell lines, rendering them as exemplary targets for further investigation [29, 30]. It may be acknowledged that many ruthenium-containing compounds including RAPTA-C [31], NAMI-A, and KP1019 [32] have officially managed to reach clinical trials for diverse therapeutic carcinoma management.

Despite advancement in the treatment, the high recurrence rate of metastasis is associated with poor prognosis of endocrine-related cancer [33]. Thus, a better understanding of the molecular mechanism underlying breast cancer proliferation and metastasis is necessary to identify the potential target for effective therapy. Synucleins are ubiquitously expressed in neuronal cells and abundantly present in presynaptic terminals and have also been involved in nonneural diseases, especially hormone-responsive breast cancers [34]. Numerous reports have also suggested that SNCG is not expressed in normal and benign breast tissues but expressed abnormally in a high percentage of advanced and metastatic cancer [35] and stimulates hormone-dependent growth of breast cancer cells both in vitro and in nude mice [36]. Research aimed at elucidating the molecular mechanism that triggers the oncogenic function of this protein reported that SNCG expression in the breast cancer cells has developed a more malignant phenotype with increased motility of the cells [34], intensified the activity of transcriptional factor of $\mathrm{ER} \alpha$ [36], enhanced resistance to antimicrotubular drugs, and expedited the microsomal instability [37]. Cumulative results indicate that SNCG is a novel unfavorable prognostic marker for the development of breast cancer and a possible target for the treatment of breast carcinoma. On the basis of this data, the current research uses molecular docking, a widely used bioinformatics technique to evaluate how the molecule of ruthenium-fluvastatin binds and interacts with the SNCG target proteins. These in silico methodologies aid towards classifying drug targets through computer-assisted designing that helps to (i) envision specific active sites for evaluating target structures, (ii) produce potential molecules that identify the target, (iii) determine their comparative receptor binding affinities, and (iv) modify molecules to optimize binding abilities [38]. AutoDock is one of the many software programs that consists of a series of automatic docking techniques developed to evaluate how molecules attach to a particular targeted protein with a preordained arrangement [39]. Therefore, our objective is to establish the optimum binding energies of the docked molecules and also to determine the ligand's binding position at the protein binding domain.

A combination of cell proliferation and apoptosis regulates the development of normal breast tissues. Conclusive evidence states that development of cancer is not only a manifestation of unregulated proliferative status along with impaired apoptosis [40, 41]. In the context of breast cancer, the $\mathrm{Bcl} 2$ gene and the tumor suppressor like p53 genes are extensively researched $[42,43]$. Bax and $\mathrm{Bcl} 2$ are indeed the key proapoptotic modulators which could additionally improve the PI3K/AKT-related cascade and other pathways related to cell survival and death [44]. Furthermore, natural agents may also affect cell migration and invasion of tumor cells by modulating the matrix metalloproteinases (MMPs). Between others, MMP9 is of particular interest, as patients with increased MMP9 expression have been identified to end up with poorer diagnosis [45]. In addition, breast cancer development includes genetic variations of $\mathrm{p} 53$, modified by the angiogenic pathway (VEGF) and mTOR-related signaling pathway, and proapoptotic protein such as Bax correlated with the increased formation of antiapoptotic protein $\mathrm{Bcl} 2$ and proliferating cell nuclear antigen (PCNA) [46, 47].

7,12-Dimethylbenz $(\alpha)$ anthracene may be the most harmful polyaromatic hydrocarbon with the widest environmental application [48]. DMBA metabolizes and produces various reactive metabolic intermediates during the carcinogenic cycle, by which stable formation of DNA adducts which are genotoxic and mutagenic initializes carcinogenic events, close to those in humans [49]. The oxidative imbalance influences different types of proteins and genes that 
modify multiple signaling cascades such as angiogenic process, apoptotic events, cell formation, repairing of DNA, proliferative events, and invasion [50, 51].

Taking all of it into account, we hypothesized and investigated by well-designed experiments in this current study that ruthenium-fluvastatin could interact with cellular proliferation and induce cell apoptosis by modulating the apoptotic regulators and downstream events such as caspase cascade thus inhibiting the invading and migrating properties of cancer cells. Chemotherapeutic actions in the breast cancer paradigm and the underlying mechanistic approach of the ruthenium-fluvastatin complex have not yet been extensively analyzed. This study delineates the synthesis of the novel ruthenium-fluvastatin complex along with characterization of its chemical structure and further investigates the chemotherapeutic efficacy against mammary cancer in both in vitro and in vivo studies.

\section{Materials and Methods}

2.1. Chemicals and Reagents. The chemicals used for experimental analysis is of pure analytical category. Extra pure methanol, fluvastatin ((E,3R,5S)-7-[3-(4-fluorophenyl)-1propan-2-ylindol-2-yl]-3,5-dihydroxyhept-6-enoic acid), TPTZ (2,4,6-tri(2-pyridyl)-s-triazine), ruthenium chloride $\left(\mathrm{RuCl}_{3} \cdot x \mathrm{H}_{2} \mathrm{O}\right)$, highly polymerized CT-DNA (calf thymus DNA), Tris-HCl, 7,12-dimethylbenz $(\alpha)$ anthracene (DMBA), foetal bovine serum (FBS), 3,3' -diaminobenzidine $(\mathrm{DAB})$, proteinase $\mathrm{K}$, insulin L-glutamine, sodium pyruvate, streptomycin, penicillin, ABTS (2,2' -azinobis 3-ethylbenzothiazoline-6-sulphonic acid diammonium salt), streptavidin peroxidase, MTT (3-(4,5-dimethyl thiazole-2-yl)-2,5-diphenyltetrazoliumbromide), DPPH (2,2-diphenyl-2-picrylhydrazyl), biotinylated goat anti-rabbit IgG, annexin $\mathrm{V}$, and propidium iodide (PI) were purchased from Sigma-Aldrich Chemical Co. (St. Louis, MO, USA). Antibodies specific for p53, VEGF (627501), caspase-3, Akt, mTOR, PI3K, and pro- and active caspase- 3 were acquired from BioLegend (Sun Diego, CA, USA). Rabbit anti-rat p53, Bax, Bcl2, Ki67, MMP9, and goat anti-rabbit IgG secondary antibodies were bought from AnaSpec Inc. (San Jose, CA, USA). The MCF-7 and MDA-MB-231 breast cancer cell lines were obtained from the American Type Culture Collection, 10801 University Boulevard, Manassas, VA 20110, USA. Kits for detecting apoptosis were purchased from Takara Bio Inc. (Japan). Other chemical agents utilized for the research purpose were procured from local companies in the finest possible form.

\subsection{Pharmacophore Analysis}

2.2.1. Target Protein Selection. The reviewed sequence of human gamma-synuclein was retrieved from the universal protein sequence database UniProt (http://www.uniprot .org/). The sequence of selected proteins was used to predict sequence similarities and to estimate the sequence template by PSI-BLAST. The specified sequence of a template was used to construct three-dimensional protein structures utilizing the Swiss model. Homology modeling using the Swiss PDB Viewer assists in envisaging the orientation of the protein structure and was validated to check the overall quality of protein and stereochemical activity of atoms and amino acids.

2.2.2. Ligand Structure Design and Pharmacophore Analysis. Using the ACD/ChemSketch software, chemical structures were designed to attach all chemical compositions and the ultimate output was saved in MOL2 format. The training sets were used to determine the pharmacophore using the Molinspiration server, and QSAR properties were envisaged using HyperChem. A training set helps to predict the complex polarity and flexibility, to examine MM3 force fields, to examine the HOMO and LUMO, and to understand new molecular orbital of individual compounds. The scaffolds were identified, and then, we accelerated screening; a screened pool is focused on biotargets to inhibit the diseases. Structural screening, fragment analysis, and pharmacological analyses were used to screen the ligand based on the interaction with target apoptotic proteins.

2.2.3. Molecular Docking. The AutoDock 4.6 software was used to predict protein-ligand exchange utilizing different factors such as preparing protein properties, adding Gaussian charges, adding hydrogen atoms with a polar amino acid zone, and planning a ligand molecule with rotatable angle bond interaction. Grid maps of different grid points, centered on the ligands of the complex structure, were used for receptors, respectively, to cover binding pockets. A set of the Lamarckian genetic algorithm was used for molecular docking simulations. Simulations were performed using up to 2.5 million energy evaluations with a maximum of 27000 generations. Each simulation was performed 10 times, yielding 10 docked conformations. The lowest energy conformations were regarded as the binding conformations between the ligands and the proteins. Further, the reverse validation processes ensured that the identified hits really fit the generated pharmacophore models and active sites of targets. All the parameters required for molecular docking and pharmacophore mapping were fixed as used in the regular process.

2.3. Synthesis of the Ruthenium-Fluvastatin Complex. Approximately $433.45 \mathrm{mg}$ ( $1 \mathrm{mmol})$ of fluvastatin sodium was dissolved in $60 \mathrm{~mL}$ HPLC analytical category ethanol at a room temperature of $27^{\circ} \mathrm{C}$, with continuous mixing using a mechanical stirrer. In another conical flask, approximately $103.5 \mathrm{mg}(0.5 \mathrm{mmol})$ of ruthenium chloride was dissolved in $40 \mathrm{~mL}$ of ethanol and added dropwise to the fluvastatin solution with continuous stirring for 24 hours. After complete mixing, the resultant solution was refluxed at $80^{\circ} \mathrm{C}$ for 3 hours. The reaction mixture was kept in a vacuum desiccator over silica gel for seven days. The obtained product was brown in color and was found to be soluble in ethanol and dimethyl sulfoxide (DMSO), with the percentage yield of the product being $87 \%$. Figure 1 (a) represents the possible structure of the ruthenium-fluvastatin complex.

2.4. Characterizations of the Ruthenium-Fluvastatin Complex. The UV-visible spectra of the ruthenium- 
<smiles></smiles>

(a)

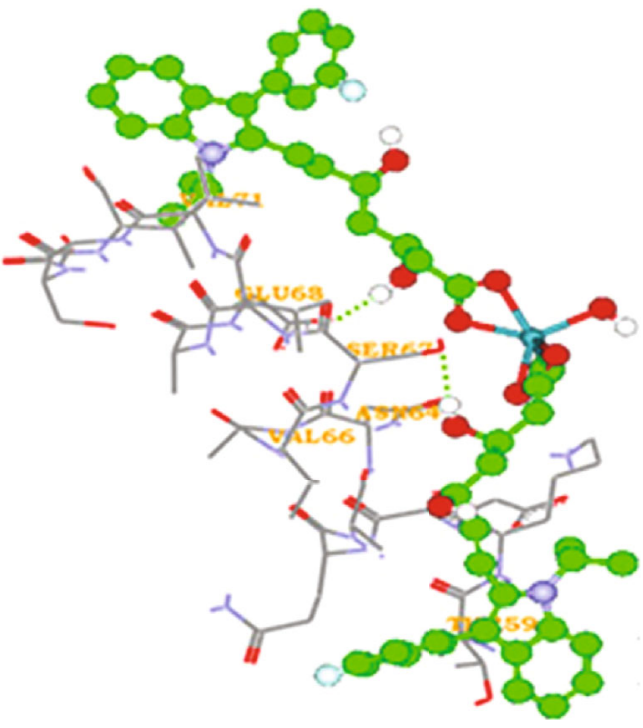

(b)

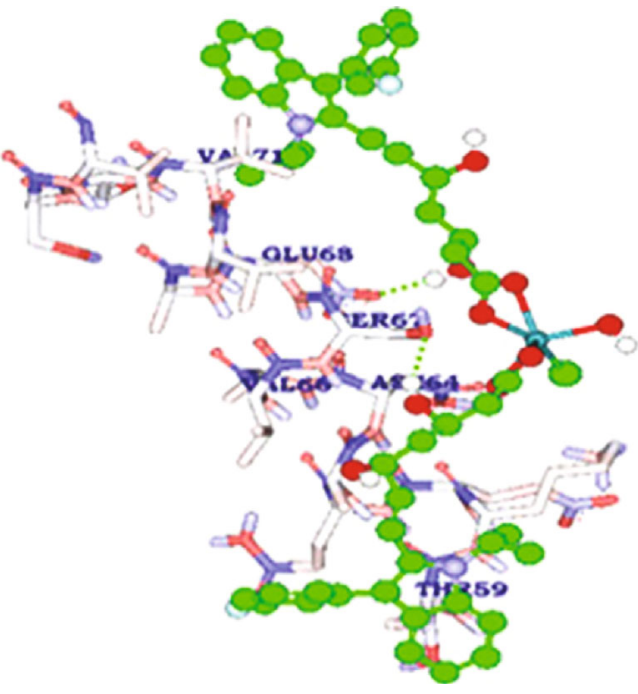

(c)

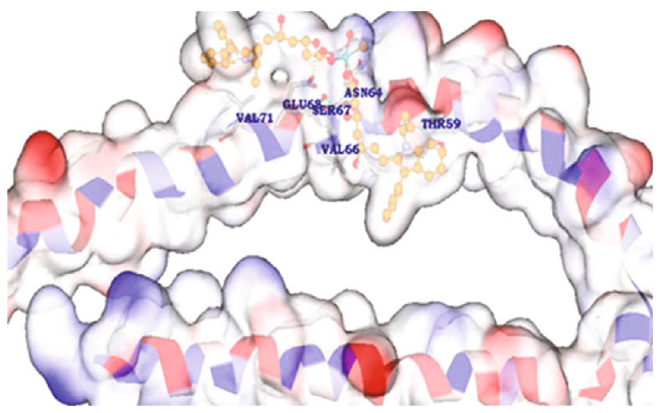

(d)

Figure 1: (a) The possible structure of the ruthenium-fluvastatin complex. (b-d) Receptor-ligand hydrogen bonding interactions of Ru-flu with active site residues of gamma-synuclein.

fluvastatin complex and fluvastatin were recorded via a UV1800 Shimadzu double-beam spectrophotometer with a typical $1.00 \mathrm{~cm}$ quartz cell. FTIR spectroscopy (ALPHA-T, Bruker, Rheinstetten, Germany) was used to document the infrared spectrum of the complex over the span of 500$4000 \mathrm{~cm}^{-1}$ wavelength to evaluate the complexation by detecting the metal oxide bond. The molecular structure of the ruthenium-fluvastatin complex was studied by employing tandem mass spectrometry (ESI-MS) techniques with electrospray ionization. Molecular ions $(\mathrm{m} / \mathrm{z})$ were scanned over a span of 150-1100. A Bruker-Avance- $600 \mathrm{MHz}$ spec- trometer was used for studying the ${ }^{1} \mathrm{H}-\mathrm{NMR}$ spectrum of the complex dissolved in DMSO. Tetramethylsilane (TMS) was used as an internal reference. Scanning electron microscopy (JEOL MAKE, UK; model: JSM6360) was used to examine the morphological appearance of the sample at an accelerating voltage of $17 \mathrm{kV}$. To examine the surface and morphological features, micrographs were recorded at different magnifications (60x, 200x, 500x, and 1000x). X-ray diffraction (XRD) of the complex was recorded by using an XPERT-PRO Diffractometer (PAN Analytical, Almelo, Netherlands) using X'celerator operating at $40 \mathrm{kV}$ and 
$30 \mathrm{~mA}$ with the Bragg-Brentano geometry with a step size of $0.033(2 \theta)$ and step time of $19.43 \mathrm{~s}$.

\subsection{Assessment of Antioxidant Status of the Ruthenium- Fluvastatin Complex by the DPPH, FRAP, and ABTS Processes}

2.5.1. DPPH Assay. Free radical scavenging ability of the complex was assessed by the DPPH radical scavenging assay according to the procedure described by Lim and his coresearcher [52]. The hydrogen atom-donating ability of the complex was determined by the decolorization of methanol solution of 2,2-diphenyl-1-picrylhydrazyl (DPPH). DPPH produces violet/purple color in methanol solution which fades to shades of yellow color in the presence of antioxidants. Subsequently, $100 \mu \mathrm{L}$ of the complex as well as ligands at different concentrations $(5,10,15,20$, and $25 \mu \mathrm{M})$ was mixed with $0.1 \mathrm{~mL}$ of DPPH solution $(0.2 \mathrm{mg} / \mathrm{mL}$ in ethanol), and the absorbance was measured at $515 \mathrm{~nm}$ every 5 -minute interval and further assessed for 30 minutes $\left(A_{\mathrm{s}}\right)$, whereas a solution containing only DPPH functioned as blank $\left(A_{\mathrm{c}}\right)$. The percentage of radical scavenging action (RSA\%) was calculated as

$$
(\operatorname{RSA} \%)=\frac{100\left(\mathrm{~A}_{c}-\mathrm{A}_{\mathrm{s}}\right)}{\mathrm{A}_{\mathrm{c}}},
$$

2.5.2. FRAP Assay. The FRAP assay was carried out by the method of Benzie and Strain [53] as developed by Griffin and Bhagooli [54]. The working FRAP reagent was prepared by mixing $300 \mathrm{mM}$ acetate buffer ( $\mathrm{pH} 3.6$ ), $10 \mathrm{mM}$ 2,4,6-tripytidyl-s-triazine (TPTZ) solution, and $20 \mathrm{mM} \mathrm{FeCl}_{3} \cdot 6 \mathrm{H}_{2} \mathrm{O}$ at a 10:1:1 ratio prior to use and heated to $37^{\circ} \mathrm{C}$ in a water bath. $3 \mathrm{~mL}$ of the FRAP reagent was added to $100 \mu \mathrm{L}$ of various concentrations $(5-40 \mu \mathrm{M})$ of the complex and ligands. Following reaction, light bluish coloration of the FRAP solution shifted to dark blue, and the change in absorbance was detected at wavelength $593 \mathrm{~nm}$ and expressed as mmol $\mathrm{Fe}^{2+} / \mathrm{g}$ of sample.

2.5.3. ABTS Assay. The radical scavenging activity of the ruthenium-fluvastatin complex by the ABTS method has been evaluated utilizing the process outlined by Pennycooke and coworkers [55]. Following the incorporation of fluvastatin and the complex to the ABTS solution (incubated at room temperature for 10-12 minutes), the absorbance was taken at $734 \mathrm{~nm}$. The equation below was used to measure the percentage of radical scavenging action (RSA\%):

$$
\text { Radical scavenging activity at } 750 \mathrm{~nm}(\%)=1-\frac{A_{\mathrm{f}}}{A_{0}} 100 \text {, }
$$

where $A_{0}$ is the absorbance of free radical cation and $A_{\mathrm{f}}$ is the absorbance observed $10 \mathrm{~min}$ after incorporation of the complex.

2.6. DNA Binding Assay of the Ruthenium-Fluvastatin Complex. CT-DNA intercalation with the complex was calculated using a UV-visible spectrophotometer (UV-1800 Shimadzu) based on the technique recorded by Dehghan et al. [56]. The intrinsic binding constant was calculated as

$$
\frac{\text { DNA }}{\varepsilon_{\mathrm{a}}-\varepsilon_{\mathrm{f}}}=\frac{\mathrm{DNA}}{\varepsilon_{\mathrm{b}}-\varepsilon_{\mathrm{f}}}+\frac{1}{\mathrm{~Kb}\left(\varepsilon_{\mathrm{b}}-\varepsilon_{\mathrm{f}}\right)},
$$

where DNA represents the number of base pairing of DNA, $\varepsilon_{\mathrm{a}}$ represents the extinction coefficient $\left(A_{\mathrm{obs}} / \mathrm{Ru}\right)$ factor, $\varepsilon_{\mathrm{f}}$ is the free drug-related extinction coefficient, and $\varepsilon_{\mathrm{b}}$ represents the bound drug-associated extinction coefficient, and the complex-associated calibration curve is derived from $\varepsilon_{\mathrm{f}}$ in the aqueous solution. $\varepsilon_{\mathrm{a}}$ represents the ratio of the recorded absorbance to the concentration of the complex by Beer's law.

\subsection{In Vitro Experimentation}

2.7.1. Cell Culture. The breast cancer cell lines MCF-7 and MDA-MB-231 were acquired from the American Type Culture Collection (ATCC) (Manassas, VA, USA). The tumor cells were normally sustained in DMEM, enriched by $10 \%$ FBS (foetal bovine serum) constituting antibiotics such as penicillin/streptomycin $\left(0.5 \mathrm{~mL}^{-1}\right)$ in an environment of $5 \%$ $\mathrm{CO}_{2}$ and $95 \%$ air at $37^{\circ} \mathrm{C}$.

2.7.2. Cell Viability Assay. The experiment was assessed by using mitochondrial succinate dehydrogenase to metabolize tetrazolium salts MTT (3-(4,5 dimethylthiozol-2-yl)-2,5diphenyltetrazolium bromide), which is yellow to produce formazan crystals. The MCF-7 and MDA-MB-231 cells were plated in a $5 \% \mathrm{CO}_{2}$ humidified incubator and exposed to a number of ruthenium-fluvastatin doses for 24 hours, containing proper growing media in a 96-well plate containing $5.0 \times 10^{3}$ cells for each well, and incubated nightly at $37^{\circ} \mathrm{C}$. Upon treatment with $15,35,75$, and $95 \mu \mathrm{M}$ concentrations of the complex for 24 hours, the medium was withdrawn and the MTT solution $(0.5 \mathrm{mg} / \mathrm{mL})$ was applied to each well and incubated at $37^{\circ} \mathrm{C}$ for the next 3 hours. On a microplate reader, the optical density of solubilized crystals in DMSO was estimated at $560 \mathrm{~nm}$. The cell viability percentage was determined by the following equation.

$$
\% \text { viability }=100-\% \text { of cytotoxicity. }
$$

The cell viability assay was performed in triplicate.

2.7.3. Assessment of Apoptotic Cells by DAPI Staining. DAPI staining was used to analyze apoptotic morphology, i.e., nuclear chromatin condensation. In 6-well plates, MCF-7 and MDA-MB231 cells were seeded. After an overnight incubation, cells were treated with varying amounts of the complex for 24 hours. Cells were then extracted, fixed in $4 \%$ paraformaldehyde, treated with 0.25 percent Triton X-100 in TBS for 15 minutes at room temperature, and stained with $50 \%$ DAPI for 30 minutes at room temperature. Following PBS washing, samples were kept in the dark at $4^{\circ} \mathrm{C}$ and studied under a fluorescence microscope in three separate independent experiments. [57].

2.7.4. Clonogenic Assay. The inhibitory effect of the ruthenium-fluvastatin complex on MCF-7 and MDA-MB- 
231 cells on proliferation was determined by the clonogenic assay. The cells were trypsinized to create a single-cell suspension and implanted in six-well plates at a density of 500 cells/well in $2 \mathrm{~mL}$ of medium supplemented with $10 \%$ FBS, kept in a humidified compartment having an atmosphere of $95 \%$ air and $5 \% \mathrm{CO}_{2}$ at $37^{\circ} \mathrm{C}$. After 24 hours of incubation, culture was replaced with fresh media containing three different concentrations of the ruthenium-fluvastatin complex at 30,70 , and $100 \mu \mathrm{M}$ in MCF-7 cells and 50, 75, and $200 \mu \mathrm{M}$ in MDA-MB-231 cells along with $2 \%$ FBS and cultured for two weeks. After 2 weeks, the cell culture medium was removed and the cells were thoroughly washed with PBS. Cell fixation was done by using $100 \%$ methanol kept at $-20^{\circ} \mathrm{C}$ for 30 minutes. Colonies were stained with $0.5 \%$ crystal violet in $25 \%(v / v)$ methanol for 1 hour at room temperature. The excess dye was removed by gently rinsing with moderate water flow for 15 minutes. Following washing and drying, the colonies were visually counted to contain $>50$ cells/colony. The clonogenicity was measured by the help of the equation below:

$$
\text { Clonogenicity }=\left(\frac{\text { Cloning number }}{500 x}\right) \times 100 .
$$

The clonogenic assay was performed in triplicate.

2.7.5. Apoptotic Assay by Flow Cytometry and Cell Cycle Analysis. MCF-7 and MDA-MB-231 cells were cultured in a 6-well plate at a density of $0.5 \times 10^{6}$ cells $/ 3 \mathrm{~mL}$ and incubated in a carbon dioxide environment overnight at $37^{\circ} \mathrm{C}$ for $24 \mathrm{~h}$. At the end of $24 \mathrm{~h}, \mathrm{MCF}-7$ cells were treated with 30,70 , and $100 \mu \mathrm{M}$ concentrations of the complex and MDA-MB-231 cells were treated with 50, 75, and $200 \mu \mathrm{M}$ concentrations of the complex followed by incubation for the next $24 \mathrm{~h}$. At the end of the treatment, the cells were harvested with trypsin-EDTA and fixed in 70\% cold ethanol. Then, the cells were treated with an FITC-conjugated annexin $\mathrm{V}$ antibody followed by incubation in the dark. After further washing, the cells were treated with propidium iodide and then analyzed in a FACS analyzer. The assay was performed in triplicate.

2.7.6. Caspase-3 Protein Detection by Flow Cytometry. MCF-7 and MDA-MB-231 cells $\left(5 \times 10^{5}\right.$ cells/well) were cultured on a twelve-well plate and incubated at $37^{\circ} \mathrm{C}$ in a humidified atmosphere with $5 \% \mathrm{CO}_{2}$ for 24 hours and subsequently treated with three concentrations of the rutheniumfluvastatin complex for 24 hours. The cells were again washed properly with ice-cold PBS and resuspended with BD Cytofix/Cytoperm Solution (51-6896KC, BD Pharmingen) $400 \mu \mathrm{L}$. The method was initiated by determining the quantity of BD Perm/wash buffer (51-6897KC, BD Pharmingen), and $20 \mu \mathrm{L}$ of rabbit anti-active caspase-3 polyclonal antibody (351-68655X, BD Pharmingen) was taken, so that each and every individual test was comprised of $100 \mathrm{~mL}$ of BD Perm/wash buffer and $20 \mu \mathrm{L}$ of anti-active caspase- 3 antibody. After incubation on ice for 20 minutes, followed by centrifugation and washing with BD Perm/wash buffer, subsequently, BD Perm/wash buffer was further added followed by incubation with the antibody for thirty minutes at room temperature. Each and every individual tube was further rinsed with $1 \mathrm{~mL}$ of BD Perm/wash buffer, centrifuged, and then finally added with $300 \mu \mathrm{L}$ of BD Perm/wash buffer and analyzed by flow cytometry (BD Accuri C6 Plus flow cytometer). Values thus obtained were processed by using the FlowJo software. The caspase-3 assay was performed in triplicate.

2.7.7. Detection of Akt, mTOR, P13K, VEGF, Procaspase-3, and Active Caspase-3 Protein Expression by Western Blot. Western blot analysis detected the expressions of Akt, mTOR, P13K, VEGF, procaspase-3, and active caspase- 3 in cells MCF-7 and MDA-MB-231. The cells were treated for 24 hours after a medium change with three different doses of the ruthenium-fluvastatin complex and maintained for 6 hours. Cell lysates were extracted, and equivalent protein amounts were analyzed using SDS-PAGE electrophoresis, followed by a shift to a PVDF (polyvinylidene difluoride) membrane, and afterwards blocked to Tris buffer $(25 \mathrm{mM})$ comprising $0.15 \mathrm{M} \mathrm{NaCl}, 0.1$ percent around 20 , and $2-5$ percent nonfat dry milk. At $4^{\circ} \mathrm{C}$, the membranes were cultured with the primary antibodies for Akt, mTOR, P13K, VEGF, procaspase-3, and active caspase-3 supplemented with a secondary antibody marked with horseradish peroxidase for $1 \mathrm{~h}$. A chemiluminescent (ECL western blotting) kit was then used to recognize protein loading against $\beta$-actin [58]. All experiments were carried out in triplicate.

\subsection{In Vivo Experimentation}

2.8.1. Animal Husbandry and Maintenance. Sprague-Dawley rats (120-125g) of both sexes and 28-day Sprague-Dawley female rats (80-100 grams) were purchased from Nanjing Medical University, Nanjing, China, and quarantined even days before experimentation. Animals were housed in a 12hour light/dark period in polypropylene containers and at $22^{\circ} \mathrm{C}\left( \pm 3^{\circ} \mathrm{C}\right)$ at room temperature and nearly $50-58 \%$ humidity. Each animal was fed a semipurified basal diet and demineralized water ad libitum. The entire animal research process was performed in conjunction with the permission of Nanjing Medical University's Animal Ethics Committee and the Government's Regulatory Body (IACUS-1912129).

\subsubsection{Toxicological Studies}

(1) Acute Oral Toxicity Study (LD50). Acute toxicity evaluation of the ruthenium-fluvastatin complex was carried out by incorporating the recommendations for research on chemicals by the Organization for Economic Cooperation and Development (OECD), TG 420 (adopted in December 2001), to establish the $\mathrm{LD}_{50}$ values of the complex. Thirty numbers of Sprague-Dawley rats of both sexes (nulliparous and nonpregnant; $120 \pm 5 \mathrm{~g}$ ) were identified and allocated in five groups (six animals per group, three of each sex) plus control (dispensed in $0.5 \%$ carboxy methyl cellulose prepared as a carrier in drinking water at a dosage of $10 \mathrm{~mL} / \mathrm{kg}$ body weight) and study groups $(2000,800,600,300$, and $100 \mathrm{mg} / \mathrm{kg}$ ruthenium-fluvastatin complex). The rats were 
allowed food and supplies immediately after drug administration and placed under three-day surveillance [59].

(2) Subacute Toxicity Studies. Sprague-Dawley rats, both male and female (120 $\pm 5 \mathrm{~g})$, were arbitrarily paired to four experimental groups: complex $(25,50,100$, and $200 \mathrm{mg} / \mathrm{kg})$ and vehicle control groups. Each unit was composed of 10 rats, 5 per gender. For further hematology, serum biochemistry, and histological experiments, the animals were orally administered with the ruthenium-fluvastatin complex and sacrificed at the $28^{\text {th }}$ day by ether anesthesia.

2.8.3. Histopathological Study of Rat Organs. Primary organs such as the liver, kidney, stomach, and testis were harvested from each experimental animal after 28 days of analysis and stored in $10 \%$ formalin solution. Tissue was drained by graded alcohol and preserved in paraffin wax at a low melting point on a 5-micron glass slide. By using xylene, the sections were deparaffinized and rehydrated by graded alcohol and subsequently stained with hematoxylin and eosin (H\&E) for microscopic examination.

\subsubsection{In Vivo Experiments}

(1) Experimental Protocol. After acclimatization, the animals were grouped into seven designated units such as I, II, III, IV, V, VI, and VII and each unit consisted of six animals. Once all the animals were 50 days old, DMBA was given in an oil emulsion as a single tail vein injection to groups II to IV at a dosage of $0.5 \mathrm{mg}$ per $100 \mathrm{~g}$ body weight. The description below denotes the experimental layout of the groups.

Group I: animals constituted the normal untreated controls and received basal diet throughout experiment. Group II: these are comprised of carcinogen- (DMBA) treated animals. Group III: carcinogen- (DMBA) induced animals were treated with the $\mathrm{Ru}$-fluvastatin complex $(25 \mathrm{mg} / \mathrm{kg}$ body weight). Group IV: carcinogen- (DMBA) induced animals were treated with the Ru-fluvastatin complex $(50 \mathrm{mg} / \mathrm{kg}$ body weight). Group V: carcinogen- (DMBA) induced animals were treated with the Ru-fluvastatin complex $(100 \mathrm{mg} / \mathrm{kg}$ body weight). Group VI: carcinogen- (DMBA) induced animals were treated with ruthenium ( $50 \mathrm{mg} / \mathrm{kg}$ body weight). Group VII: carcinogen- (DMBA) induced animals were treated with fluvastatin ( $50 \mathrm{mg} / \mathrm{kg}$ body weight). Following 16 weeks of treatment, the animals were sacrificed in light ether anesthesia from each group preceded by midline incision from the pubis to the submaxillary region. Dissection of the skin was undertaken to reveal the six sections of mammary glands.

(2) Histopathology of Mammary Tissue. Ten animals were randomly selected from each individual group, excising the thoracic and abdominal inguinal mammary tissue from rats anesthetized with ether. Part of the breast tissue was set in $10 \%$ neutral buffered formalin, carefully washed, paraffincoated, sliced into $5 \mu \mathrm{m}$ thick segments, and mounted on slides and subsequently treated with hematoxylin and eosin for histopathological investigations ( $\mathrm{H} \& \mathrm{E})$. All experiments were performed in triplicate.

(3) Antioxidant Assay of Mammary Tissues. Mammary tissue was crushed and homogenized (10 percent $w / v)$ in $0.1 \mathrm{M}$ phosphate buffer ( $\mathrm{pH} 7.0$ ) and centrifuged for $10 \mathrm{~min}$, and thus, the generated supernatant had been used for the measurement of enzymatic antioxidants. The catalase reaction was analyzed using the method defined by Sinha and his associates [60]. The absorbance was evidenced at $620 \mathrm{~nm}$; the CAT action was reported as $\mu \mathrm{mol}$ of $\mathrm{H}_{2} \mathrm{O}_{2} / \mathrm{min} / \mathrm{mg}$ protein consumed. Superoxide dismutase activity was assessed using the Awasthi technique [61]. This activity was expressed as units $/ \mathrm{min} / \mathrm{mg}$ protein. The GPx evaluation was carried out using the process provided by Rotruck et al. [62]. The activity was calculated as $\mu \mathrm{mol}$ of GSH consumed $/ \mathrm{min} / \mathrm{mg}$ protein. All experiments were performed in triplicate.

(4) Immunohistochemical Analysis of Mammary Tissue. The tissues coated with formalin and set in paraffin are sliced into $5 \mu \mathrm{m}$ thickness to position on the glass slides and deparaffinized together with immersion in $\mathrm{H}_{2} \mathrm{O}_{2}$. For 1 hour, the segments were coated with goat serum, preceded by exposure to anti-mouse p53, Bcl2, Bax, and MMP9 antibodies (1:50 ratio) and maintained overnight at $4^{\circ} \mathrm{C}$. The slides were immersed with PBS and subsequently cultivated for about 30 min with the HRP-conjugated secondary antibody streptavidin biotin and subsequently treated with DAB to the segments and counterstained with hematoxylin. The labeling index was measured as the number of positively stained cells with p53, Bcl2, Bax, and MMP9 to the total cell count. All experiments were performed in triplicate.

(5) Cell Proliferating Assay. The tissues coated with formalin and set in paraffin are sliced into $5 \mu \mathrm{m}$ thickness to position on the glass slides and deparaffinized accompanied by submersion in $\mathrm{H}_{2} \mathrm{O}_{2}$. The segments were covered with goat serum for 1 hour and exposed to the anti-mouse Ki-67 antibody at $4^{\circ} \mathrm{C}$ overnight. At room temperature, the positive test slides were processed for $30 \mathrm{~min}$ with the streptavidin biotin horseradish peroxidase complex. Tissues were treated with $\operatorname{DAB}\left(3,3^{\prime}\right.$-diaminobenzidine) and hematoxylin [63]. All experiments were performed in triplicate.

(6) TUNEL Assay of Mammary Tissues. Tissues fixed in formalin, implanted in paraffin, and coated with poly-L-lysine were screened for 15 minutes in proteinase $\mathrm{K}$ solution $(20 \mu \mathrm{g} / \mathrm{mL}$ in PBS) and washed with water distilled twice. The tissues were then soaked with $\mathrm{H}_{2} \mathrm{O}_{2}(2 \%$ in PBS) at room temperature for $5 \mathrm{~min}$, accompanied by treatment with the terminal deoxynucleotidyl transferase (TdT) buffer $(30 \mathrm{mM}$ Trizma base, pH 7.2, $140 \mathrm{mM}$ sodium cacodylate, and $1 \mathrm{mM}$ cobalt chloride) accompanied by a $\mathrm{TdT}$ reaction solution containing $\mathrm{TdT}$ and $\mathrm{dUTP}$ at $37^{\circ} \mathrm{C}$ for $90 \mathrm{~min} ; 2$ percent of the normal saline citrate was then added to the tissues (10 $\mathrm{min})$ at room temperature to interrupt the reaction. After washing with PBS, the tissue segments were soaked with antidigoxigenin peroxidase for 30 minutes at RT. Tissues were stained with $\mathrm{DAB}$ and counterstained with hematoxylin. 
Slides then were cleaned, dehydrated, and stored. Apoptotic cells were thus detected by brown staining of the nuclei [63]. All experiments were performed in triplicate.

(7) Evaluation of Labeling and Apoptotic Index. The labeling index (LI) was determined by counting the proportion of Ki67 -positive nuclei per total number of cells. The apoptotic index (AI) was calculated by measuring the TUNNELpositive cell percentage to the total cell number.

2.9. Statistical Analysis. The findings were set to mean \pm standard mean error (SEM). Statistical assessment was carried out using the $t$-test and one-way variance analysis (ANOVA) using graph pad prism techniques, further verified by post hoc measurement check (Dunnett's $t$-test), and difference was found to be statistically significant by using $p$ $<0.05$. All assays have been conducted in triplicate.

\section{Results}

3.1. Pharmacophore Analysis. It is of interest to design the inhibitors for the breast cancer target synuclein gamma (SNCG) protein, using molecular docking-based virtual screening followed by molecular docking. The protein structures of SNCG were retained from PDB, and the resultant structures were used for molecular modeling methods to check the resolution of amino acid arrangement within the complex protein structures and predict the active site of the amino acids. The docking results shows that SNCG interacted significantly with ruthenium-fluvastatin within the active site amino acids of both polar and electrostatic charges within the target amino acids of Thr59, Asn64, Val66, Ser67, Glu68, and Val71 with substantial energy of $-23.168 \mathrm{kcal} / \mathrm{mol}$ (Table 1 and Figures 1(b)-1(d)).

3.2. Instrumental Analysis. The electronic spectrum or UV spectrum of fluvastatin has shown absorption bands in two regions $230-240 \mathrm{~nm}$ and $300-310 \mathrm{~nm}$ due to interligand interaction. The complex only showed charge transfer between ligand to metal and metal to ligand as there was no appreciable change found in the UV-visible spectrum of the complex. So, no d-d transitions are expected due to the complex formation. The first range of the wavelength can be assigned to $\pi \rightarrow \pi *$ transitions in the aromaticity of the double bond. The other range of the wavelength is most probably due to the $n \rightarrow \pi *$ transition of mainly pyrrole, carboxylate, and hydroxyl group (Figure 2(a)). The FTIR study of the fluvastatin and ruthenium-fluvastatin complex was done to determine the coordination sites and binding properties of fluvastatin with ruthenium, as shown in Figures 2(b) and 2 (c), and the analysis of the data was done in Table 2. The $v(\mathrm{O}-\mathrm{H})$ frequencies appeared as broadbands at $3376.46 \mathrm{~cm}^{-1}$ in the case of fluvastatin, and in the case of the ruthenium-fluvastatin complex, the bands were found at $3412.27 \mathrm{~cm}^{-1}$ which shows the existence of water molecules. The $v(\mathrm{C}-\mathrm{N})$ stretching mode in fluvastatin appeared at $1215.98 \mathrm{~cm}^{-1}$ and was shifted to $1220.12 \mathrm{~cm}^{-1}$ after the complex formation. The $v$ (C-F) stretching appeared at $967.80 \mathrm{~cm}^{-1}$ in the spectrum of fluvastatin and shifted to
970.13 after the formation of the complex. At $1105.21 \mathrm{~cm}^{-1}$, a characteristic peak of $v(\mathrm{C}-\mathrm{O})$ was found in fluvastatin and shifted to 1098.12 after complex formation. Another characteristic peak was found at $1570.14 \mathrm{~cm}^{-1}$ for $v(C=C)$ stretching, and that also shifted at $1543.68 \mathrm{~cm}^{-1}$ in the case of the complex. A characteristic peak for the formation of the metal oxide bond was found at $600.14 \mathrm{~cm}^{-1}$ (Figure 2(b)) which was absent in the case of the free fluvastatin. These results indicate that the oxygen group $(=\mathrm{O}$ and $-\mathrm{O})$ is responsible for the chelation and formation of the ruthenium-fluvastatin complex. The ${ }^{1} \mathrm{H}$ NMR spectrum of the complex shows that every signal or peak is also present in the spectrum of the complex with very less appreciable changes in their position as some sort of chemical shifts have been found after the formation of the complex; in the case of the complex, the appearance of signals of the protons of the two methyl groups slightly shifted at $\delta 1.350 \mathrm{ppm}$, two methylene groups of the 6-heptanoate as a multiplet shifted at $\delta$ $2.235-2.504 \mathrm{ppm}$, the three protons $-\mathrm{CH}-\mathrm{N}$ and $2-\mathrm{CH}-\mathrm{OH}$ as multiplet shifted at $\delta 4.996 \mathrm{ppm}$, and $2-\mathrm{OH}$ shifted at $\delta$ $4.754 \mathrm{ppm}$. The two protons of the double bond of the side chain give signal as doublet at $\delta 5.708$ and $6.598 \mathrm{ppm}$, and the eight aromatic protons give signal as a multiplet at $\delta$ 7.004-7.445 ppm. Hence, it indicates that the chelation occurred on the carboxylate site. The mass spectrum of the complex is depicted in Figure 3(a) where the peak $\mathrm{m} / \mathrm{z}$ at 975.47 designates the formation of the complex containing 2 fluvastatin +1 ruthenium +1 chloride +1 water molecule, the peak $\mathrm{m} / z 891.33$ designates the 2 fragmented fluvastatin +1 ruthenium +1 chloride +1 water molecule, and the peak $\mathrm{m} / \mathrm{z}$ at 410.46 shows the free fluvastatin. The various fragmentations of the complex are depicted in Figure 3(b). The surface morphology of the ruthenium-fluvastatin complex has been examined by SEM which is shown in Figures 4(b)-4(d); different magnifications of the sample were observed which correspond to the crystalline nature irregular form of the compound. The higher magnifications confirm the crystalline nature of the complex. The crystallinity as well as the physical state of the complex was further investigated by the X-ray diffraction study; Figure 4(a) shows the appearance of sharp peaks which are typical characteristics of crystalline nature of the complex; the sharp peaks were observed at different diffraction angles such as 7.09, 10.24, $19.05,22.78,27.27,29.12$, and $35.88 \mathrm{~A}^{\circ}$. The sharp peaks in the diffractogram of the complex suggested that the complex is in crystalline nature.

\subsection{In Vitro Antioxidant Capacity of the Ruthenium- Fluvastatin Complex}

3.3.1. Ruthenium-Fluvastatin Complex Was Capable of Scavenging DPPH, FRAP, and ABTS Radicals. Figure 5(a) indicates the scavenging actions of fluvastatin and ruthenium-fluvastatin by ABTS methods. Absorption of the effective ABTS solution at $734 \mathrm{~nm}$ was observed to substantially decrease in the presence of different concentrations of the complex. The complex's ABTS radical scavenging activity has been found to be better than that of the free fluvastatin. The presence of hydroxyl groups causes statins to have 
TABLE 1: Ligand with its binding energy values from docking studies.

\begin{tabular}{|c|c|c|c|c|c|c|c|}
\hline Name & $\begin{array}{c}\text { Electrostatic } \\
\text { energy }\end{array}$ & $\begin{array}{l}\text { Van der waals } \\
\text { energy }\end{array}$ & $\begin{array}{l}\text { Cdocker } \\
\text { energy }\end{array}$ & $\begin{array}{l}\text { Cdocker } \\
\text { interaction energy }\end{array}$ & $\begin{array}{c}\text { Calculate } \\
\text { binding energy }\end{array}$ & $\begin{array}{l}\text { H-bond } \\
\text { count }\end{array}$ & Interacting amino acids \\
\hline $\begin{array}{l}\text { Ruthenium- } \\
\text { fluvastatin }\end{array}$ & -23.168 & 3.03 & -234.9 & 45.31 & -56.3119 & 2 & $\begin{array}{c}\text { Thr59,Asn64, Val66, Ser67, } \\
\text { Glu68, Val71 }\end{array}$ \\
\hline
\end{tabular}

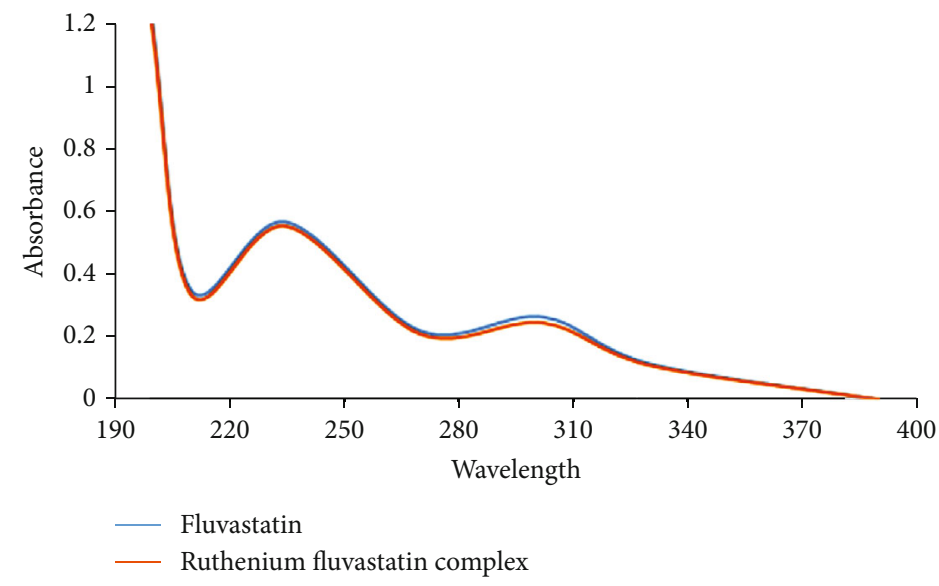

(a)

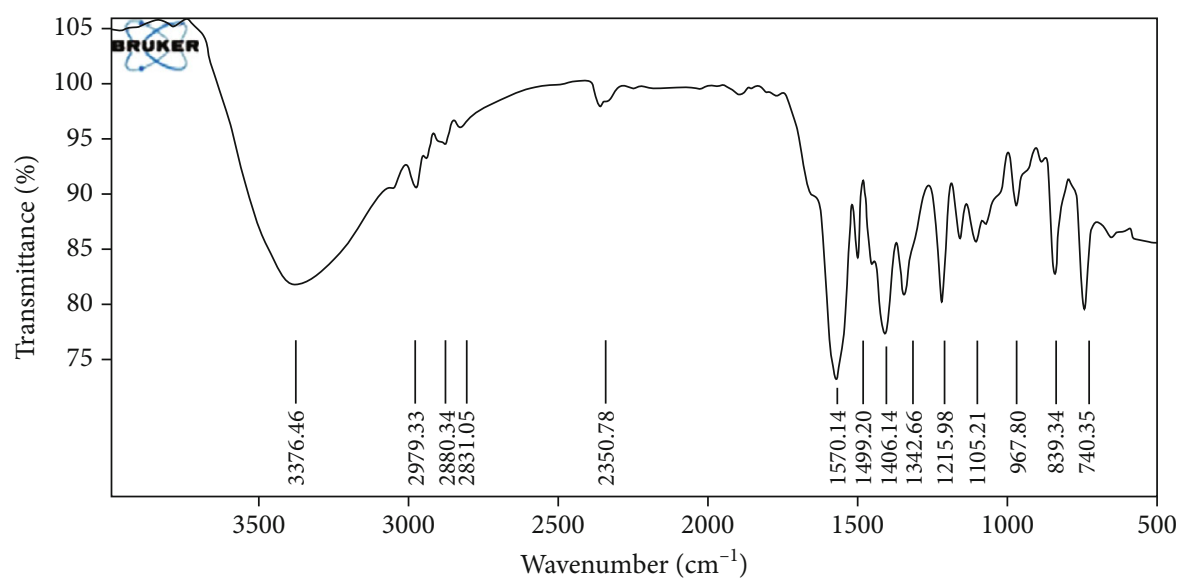

(b)

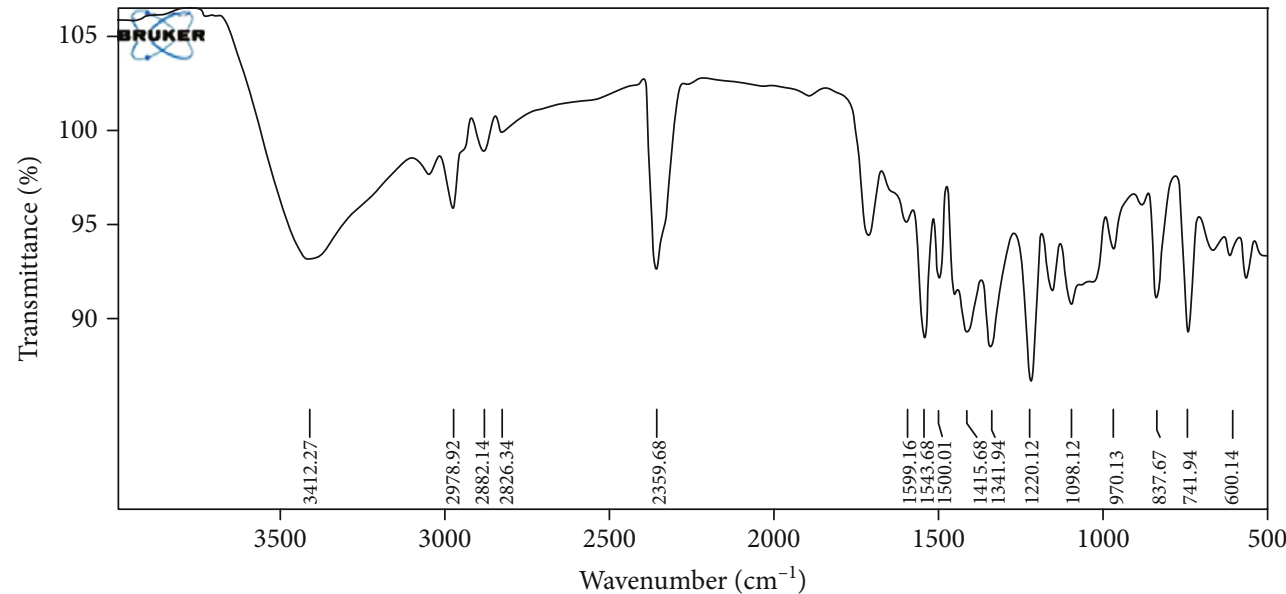

(c)

FIGURE 2: (a) UV-visible spectra of fluvastatin and the ruthenium-fluvastatin complex. (b) FTIR spectra of fluvastatin. (c) FTIR spectra of the ruthenium-fluvastatin complex. 
TABLE 2: FTIR spectrum of fluvastatin and the rutheniumfluvastatin complex (band position $\left(\mathrm{cm}^{-1}\right)$ ).

\begin{tabular}{lcccccc}
\hline \multirow{2}{*}{ Compound } & $v(\mathrm{O}-$ & $v(\mathrm{C}-$ & $v(\mathrm{C}-$ & $v(\mathrm{C}-$ & $v$ & $v(\mathrm{M}-$ \\
& $\mathrm{H})$ & $\mathrm{N})$ & $\mathrm{F})$ & $\mathrm{O})$ & $(\mathrm{C}=\mathrm{C})$ & $\mathrm{O})$ \\
\hline Fluvastatin & 3376.46 & 1215.98 & 967.80 & 1105.21 & 1570.14 & - \\
Complex & 3412.27 & 1220.12 & 970.13 & 1098.12 & 1543.68 & 600.14 \\
\hline
\end{tabular}

antioxidant activity. The complex's higher antioxidant activity is due to the hydroxyl groups, and their capacity to contribute hydrogen atoms improved after ruthenium chelation.

Figure 5(b) illustrates the different DPPH absorption patterns of fluvastatin and the ruthenium-fluvastatin complex at $515 \mathrm{~nm}$, with increasing amount of time and concentration. With the increase in concentration and time, the complex showed higher DPPH absorption than the fluvastatin molecule. The complex represented better inhibitory effect compared to the free fluvastatin; the radical-sensitive $\mathrm{Ru}-\mathrm{O}$ bond was introduced to the ruthenium-fluvastatin complex which synergistically enhances antioxidant activities of fluvastatin. In Figure 5(b), the plot illustrated the radical scavenging activity of fluvastatin and the complex, where it has been found that fluvastatin scavenged free radicals to about $47.10 \%$ and the complex scavenged about $63.17 \%$ at the same given reaction time.

The absorption of fluvastatin and the rutheniumfluvastatin complex in the presence of $\mathrm{Fe}^{+3}$-TPTZ was estimated at $593 \mathrm{~nm}$ by absorbance variability during $10 \mathrm{~min}$ of FRAP reagent interaction with the subjected compound. The absorbance reduction is equivalent to the antioxidant quality. Figure 5(c) shows that the antioxidant capacity of the complex is improved compared with free fluvastatin. These findings indicate that the complex of fluvastatin and ruthenium is capable of making a donation of protons and thus could have the ability to end a chain reaction. Metal chelation further increases the transfer of electrons from fluvastatin and thus augments the redox potential of the ruthenium-fluvastatin complex.

\subsection{Ruthenium-Fluvastatin Complex Is Capable of Binding} with CT-DNA. The broad absorption range in the presence of CT-DNA (5 microns) can be seen in Figure 5(d). A decline in the absorption rate (hypochromism) of the absorption peak is observed following the addition of the concentrations of the complex to CT-DNA. The intensity changes can be recognized within the intraligand transition band at $383 \mathrm{~nm}$, after raising the complex concentration in the DNA. These absorption spectra disclose that the complex interacts with DNA by stacking action between the ligand's chromophore via the intercalative mode and the DNA base pairs.

\subsection{In Vitro Assessment}

3.5.1. Ruthenium-Fluvastatin Complex Instigates the Repression of Cell Viability. The MTT assay was performed to investigate the inhibitory effect of the rutheniumfluvastatin complex on MCF-7 and MDA-MB-231 cells.
The cell viability evaluation revealed that the rutheniumfluvastatin complex showed a dose-dependent inhibitory impact on human breast cancer cells MCF-7 and MDAMB-231 (Figures 6(a) and 6(b)). Treatment with the complex was observed to decrease the viability of the MCF-7 cells to $85 \%, 69 \%, 58 \%, 49 \%$, and $31 \%$, respectively, at doses of 15 , $35,55,75$, and $95 \mu \mathrm{M}$. Likewise, findings were observed in MDA-MB-231 cells where cell viability decreased to $93 \%$, $87 \%, 80 \%, 73 \%$, and $62 \%$ at concentrations $15,35,55,75$, and $95 \mu \mathrm{M}$ after 24 hours. Exposure to the complex at $95 \mu \mathrm{M}$ in MCF7 cells was observed to have a maximum inhibition rate of $69 \%$, while stimulation with $95 \mu \mathrm{M}$ of the complex on MDA-MB-231 cells displayed a maximum inhibition rate of $38 \%$ at 24 hours.

3.5.2. Ruthenium-Fluvastatin Complex Causes Chromatin Condensation. Cells containing condensed chromatin morphologically usually signify that the cells might be undergoing apoptosis and fluorescence with bright blue color in the presence of DAPI. Treatment with the complex causes dose-dependent nuclear condensation in both cell lines (Figures 6(c) and 6(d)). It has been observed that intervention with $100 \mu \mathrm{M}$ of the complex in MCF-7 cells and $200 \mu \mathrm{M}$ of the complex in MDA-MB-231 cells displayed maximum chromatin condensation after 24 hours.

\subsubsection{Ruthenium-Fluvastatin Complex Encourages Colony} Inhibition Capability. The relevance of the tumor-colony forming assessment for screening new drugs has often been identified as an important tool for research. The ruthenium-fluvastatin complex effectively stimulates the capacity of MCF-7 and MDA-MB-231 cells to inhibit colony formation (Figure 7(a)). In MCF-7 and MDA-MB-231 cells, the ruthenium-fluvastatin complex was substantially successful in suppressing the colony number (Figures 7(b) and 7(e)) and size (Figures 7(c) and 7(f)) relative to control cells. Plating efficiency (PE) was measured for the rutheniumfluvastatin complex for both MCF-7 and MDA-MB-231 cells (Figures $7(\mathrm{~d})$ and $7(\mathrm{~g})$ ), and the findings indicate that $\mathrm{PE}$ was substantially decreased in MCF-7 and MDA-MB-231 at the maximum doses of the ruthenium-fluvastatin complex.

3.5.4. Ruthenium-Fluvastatin Complex Initiates Apoptosis Arrests of the Cell Cycle. MCF-7 and MDA-MB-231 undergoing apoptosis were observed by staining them with annexin $\mathrm{V}$ and PI by treating them with three different concentrations, respectively, of the complex for 24 hours. A flow cytometric study can differentiate stained cells into four categories, namely, viable (annexin V-PI-), early apoptosis (annexin V $+\mathrm{PI}-$ ), late apoptosis (annexin $\mathrm{V}+\mathrm{PI}+$ ), and necrotic (annexin V-PI+) cells. Figures 8(a) and 8(b) show the division of cells receiving therapy with specific complex concentrations after 24 hours. The percentages of apoptotic cells are 14.31, 39.91 , and $64.25 \%$ after exposure to 30,70 , and $100 \mu \mathrm{M}$ of the complex in MCF-7 cells and 18.2, 40.73, and $47.73 \%$ following treatment with 50,75 , and $200 \mu \mathrm{M}$ of the complex in MDA-MB-231 cells as compared to control (Figures 8(c) and 8(e)). Besides, a dose-dependent increase was also identified 


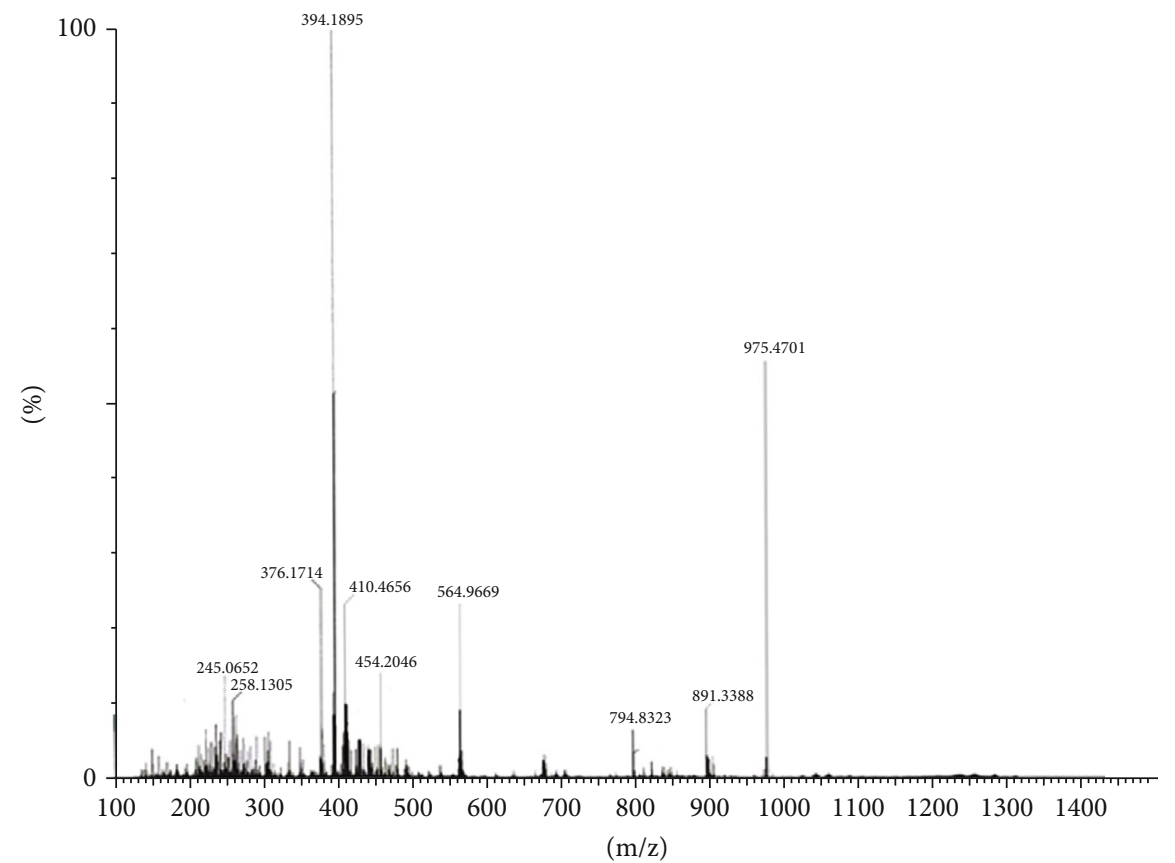

(a)

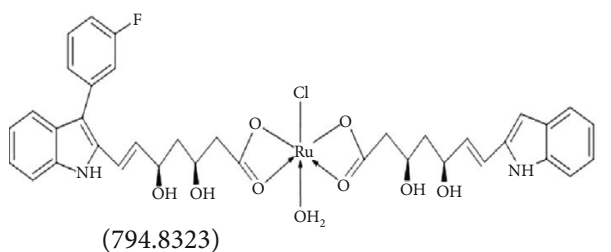

(794.8323)
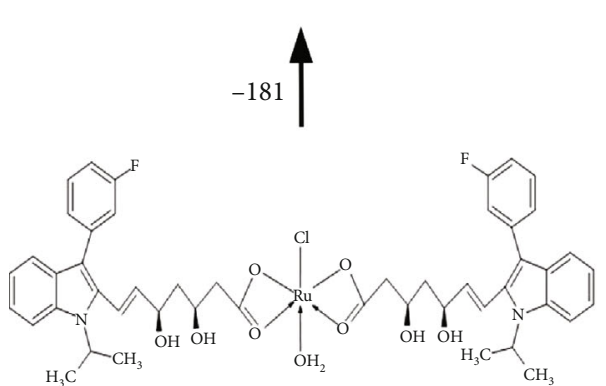

(975.4701)

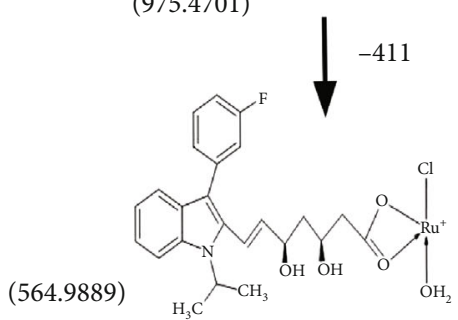

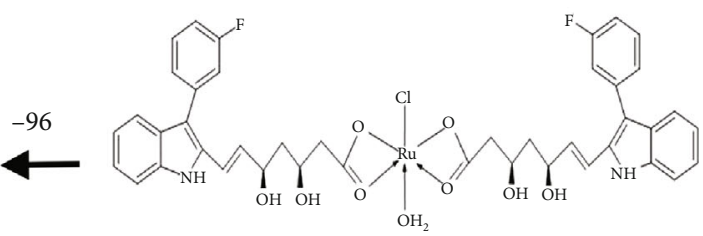

(891.3388)
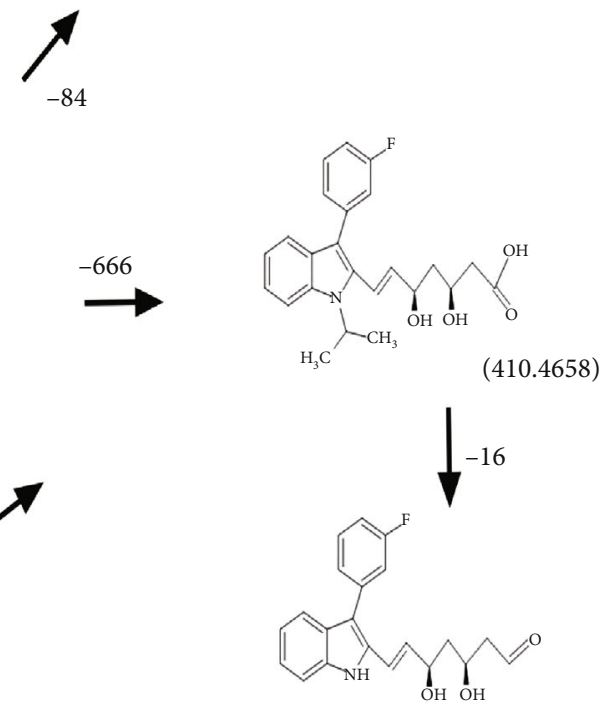

(394.1895)

(b)

Figure 3: (a) Mass spectroscopy of the ruthenium-fluvastatin complex. (b) Possible fragmentation mechanism of the ruthenium-fluvastatin molecule. 


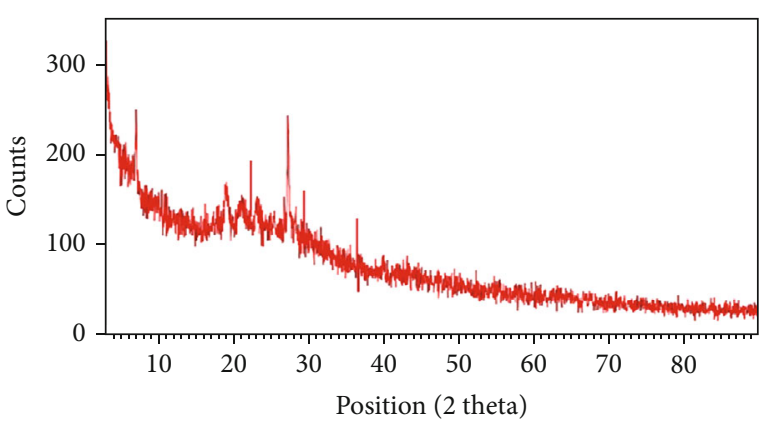

(a)

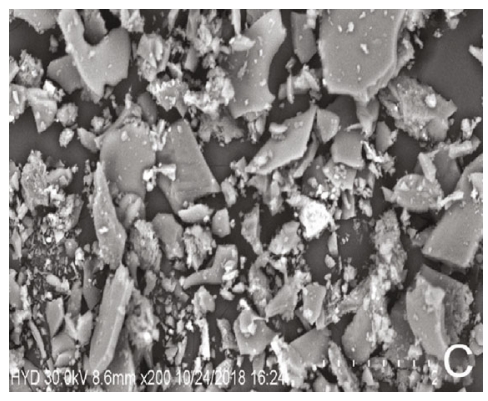

(c)

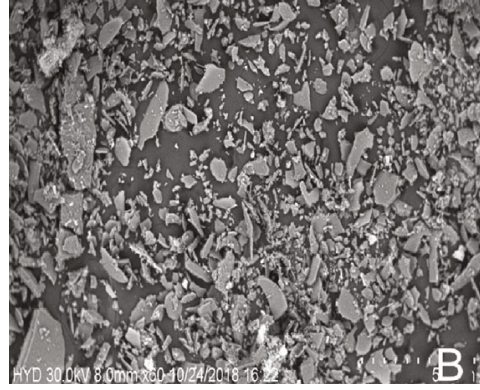

(b)

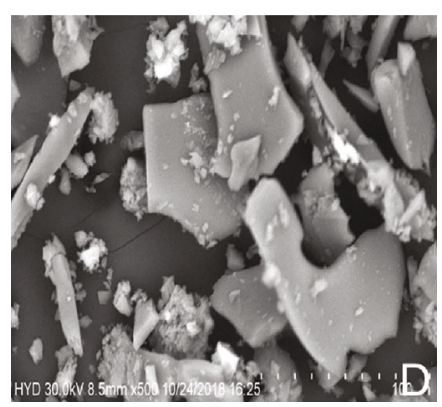

(d)

FIgURe 4: (a) X-ray diffractogram of the ruthenium-fluvastatin complex. Scanning electron microscopy (SEM) of the complex at (b) $200 \mu \mathrm{m}$ (c) $100 \mu \mathrm{m}$, and (d) $50 \mu \mathrm{m}$.

in the early apoptotic cells after 24 hours of complex therapy (Figures 8(d) and 8(f)).

Flow cytometric assessment was used to analyze the proliferation processes of the cell cycle along with the content of the cellular DNA. The proportion of subdiploid cells within the cell cycle histogram is the indication of the apoptotic cells (Figures 9(a) and 9(b)). MCF-7 cells exposed to $30 \mu \mathrm{M}$, $70 \mu \mathrm{M}$, and $100 \mu \mathrm{M}$ complex concentrations indicated $65.71 \%, 61.18 \%$, and $52.97 \%$ cells in the G0/G1 stage. Comparable findings were reported in MDA-MB-231 cells, where exposure to $50 \mu \mathrm{M}, 75 \mu \mathrm{M}$, and $200 \mu \mathrm{M}$ of the complex yielded $63.77 \%, 55.66 \%$, and $41.94 \%$ of cells in the G0/G1 stage. At the same time, a rise in cells in the $S$ phase was observed for both cell types in a dose-dependent fashion after complex therapy (Figures 9(c) and 9(d)). It should also be reported that the complex causes a dose-dependent decline in the number cells in the G0/G1 stage for both cell lines.

3.5.5. Ruthenium-Fluvastatin Complex Initiates Caspase-3Mediated Apoptosis. Quantification of caspase-3 was performed in triplicate in MCF and MDA-MB-231cells, by using flow cytometric analysis, and the results have been determined depending on the percentage of the cell population in respect to the caspase- 3 enzymatic activity throughout the apoptotic process. The flow cytometric evaluation of the effect of caspase- 3 ruthenium-fluvastatin complex treatments on both cell types after 24 hours is shown in Figures 9(e) and 9(f). The quadrant M1 represented the number of live cells without caspase-3, while quadrant M2 corresponds to the number of active caspase-3-designated apoptotic cells. After drug therapy, the percentage of caspase-3-demarcated apoptotic cells in quadrant M2 is substantially better than that of viable cells in quadrant M1, while unexposed cells display a lower percentage of viable cells in quadrant M1 relative to the caspase-3-demarcated apoptotic cells in quadrant M2. This observation is at par with the result of the apoptotic analysis, as an increment of the caspase- 3 corresponds with the increase in the late apoptotic cells.

3.5.6. Ruthenium-Fluvastatin Complex Modulates Expression of PI3K, Akt, mTOR, EGFR, VEGF, and Cleaved Caspase-3. Western blot experimentation was performed to establish the inhibition of MCF-7 and MDA-MB-231 cell growth by the complex through diverse cell cycle modulatory factor variation. We verified the effects of ruthenium-fluvastatin complex treatment on various proteins like PI3K, Akt, mTOR, EGFR, VEGF, and cleaved caspase-3 in MCF-7 and MDAMB-231 human breast cancer cells. After 24 hours of exposure to the ruthenium-fluvastatin complex in both MCF-7 and MDA-MB-231 cells, a dose-dependent downregulation of PI3K, Akt, mTOR, EGFR, and VEGF was identified (Figures 10(a) and 10(b)). Nonetheless, a significant upregulation of cleaved caspase-3 was observed in both MCF-7 and MDA-MB-231 cells after 24 hours of exposure to rutheniumfluvastatin therapy.

\subsection{Toxicity Study}

3.6.1. Acute and Subacute Toxicity Study. The $\mathrm{LD}_{50}$ dosage of the ruthenium-fluvastatin complex was estimated to be $300 \mathrm{mg} / \mathrm{kg}$. 25, 50, 100, and $200 \mathrm{mg} / \mathrm{kg}$ were chosen as the 


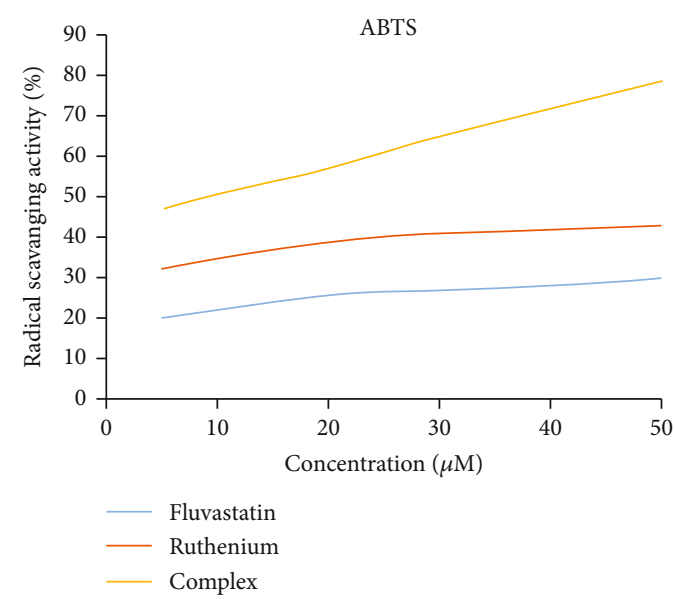

(a)

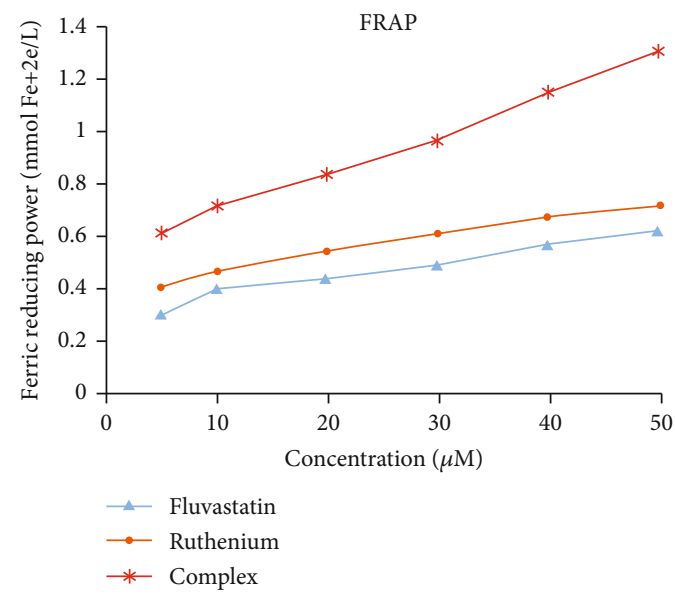

(c)

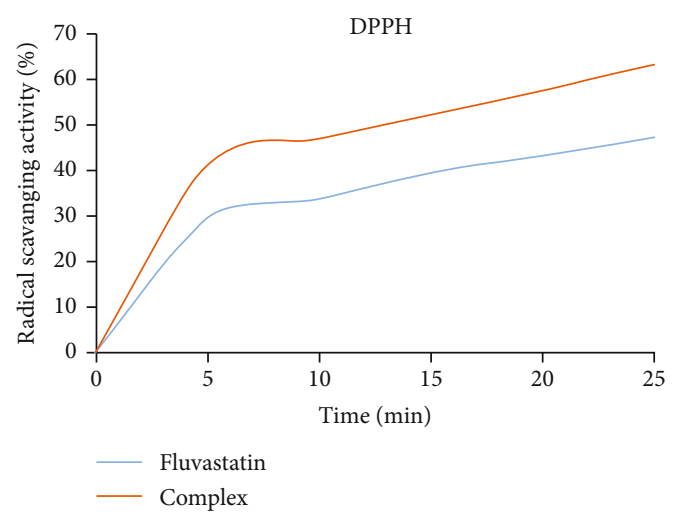

(b)

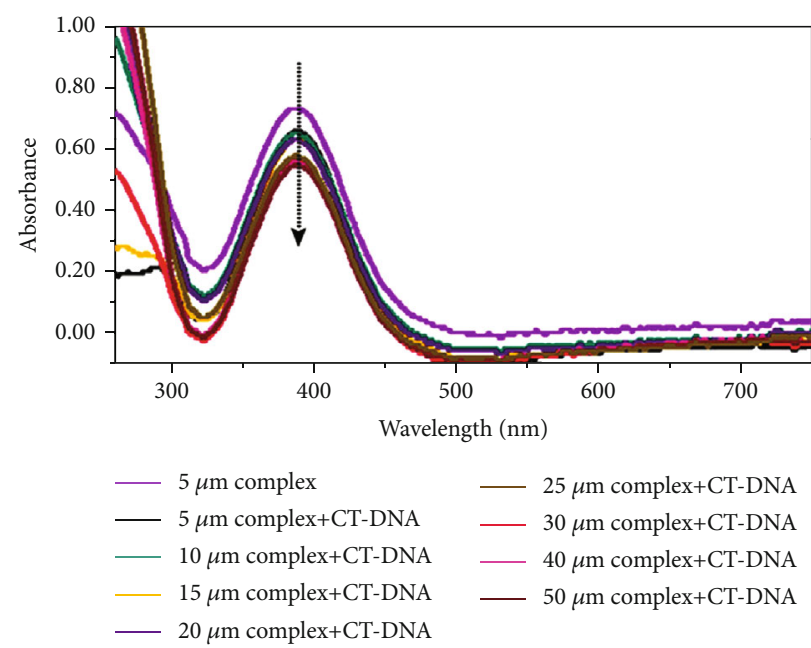

(d)

FIgURE 5: Measurement of antioxidant activity of the complex. Antioxidant activity of the ruthenium-fluvastatin complex by the (a) ABTS method, (b) DPPH method, and (c) FRAP method. (d) Absorbance spectra of CT-DNA in the presence of the ruthenium-fluvastatin complex. 


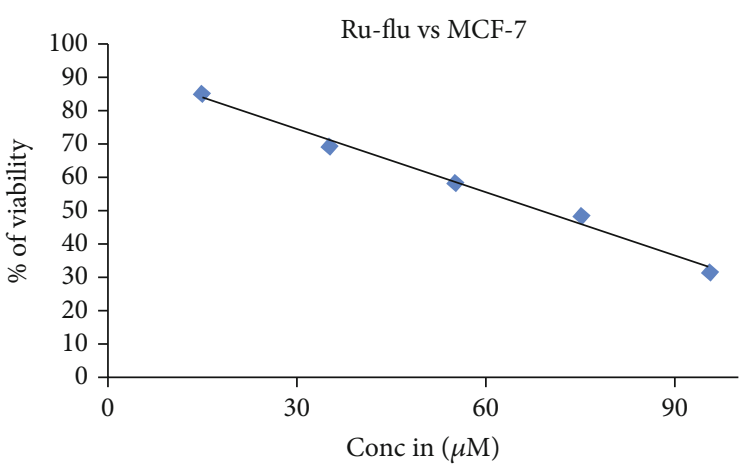

(a)
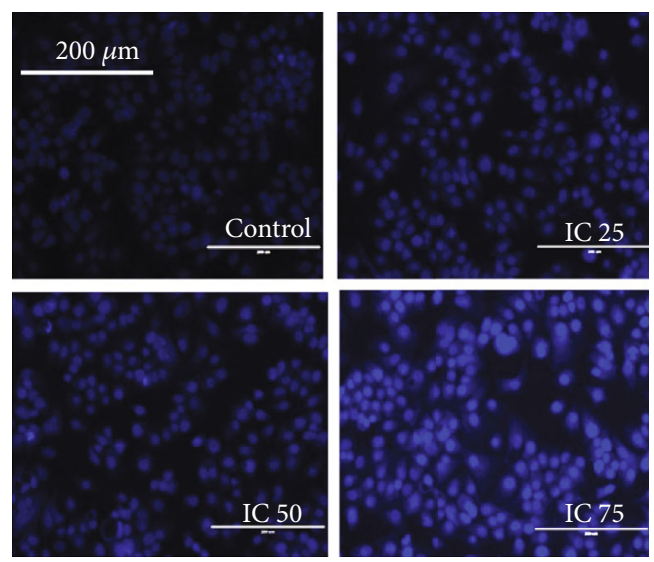

(c)

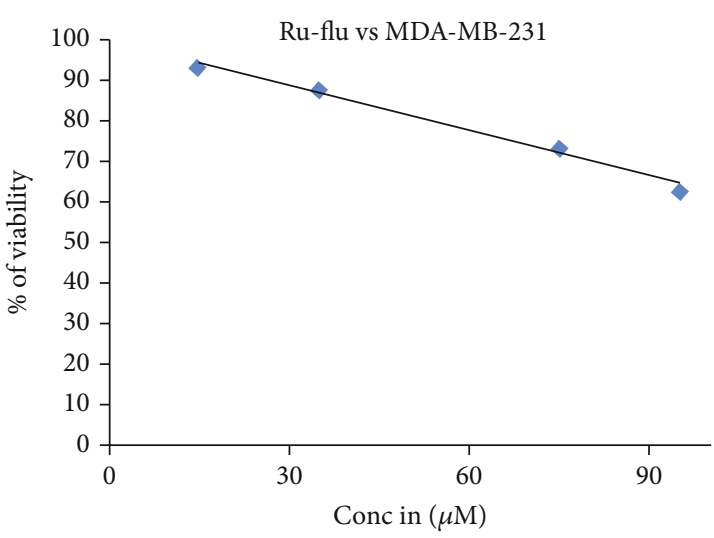

(b)
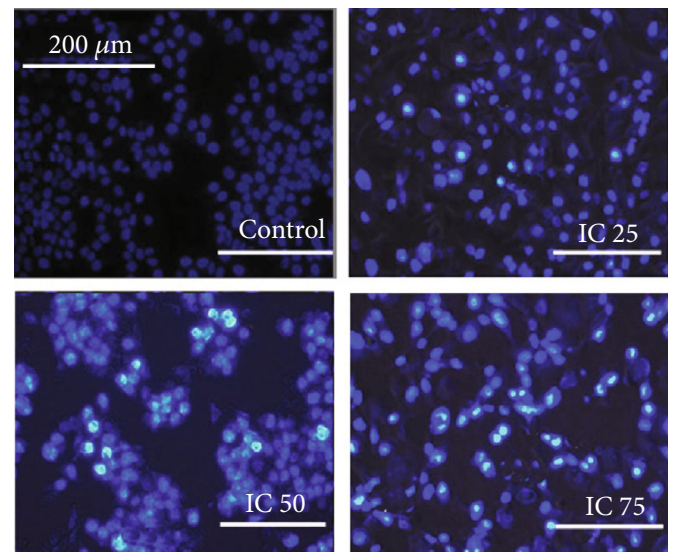

(d)

FIGURE 6: Effects of the ruthenium-fluvastatin complex on cell viability of (a) MCF-7 cells and (b) MDA-MB-231 cells at 24 hours. (c) DAPIstained MCF-7 cells after 24 hours of treatment with the ruthenium-fluvastatin complex. (d) DAPI-stained MDA-MB-231 cells after 24 hours of treatment with the ruthenium-fluvastatin complex.

subacute toxic doses following the $\mathrm{LD}_{50}$ dose evaluation. No treatment-related deaths in animals treated with 25, 50, 100, or $200 \mathrm{mg} / \mathrm{kg}$ of the complex were recorded during subacute toxicity evaluation (28 days).

\subsection{Analysis of Hematological and Serum Biochemical} Parameters. Tables 3-6 demonstrate the serum biochemical and hematology analysis of the treated and control animals. $\mathrm{WBC}$ and $\mathrm{RBC}$ quantities in the ruthenium-fluvastatin complex $(200 \mathrm{mg} / \mathrm{kg})$ dose groups were substantially improved in comparison to those of control animals. ALP, ALT, and AST were slightly higher than those of the control group at $200 \mathrm{mg} / \mathrm{kg}$ dose $(p<0.05)$. Glucose and BUN were both changed $(p<0.05)$ in animals administered with $200 \mathrm{mg} / \mathrm{kg}$ of drug. The complex at a dose of $200 \mathrm{mg} / \mathrm{kg}$ induces toxicity in animal models to some extent and was thus not considered a standard for subsequent research.

3.8. Histopathology. Histopathology of the kidney (Figure 11(a) A) of the control group exhibited the normal arrangement of architectural organization. The principal morphological disparity was observed at the dose of $200 \mathrm{mg} / \mathrm{kg}$ (Figure 11(a) E). 25 and $50 \mathrm{mg} / \mathrm{kg}$ doses did not suggest any significant animal anomalies (Figure 11(a) B and C), while mild Bowman's capsule thickening was found in animals administered with $100 \mathrm{mg} / \mathrm{kg}$ complex doses (Figure 11(a) D). Capsular membrane thickening (tm), cytoplasmic debris (cd), pyknotic nucleus (pn), vacuolization (v), and node sclerosis (n) were detected at $200 \mathrm{mg} / \mathrm{kg}$ doses of the complex. Liver histopathology (Figure 11(b) A) denoted normal hepatic structures in the control population while maximal doses $(200 \mathrm{mg} / \mathrm{kg})$ of the ruthenium- fluvastatin complex delineated focal inflammation (fi), hepatocyte degeneration (d), and mononuclear periportal infiltration (pmi) (Figure 11(b) E). Animals given doses of 25, 50, and $100 \mathrm{mg} / \mathrm{kg}$ showed no critical deformity (Figure 11(b) BD). Figure 11(c) A shows the microscopic examination of the stomach, where a dosage of $200 \mathrm{mg} / \mathrm{kg}$ of the ruthenium-fluvastatin complex revealed congestion (c), hemorrhages $(\mathrm{H})$, and hyperplasia of the glandular gastric zone (Hyp) (Figure 11(c) E). Yet histopathological differences were not found at the lower dose range $(25 \mathrm{mg} / \mathrm{kg}$, $50 \mathrm{mg} / \mathrm{kg}$, and $100 \mathrm{mg} / \mathrm{kg}$ ) (Figure 11(c) B-D). Figure 11(d) A shows the microscopic evaluation of tests where $200 \mathrm{mg} / \mathrm{kg}$ (Figure 11(d) E) of the ruthenium-fluvastatin complex administered in the animal population displayed 


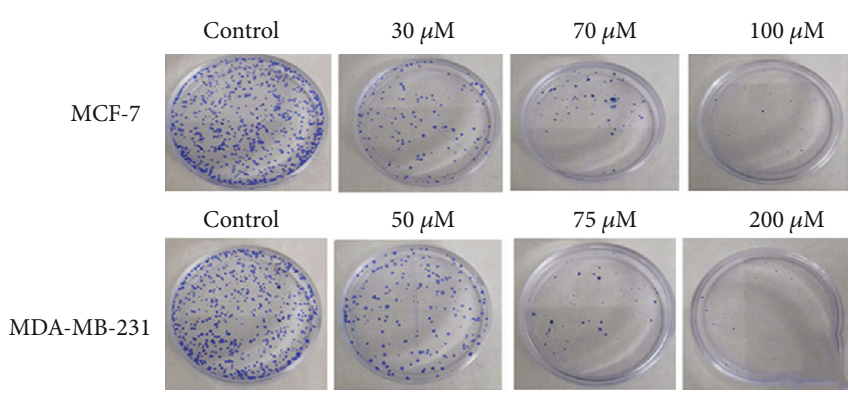

(a)

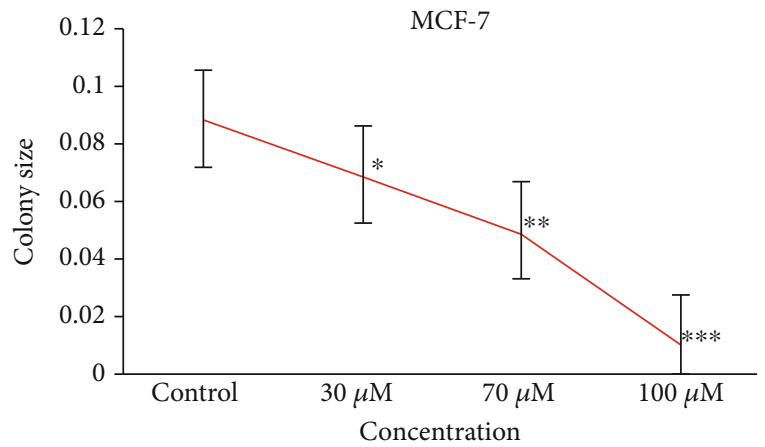

(c)

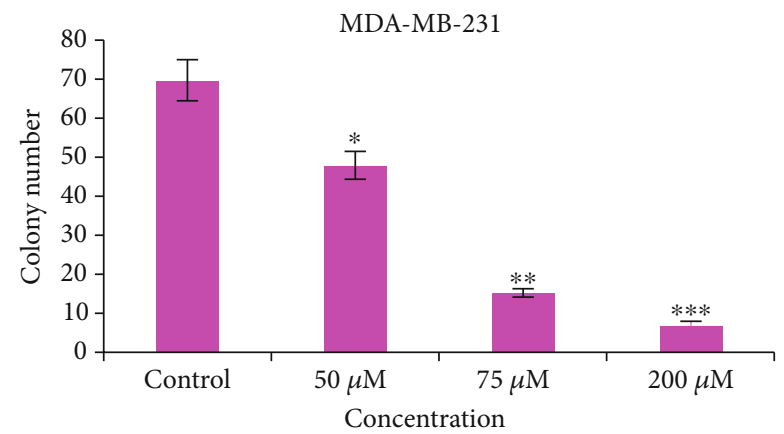

(e)

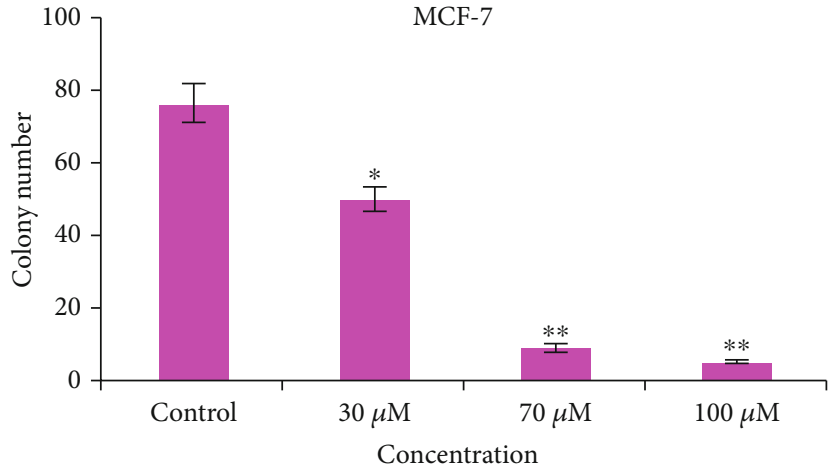

(b)

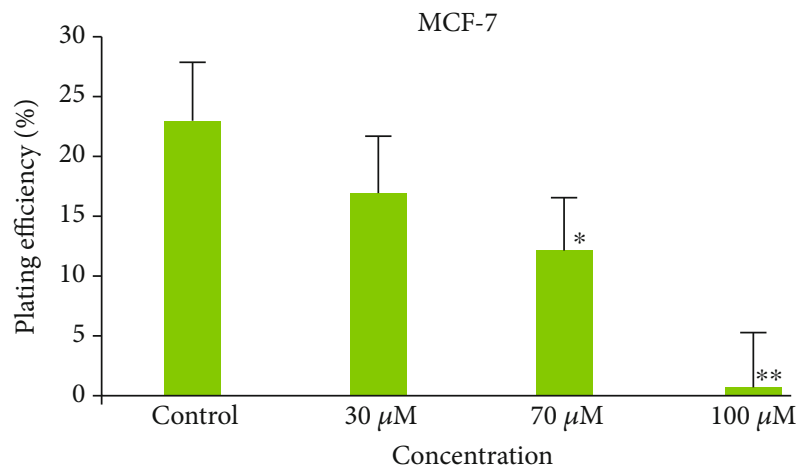

(d)

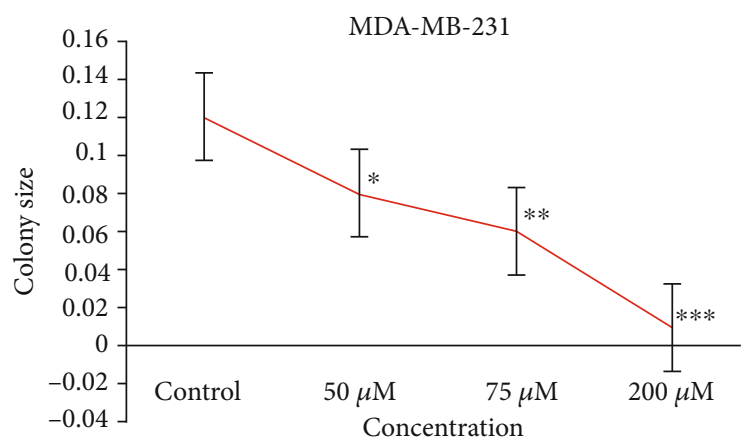

(f)

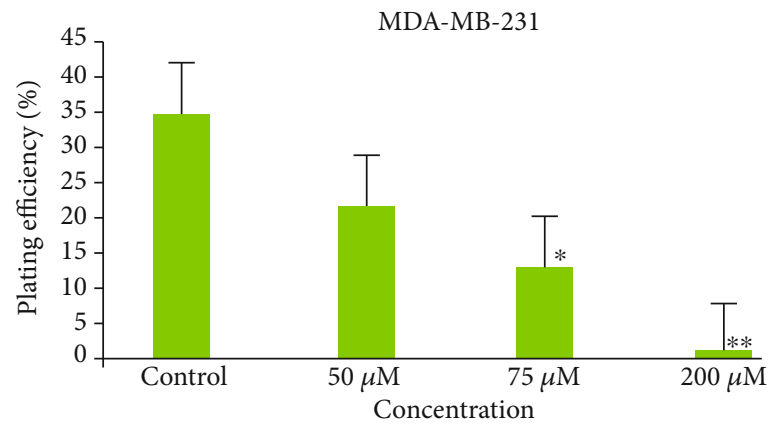

(g)

Figure 7: (a) Clonogenic assay of MCF-7 and MDA-MB-231 cells after 24 hours of treatment with the ruthenium-fluvastatin complex. (b) Quantification of the colony number for MCF-7 cells. (c) Quantification of colony size of the clonogenic assay of MCF-7 cells. (d) Plating efficiency for the clonogenic assay of MCF-7 cells. (e) Quantification of the colony number for MDA-MB-231 cells. (f) Quantification of colony size for MDA-MB-231 cells. (g) Plating efficiency for the clonogenic assay of MDA-MB-231 cells. Quantification of the colony number and size was performed using the ImageJ public domain software. Data represent means \pm SD from three different experiments in triplicate. The results were compared using ANOVA, followed by Tukey's post hoc analysis. Asterisks represent ${ }^{*} p<0.05$, ${ }^{* *} p<0.01$, and ${ }^{* * *} p<0.001$ as compared to carcinogen control. 
MCF-7
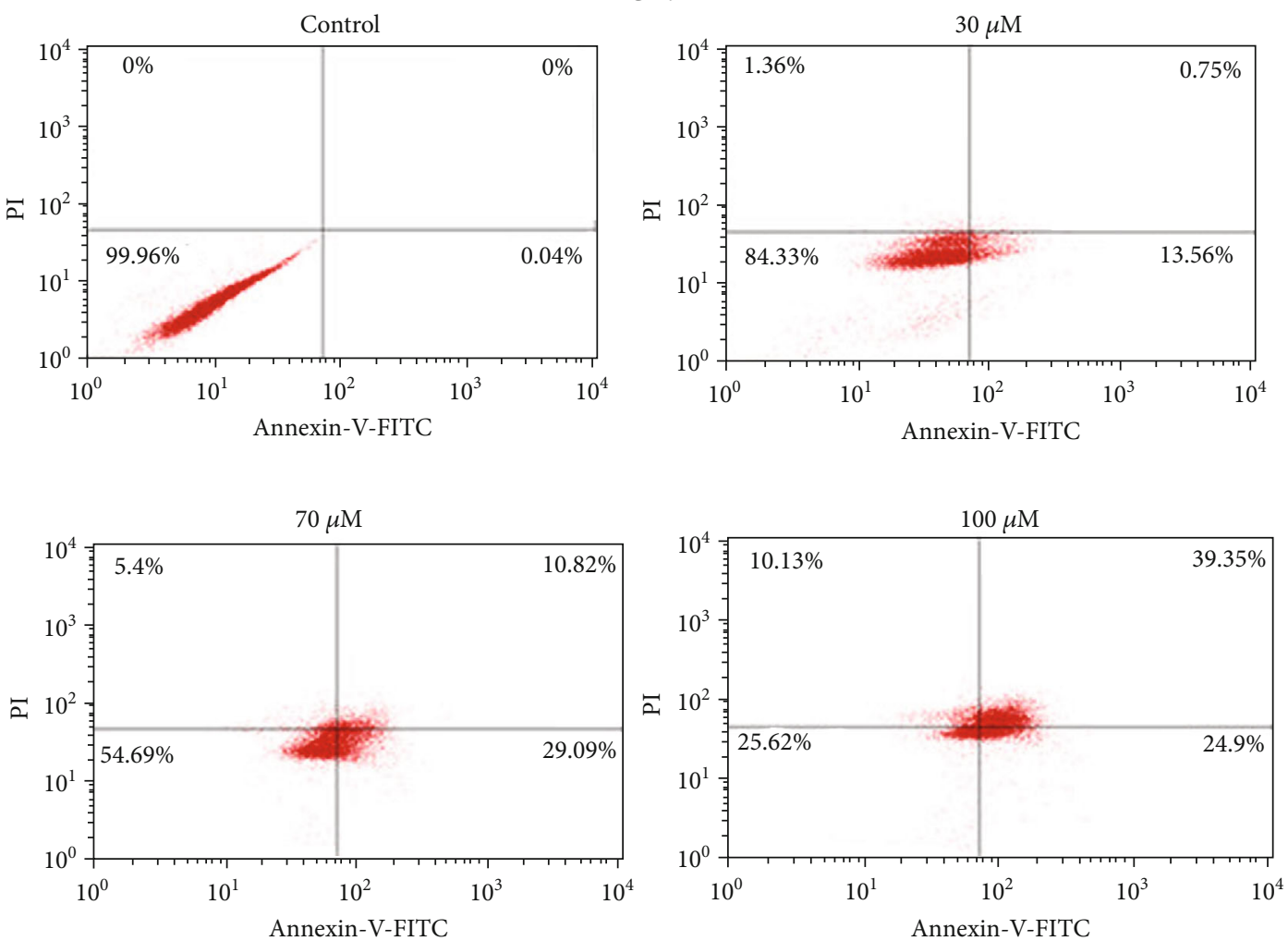

(a)

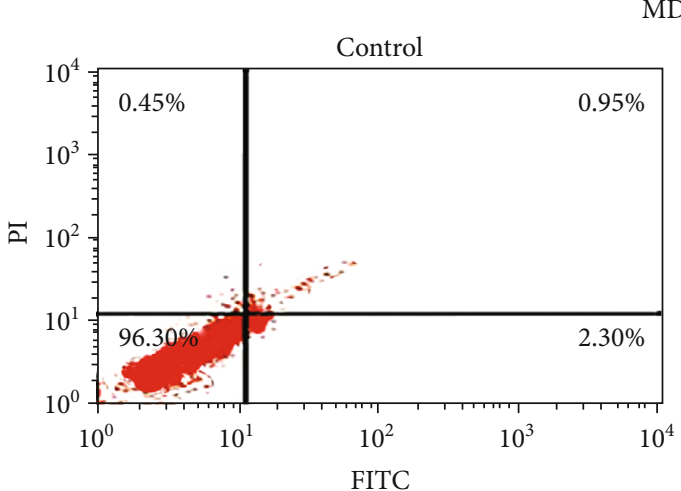

MDA-MB-231
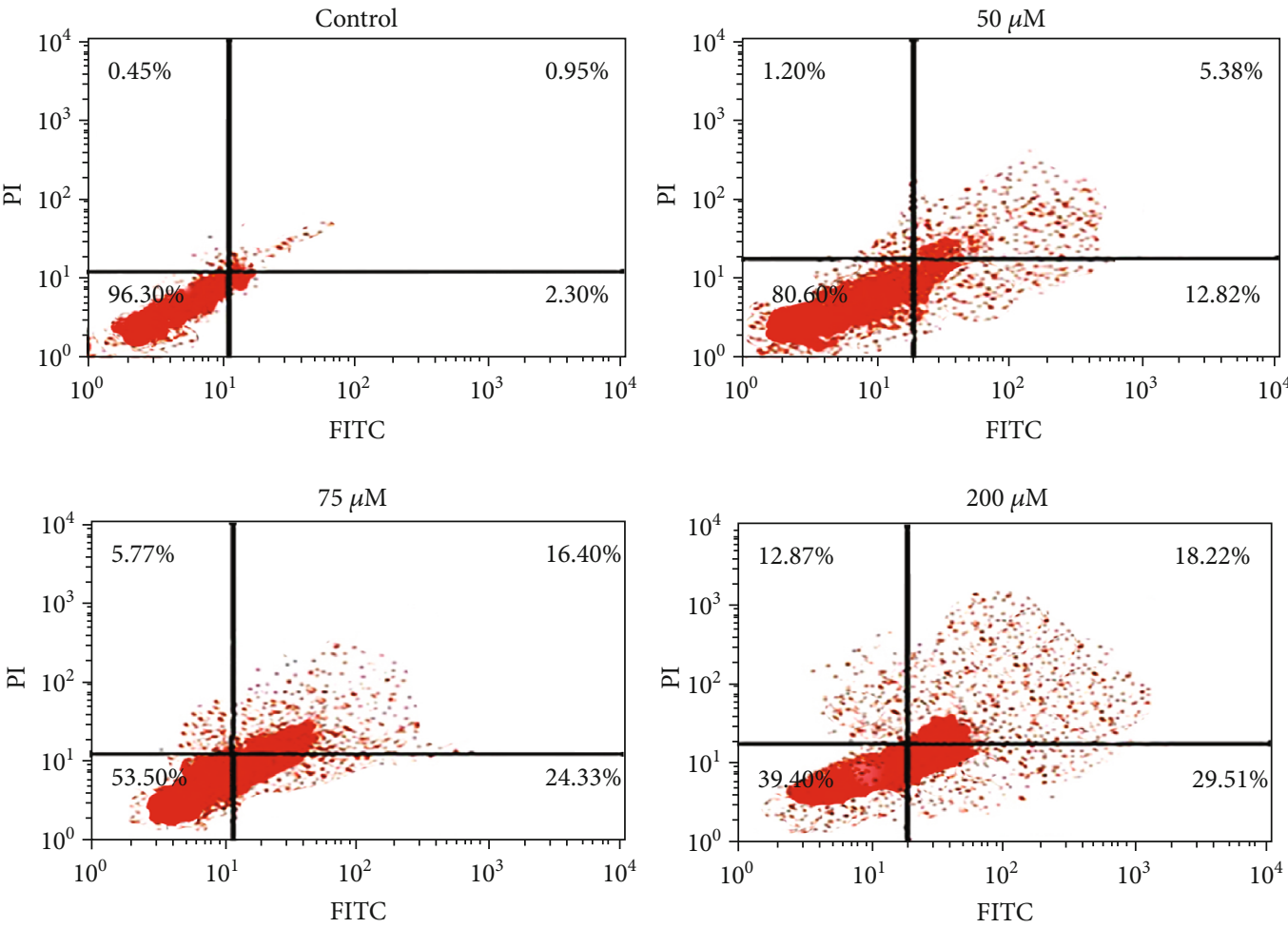

(b)

FIgURE 8: Continued. 


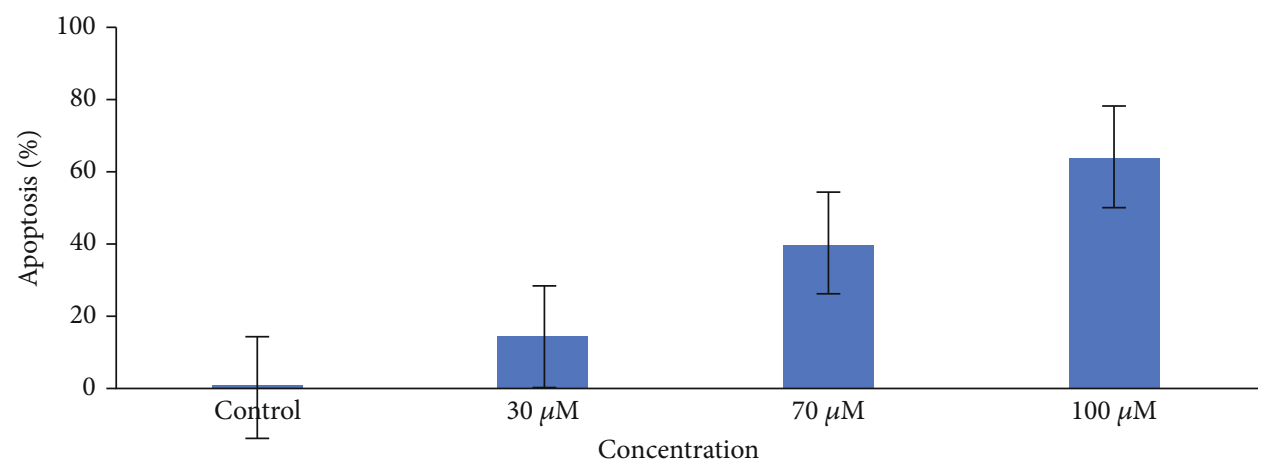

(c)

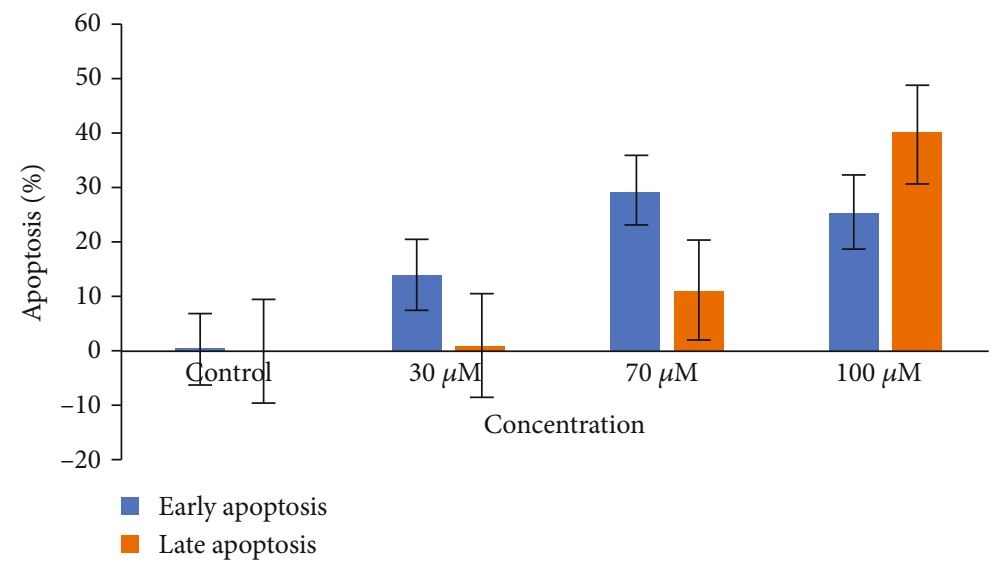

(d)

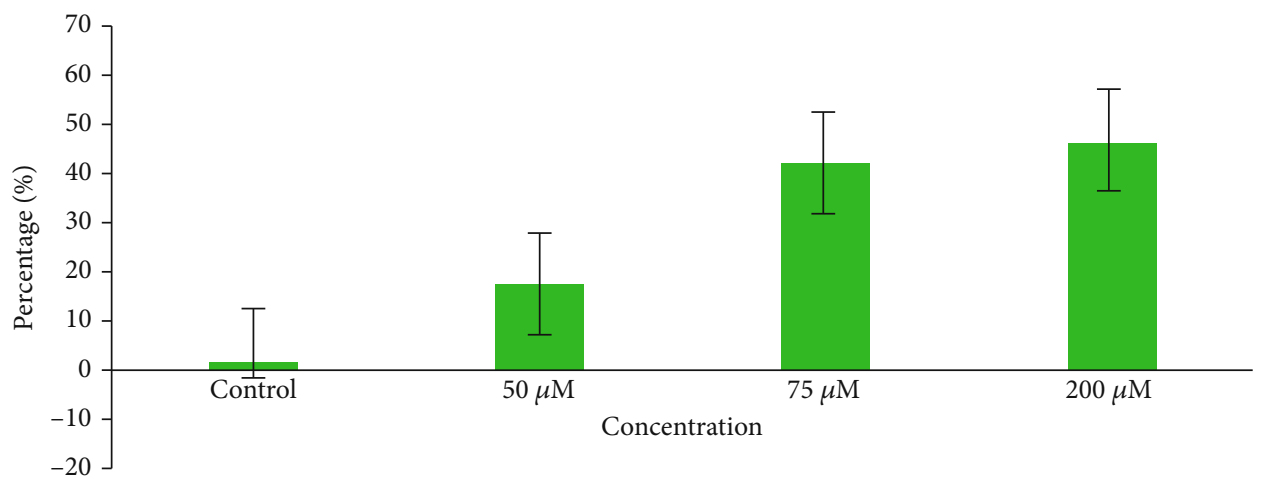

(e)

FIgURe 8: Continued. 


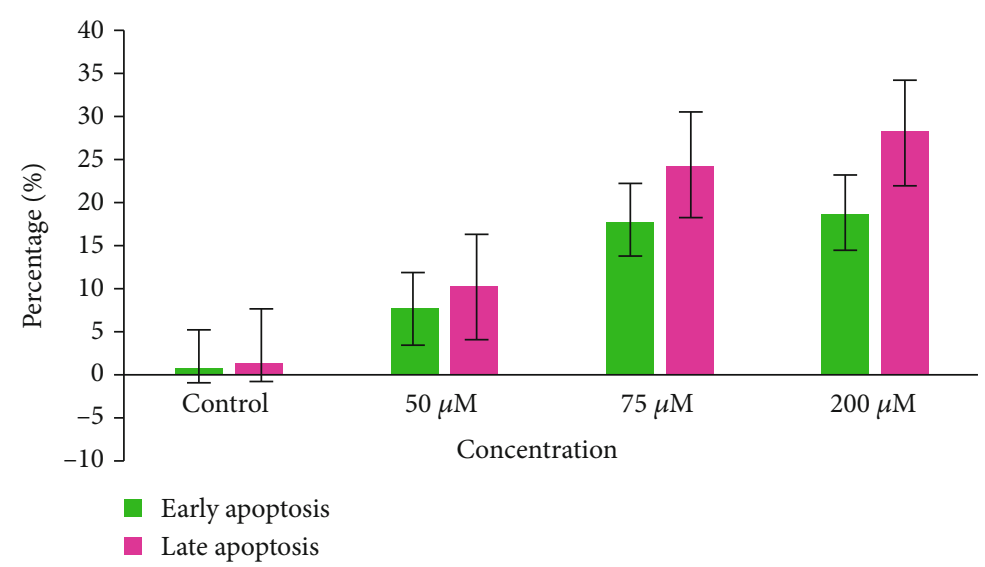

(f)

Figure 8: (a) Detection of apoptosis in MCF-7 cells by flow cytometry after treatment with the ruthenium-fluvastatin complex. (b) Detection of apoptosis in MDA-MB-231 cells by flow cytometry after treatment with the ruthenium-fluvastatin complex. (c) Percentage of apoptotic cells versus concentration in MCF-7 cells. (d) Percentage of apoptotic cells in the early and late apoptosis stage in MCF-7 cells. (e) Percentage of apoptotic cells versus concentration in MDA-MB-231 cells. (f) Percentage of apoptotic cells in the early and late apoptosis stage in MDA-MB-231 cells.

degeneration in seminiferous tubules (D) and edema in interstitial tissues (E), and at $100 \mathrm{mg} / \mathrm{kg}$ dose level (Figure 11(d) D), degeneration (D) and hyperplasia (Hyp) were detected, but no histopathological changes were found at the lower dosage points (25 mg/kg and $50 \mathrm{mg} / \mathrm{kg}$ ) (Figure 11(d) B and C).

\subsection{In Vivo Carcinogenesis Study}

3.9.1. Histopathology of Mammary Tissue. The normal control (group I) illustrates normal alveolar septa (as), alveoli (a), acinus (ac), serous gland (sg), and terminal duct lobular units (td) of mammary tissue kept intact as seen in Figure 12(a). The DMBA-treated section of group II animals revealed atrophy of the periductal, stromal, and fatty tissue glands (psf), atrophy of the underlying fatty tissue (ag), atrophy of the serous glands (asg) surrounding stromal fibrosis, and hyperplasia of the serous and mucous glands (ah) in their mammary tissues (Figure 12(b)). Slight hyperplasia of serous and mucinous glands (Figures $12(\mathrm{c})$ and 12(d)) was seen in the histological analysis of 25 and $50 \mathrm{mg} / \mathrm{kg}$ rutheniumfluvastatin complex-treated groups while in the highest dose category $(100 \mathrm{mg} / \mathrm{kg})$, there has been no evidence of hyperplasia or cell proliferation in mammary tissue and normal morphology of the cells covering the ducts was observed (Figure 12(e)). The $50 \mathrm{mg} / \mathrm{kg}$ fluvastatin-treated model revealed typical histological composition of rat mammary tissue (Figure $12(\mathrm{~g})$ ), while $50 \mathrm{mg} / \mathrm{kg}$ ruthenium-treated animals showed gland atrophy with surrounding fatty tissue (ag) and serous gland atrophy (asg) (Figure 12(f)).

3.9.2. Antioxidant Evaluation of Mammary Tissues. The fragmented mammary tissue of the carcinogen control animals has been observed with reduced levels of SOD and CAT and reduced glutathione. The animals treated with $100 \mathrm{mg} / \mathrm{kg}$ ruthenium-fluvastatin complex reported a marked rise in
SOD, CAT, and glutathione quantities in the homogenized mammary tissues as compared to carcinogenic control and other groups (Figure 12(h)).

\subsubsection{Immunohistochemical Evaluation of Mammary}

Tissues. To outline the influence of ruthenium-fluvastatin therapy on mammary cancer in rats, immunohistochemical staining approaches have been used to determine the existence of cellular biomarkers such as $\mathrm{Bax}, \mathrm{Bcl} 2, \mathrm{p} 53$, and MMP9 (Figure 13) (Table 7). It was found that DMBA treatment greatly raised levels of $\mathrm{Bcl} 2$ (Figure 13(b) B) and MMP9 (Figure 13(d) B), while also downregulating the levels of Bax (Figure 13(c) B) and p53 (Figure 13(a) B) as compared to the control group (A in Figures 13(a)-13(d)) $(p<0.05)$. The expression of Bax (Figure 13(c) C-E) and p53 (Figure 13(a) $\mathrm{C}-\mathrm{E})$ was greatly improved by ruthenium-fluvastatin therapy, but Bcl2 (Figure 13(b) C-E) and MMP9 (Figure 13(d) C-E) were significantly decreased after rutheniumfluvastatin therapy. The dosage of $100 \mathrm{mg} / \mathrm{kg}$ rutheniumfluvastatin complex was effective in raising the concentrations of Bax and p53 while the concentrations of $\mathrm{Bcl} 2$ and MMP9 $(p<0.01)$ showed a substantial decrease relative to those of carcinogen-treated animals. The presence of the above-mentioned biomarkers allows one to believe that the complex focuses on apoptosis and thus regulates the cell cycle to effectively constrain the progression of the disease.

\subsubsection{Inhibition of Ki-67 by the Ruthenium-Fluvastatin} Complex in the Mammary Tissue. The potency of the ruthenium-fluvastatin molecule in mammary tissue proliferation has been depicted in Figure 14(a). The LI (labeling index) is measured as a proportion of Ki-67 tagged cells shown in Table 8. A substantial improvement in the Ki67-LI activity was found in the DMBA-treated animals (Figure 14(a) B) compared with the normal control group (Figure 14(a) A), but a small decrease in the Ki-67-LI 

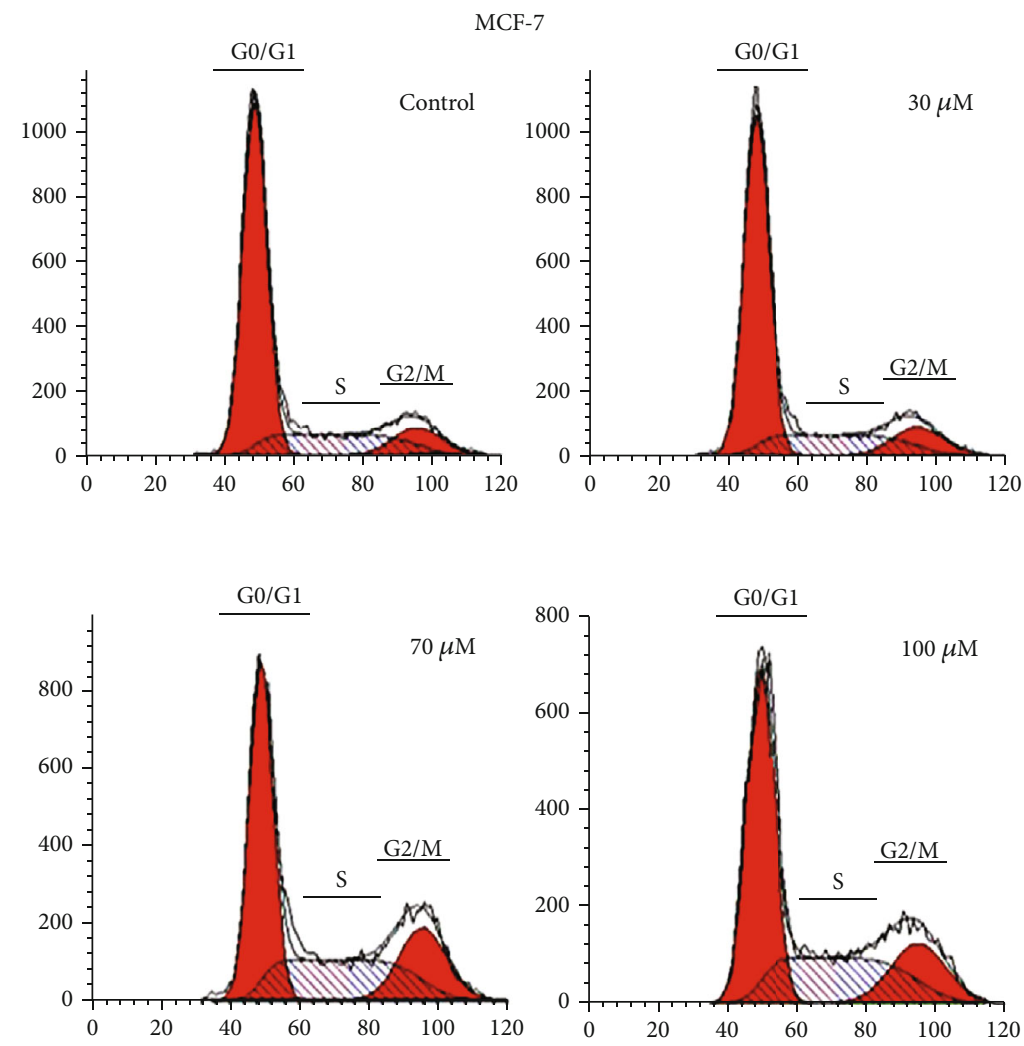

(a)

MDA-MB-231
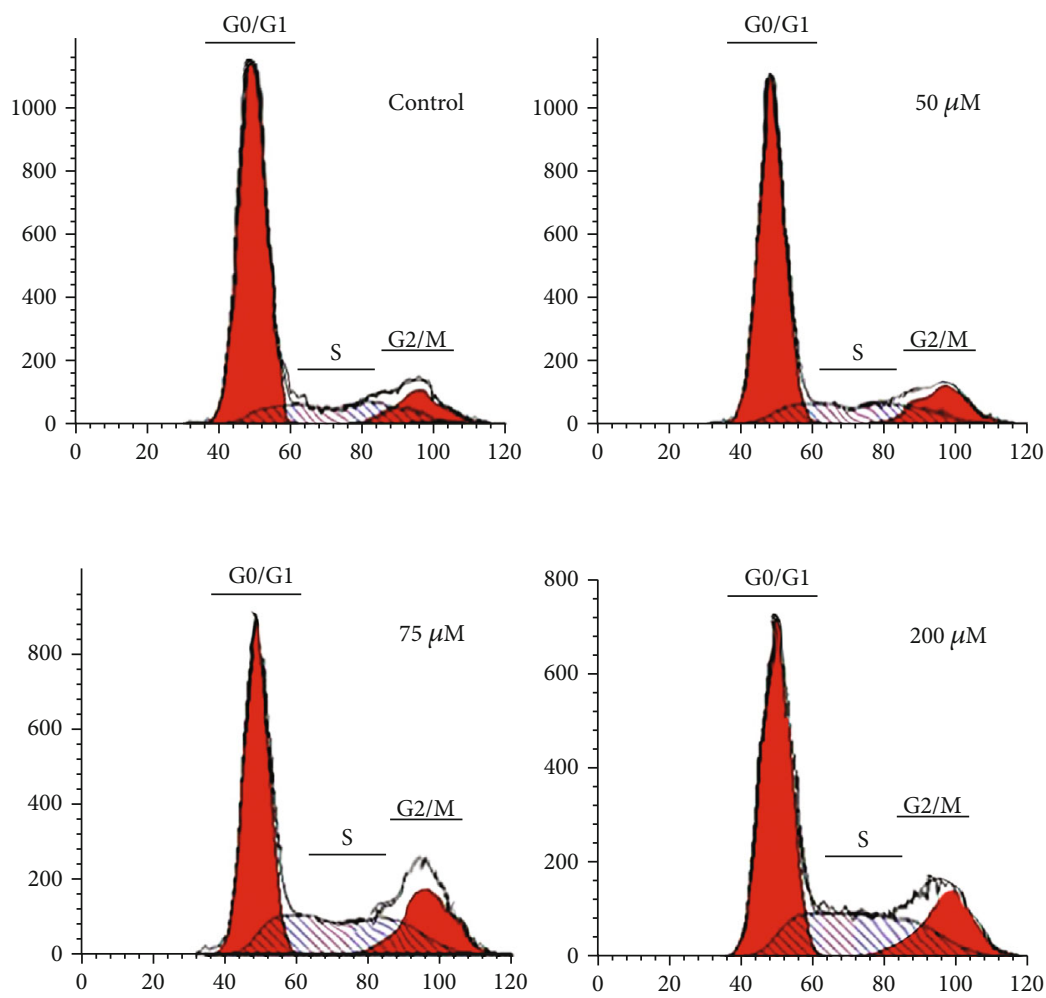

(b)

Figure 9: Continued. 


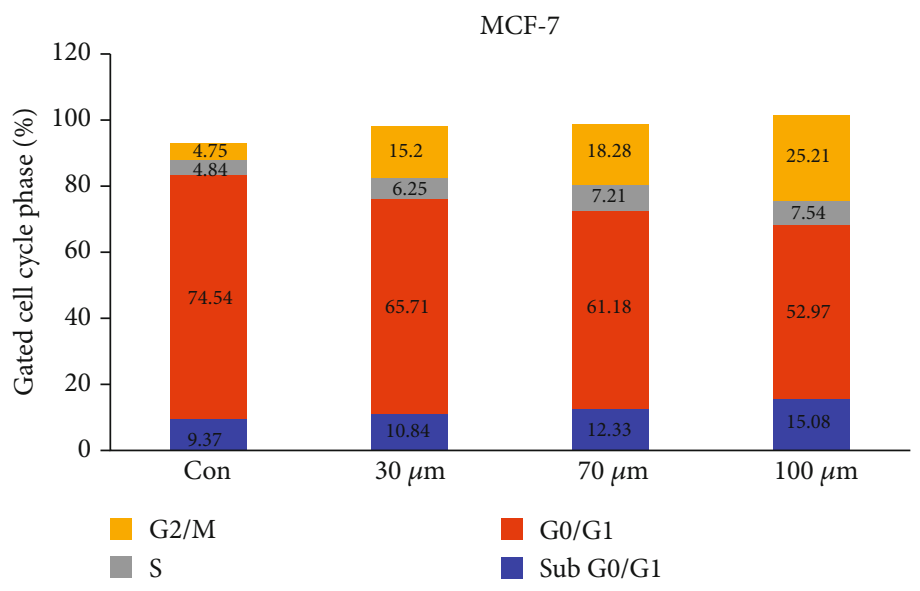

(c)

MDA-MB-231

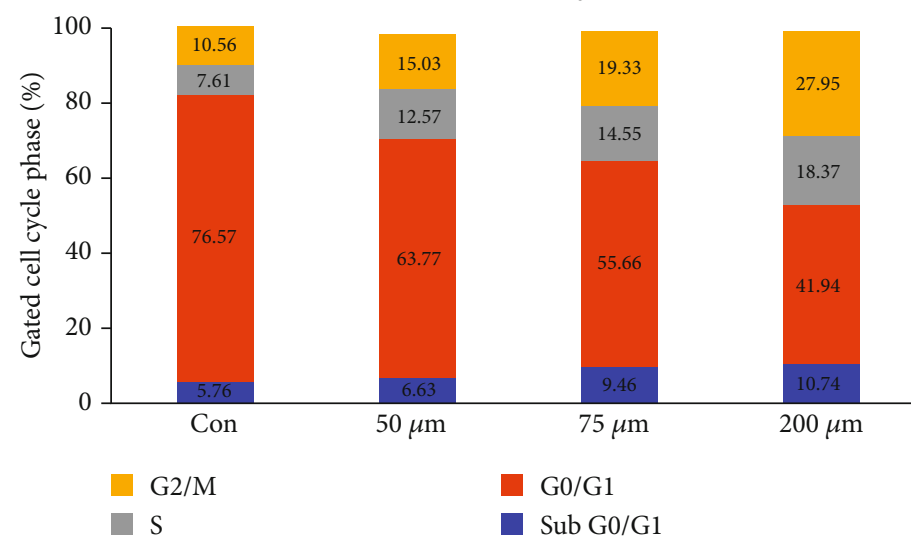

(d)

FIGURE 9: Continued. 

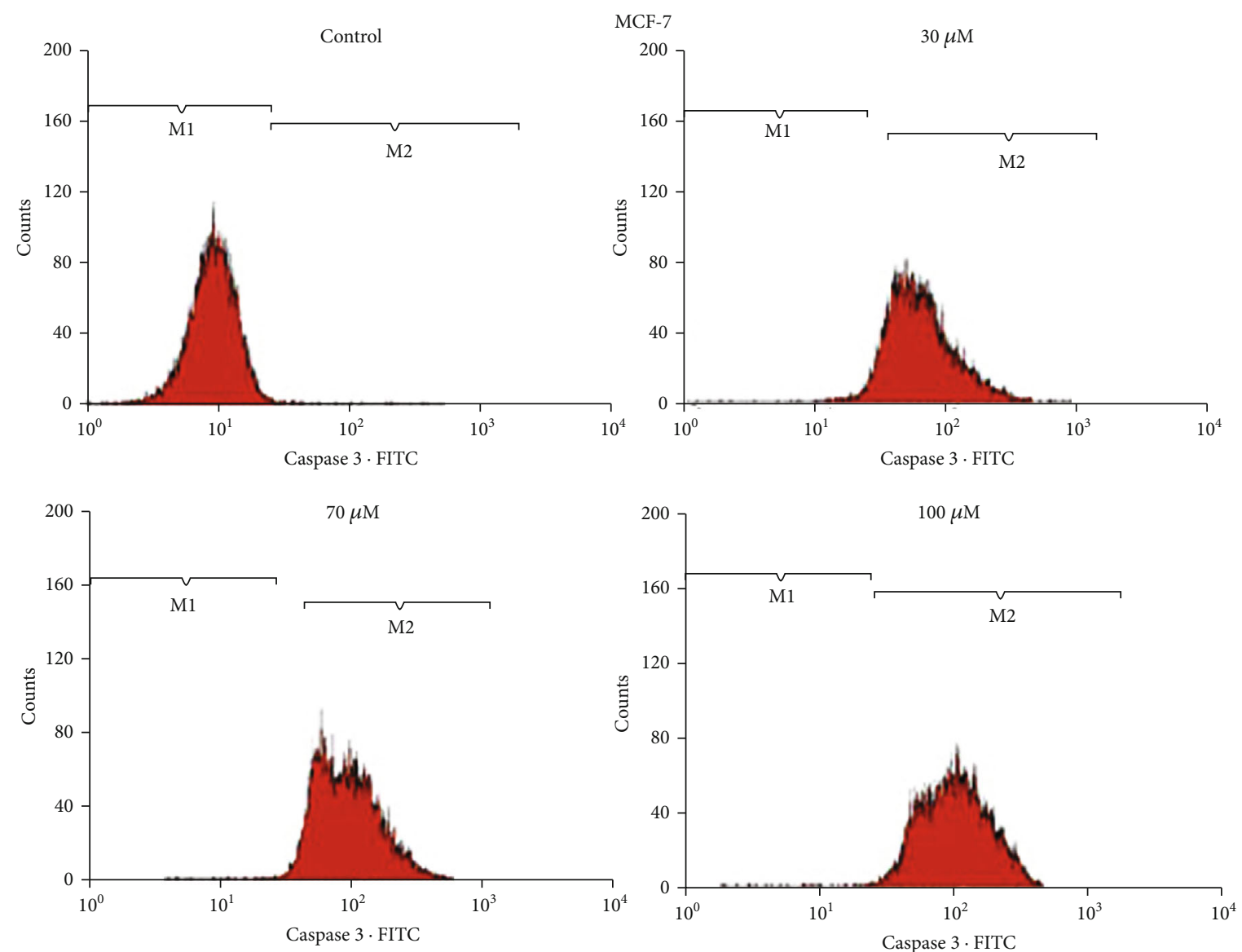

(e)

FIgURe 9: Continued. 

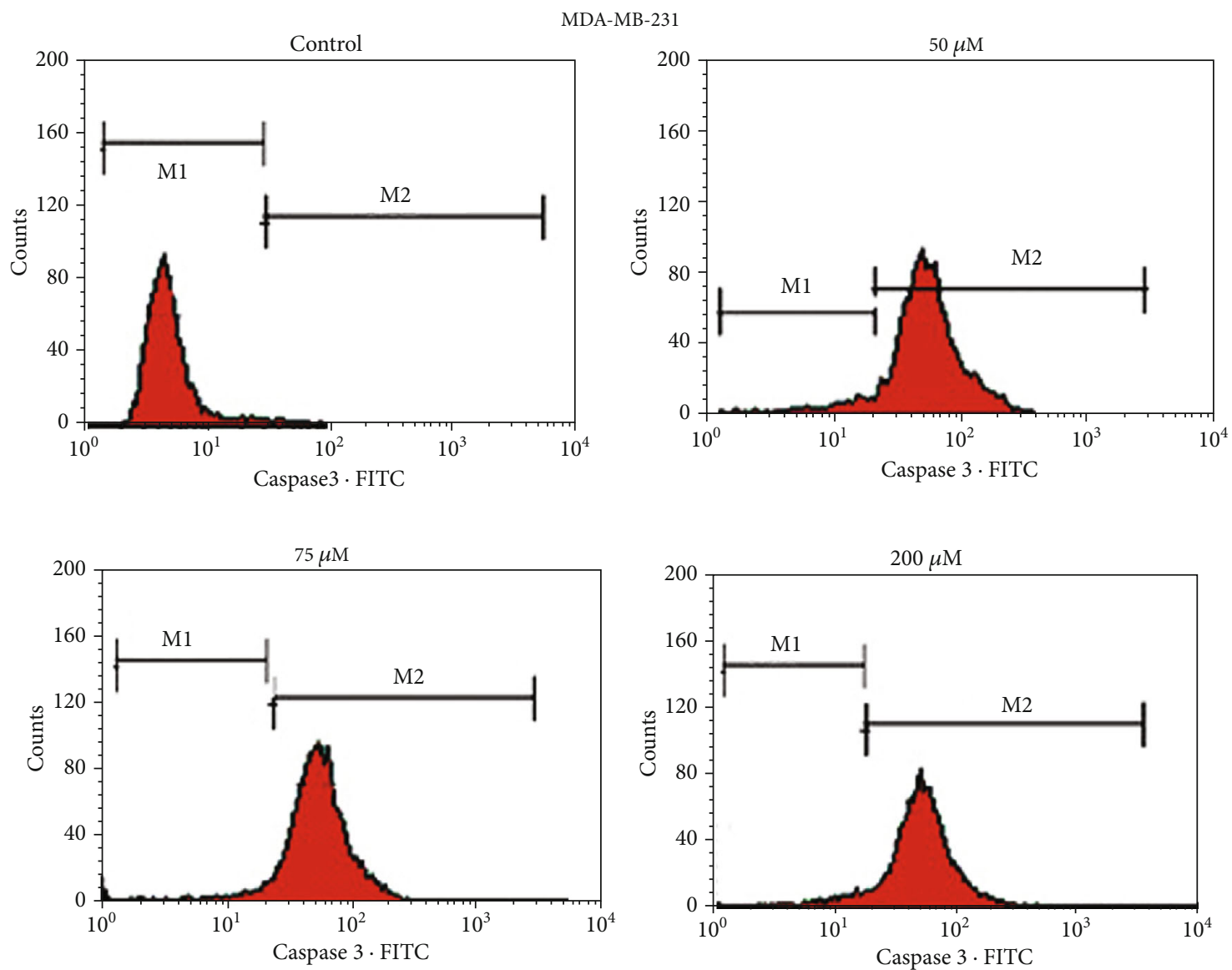

(f)

FIgURE 9: (a) Analysis of cell cycle phase distribution of MCF-7 cells after the treatment with the ruthenium-fluvastatin complex. (b) Analysis of cell cycle phase distribution of MDA-MB-231cells after the treatment with the ruthenium-fluvastatin complex. (c) Quantitative distribution of MCF-7 cells in different phases of the cell cycle. (d) Quantitative distribution of MDA-MB-231 cells in different phases of the cell cycle. (e) Expression of caspase-3 proteins in MCF-7 cells after 24 hours of treatment with the ruthenium-fluvastatin complex. (f) Expression of caspase-3 proteins in MDA-MB-231 cells after 24 hours of treatment with the ruthenium-fluvastatin complex.

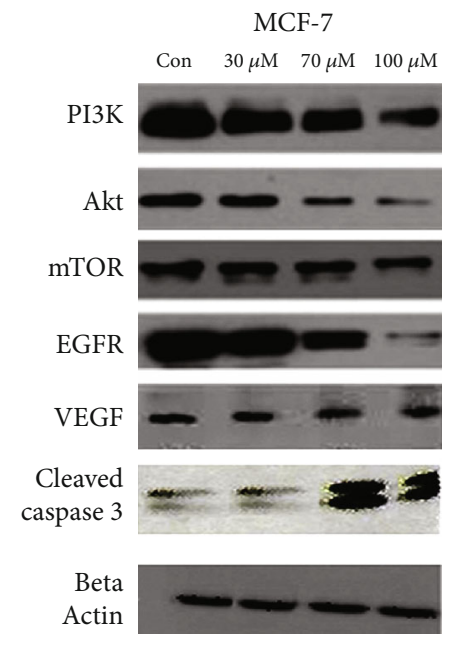

(a)

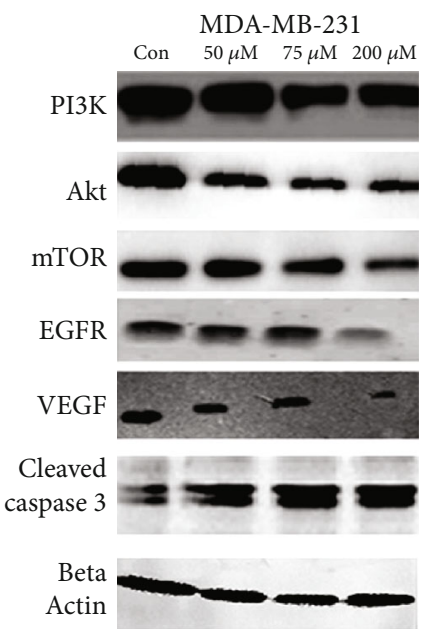

(b)

Figure 10: (a) Western blot analysis of expressions of PI3K, Akt, mTOR, EGFR, VEGF, and cleaved caspase-3 in MCF-7 cells. (b) Western blot analysis of expressions of PI3K, Akt, mTOR, EGFR, VEGF, and cleaved caspase-3 in MDA-MB-231 cells. 
TABLE 3: Hematological finding in male Swiss albino mice treated with the ruthenium-fluvastatin complex for a 28-day repeated-dose oral subacute toxicity study.

\begin{tabular}{|c|c|c|c|c|c|}
\hline Parameters $( \pm$ SEM) & Control & $\begin{array}{c}\text { Ru-flu complex } \\
(200 \mathrm{mg})\end{array}$ & $\begin{array}{c}\text { Ru-flu complex } \\
(100 \mathrm{mg})\end{array}$ & $\begin{array}{c}\text { Ru-flu complex } \\
(50 \mathrm{mg})\end{array}$ & $\begin{array}{c}\text { Ru-flu complex } \\
(25 \mathrm{mg})\end{array}$ \\
\hline Hemoglobin (\%) & $12.30 \pm 0.015$ & $13.44 \pm 0.01$ & $12.64 \pm 0.01$ & $12.25 \pm 0.01$ & $12.60 \pm 0.02$ \\
\hline Total RBC $\left(\times 10^{6} / \mu\right)$ & $4.27 \pm 0.003$ & $5.10 \pm 0.001^{\#}$ & $4.51 \pm 0.001$ & $4.33 \pm 0.002$ & $4.62 \pm 0.001$ \\
\hline $\begin{array}{l}\text { Platelet count } \\
\left(\times 10^{5} / \mu\right)\end{array}$ & $2.85 \pm 0.001$ & $3.25 \pm 0.03$ & $2.55 \pm 0.004$ & $2.58 \pm 0.001$ & $2.78 \pm 0.001$ \\
\hline $\mathrm{WBC}\left(\times 10^{3} / \mu\right)$ & $8.74 \pm 0.02$ & $13.21 \pm 0.02^{\#}$ & $11.73 \pm 0.02$ & $3.46 \pm 0.01$ & $6.4 \pm 0.04$ \\
\hline MCV (fL) & $88.86 \pm 0.01$ & $91.34 \pm 0.01$ & $88.50 \pm 0.03$ & $89.85 \pm 0.01$ & $88.84 \pm 0.01$ \\
\hline $\mathrm{MCH}(\mathrm{pg})$ & $28.44 \pm 0.01$ & $28.97 \pm 0.09$ & $28.14 \pm 0.01$ & $28.17 \pm 0.03$ & $28.13 \pm 0.01$ \\
\hline $\mathrm{MCHC}(\%)$ & $31.19 \pm 0.02$ & $31.75 \pm 0.06$ & $32.84 \pm 0.01$ & $32.26 \pm 0.01$ & $32.56 \pm 0.02$ \\
\hline Neutrophil (\%) & $28.59 \pm 0.10$ & $29.14 \pm 0.02$ & $25.24 \pm 0.12$ & $27.50 \pm 0.15$ & $27.18 \pm 0.03$ \\
\hline Eosinophil (\%) & $2.08 \pm 0.03$ & $6.08 \pm 0.03$ & $6.08 \pm 0.03$ & $5.20 \pm 0.08$ & $1.04 \pm 0.01$ \\
\hline Monocytes (\%) & $1.20 \pm 0.08$ & $2.10 \pm 0.06$ & $1.20 \pm 0.08$ & $1.20 \pm 0.08$ & $2.10 \pm 0.06$ \\
\hline Basophil (\%) & $0.0 \pm 0.0$ & $0.0 \pm 0.0$ & $0.0 \pm 0.0$ & $0.0 \pm 0.0$ & $0.0 \pm 0.0$ \\
\hline
\end{tabular}

Standard error of mean $=$ standard deviation $(\mathrm{SD}) / \sqrt{ }$ total subject. Results are analyzed by the $t$-test and one-way ANOVA and confirmed by Dunnett's multiple comparison test. MCV: mean corpuscular volume; MCH: mean corpuscular hemoglobin; MCHC: mean corpuscular hemoglobin concentration; RBC: red blood cell; WBC: white blood cell. " Significant difference at $p<0.05$, when compared with the control group.

TABLE 4: Hematological finding in female Swiss albino mice treated with the ruthenium-fluvastatin complex for a 28-day repeated-dose oral subacute toxicity study.

\begin{tabular}{lccccc}
\hline Parameters $( \pm$ SEM) & Control & $\begin{array}{c}\text { Ru-flu complex } \\
(200 \mathrm{mg})\end{array}$ & $\begin{array}{c}\text { Ru-flu complex } \\
(100 \mathrm{mg})\end{array}$ & $\begin{array}{c}\text { Ru-flu complex } \\
(50 \mathrm{mg})\end{array}$ & $\begin{array}{c}\text { Ru-flu complex } \\
(25 \mathrm{mg})\end{array}$ \\
\hline Hemoglobin $(\%)$ & $12.36 \pm 0.024$ & $13.36 \pm 0.13$ & $12.58 \pm 0.02$ & $12.14 \pm 0.024$ & $13.02 \pm 0.17$ \\
Total RBC $\left(\times 10^{6} / \mu\right)$ & $4.38 \pm 0.005$ & $5.16 \pm 0.24^{\#}$ & $4.61 \pm 0.004$ & $4.42 \pm 0.003$ & $4.71 \pm 0.003$ \\
Platelet count & $2.85 \pm 0.002$ & $3.11 \pm 0.005$ & $2.53 \pm 0.002$ & $2.58 \pm 0.002$ & $2.78 \pm 0.002$ \\
$\left(\times 10^{5} / \mu\right)$ & $8.84 \pm 0.03$ & $13.36 \pm 0.02^{\#}$ & $11.88 \pm 0.02$ & $3.72 \pm 0.03$ & $5.14 \pm 0.004$ \\
WBC $\left(\times 10^{3} / \mu\right)$ & $88.96 \pm 0.02$ & $91.34 \pm 0.02$ & $88.54 \pm 0.05$ & $89.06 \pm 0.23$ & $89.12 \pm 0.23$ \\
MCV (fL) & $28.16 \pm 0.19$ & $29.98 \pm 0.03$ & $28.04 \pm 0.03$ & $28.06 \pm 0.02$ & $27.64 \pm 0.26$ \\
MCH (pg) & $32.35 \pm 0.044$ & $32.79 \pm 0.05$ & $31.83 \pm 0.05$ & $31.41 \pm 0.02$ & $31.77 \pm 0.03$ \\
MCHC (\%) & $28.72 \pm 0.24$ & $32.36 \pm 0.05$ & $24.92 \pm 0.20$ & $26.92 \pm 0.20$ & $24.12 \pm 0.31$ \\
Neutrophil $(\%)$ & $2.21 \pm 0.09$ & $2.27 \pm 0.12$ & $2.08 \pm 0.04$ & $3.08 \pm 0.04$ & $2.02 \pm 0.02$ \\
Eosinophil (\%) & $2.02 \pm 0.02$ & $2.32 \pm 0.09$ & $1.15 \pm 0.04$ & $1.25 \pm 0.06$ & $2.15 \pm 0.01$ \\
Monocytes $(\%)$ & $0.0 \pm 0.0$ & $0.0 \pm 0.0$ & $0.0 \pm 0.0$ & $0.0 \pm 0.0$ & $0.0 \pm 0.0$ \\
Basophil $(\%)$ & & & & \\
\hline
\end{tabular}

Standard error of mean $=$ standard deviation $(\mathrm{SD}) / \sqrt{ }$ total subject. Results are analyzed by the $t$-test and one-way ANOVA and confirmed by Dunnett's multiple comparison test. MCV: mean corpuscular volume; $\mathrm{MCH}$ : mean corpuscular hemoglobin; MCHC: mean corpuscular hemoglobin concentration; RBC: red blood cell; WBC: white blood cell. "Significant difference at $p<0.05$, when compared with the control group. 
TABLE 5: Serum biochemistry findings in male Swiss albino mice treated with the ruthenium-fluvastatin complex for a 28-day repeated-dose oral subacute toxicity test.

\begin{tabular}{lccccc}
\hline Parameters $( \pm$ SEM) & Control & $\begin{array}{c}\text { Ru-flu complex } \\
(200 \mathrm{mg})\end{array}$ & $\begin{array}{c}\text { Ru-flu complex } \\
(100 \mathrm{mg})\end{array}$ & $\begin{array}{c}\text { Ru-flu complex } \\
(50 \mathrm{mg})\end{array}$ & $\begin{array}{c}\text { Ru-flu complex } \\
(25 \mathrm{mg})\end{array}$ \\
\hline AST & $31.28 \pm 0.12$ & $50.01 \pm 0.02^{\#}$ & $40.05 \pm 0.01$ & $35.39 \pm 0.07$ & $32.15 \pm 0.04$ \\
ALT & $31.28 \pm 0.08$ & $50.06 \pm 0.02^{\#}$ & $37.54 \pm 0.04$ & $45.48 \pm 0.07$ & $34.08 \pm 0.04$ \\
ALP & $76.65 \pm 15.25$ & $103.7 \pm 53.1^{\#}$ & $78.8 \pm 14.27$ & $77.3 \pm 11.80$ & $76.5 \pm 15.21$ \\
Total protein (g/dL) & $6.22 \pm 0.22$ & $2.23 \pm 0.26^{\#}$ & $6.66 \pm 0.15$ & $6.14 \pm 0.10$ & $6.22 \pm 0.14$ \\
Blood urea nitrogen & $18.10 \pm 0.03$ & $30.16 \pm 0.02^{\#}$ & $28.56 \pm 0.02$ & $28.44 \pm 0.04$ & $19.06 \pm 0.02$ \\
$(\mathrm{mg} / \mathrm{dL})$ & $0.60 \pm 0.002$ & $0.60 \pm 0.002$ & $0.60 \pm 0.002$ & $0.55 \pm 0.002$ & $0.50 \pm 0.004$ \\
Creatinine (mg/dL) & $115.2 \pm 0.37$ & $129.4 \pm 0.40^{\#}$ & $115.2 \pm 0.37$ & $115.7 \pm 0.23$ & $119.4 \pm 0.40$ \\
Glucose $(\mathrm{mg} / \mathrm{dL})$ & $47.10 \pm 0.044$ & $50.12 \pm 0.05$ & $47.08 \pm 0.03$ & $45.09 \pm 0.04$ & $43.06 \pm 0.04$ \\
Cholesterol (mg/dL) & & & & \\
\hline
\end{tabular}

Standard error of mean = standard deviation $(\mathrm{SD}) / \sqrt{ }$ total subject. Results are analyzed by the $t$-test and one-way ANOVA and confirmed by Dunnett's multiple comparison test. " Significant difference at $p<0.05$, when compared with the control.

TABLE 6: Serum biochemistry in female Swiss albino mice treated with the ruthenium-fluvastatin complex for a 28-day repeated-dose oral subacute toxicity study.

\begin{tabular}{lccccc}
\hline Parameters $( \pm$ SEM) & Control & $\begin{array}{c}\text { Ru-flu complex } \\
(200 \mathrm{mg})\end{array}$ & $\begin{array}{c}\text { Ru-flu complex } \\
(100 \mathrm{mg})\end{array}$ & $\begin{array}{c}\text { Ru-flu complex } \\
(50 \mathrm{mg})\end{array}$ & $\begin{array}{c}\text { Ru-flu complex } \\
(25 \mathrm{mg})\end{array}$ \\
\hline AST & $31.18 \pm 0.12$ & $50.11 \pm 0.02^{\#}$ & $40.15 \pm 0.01$ & $35.49 \pm 0.07$ & $32.05 \pm 0.04$ \\
ALT & $31.38 \pm 0.08$ & $50.16 \pm 0.02^{\#}$ & $37.64 \pm 0.04$ & $45.38 \pm 0.07$ & $34.12 \pm 0.04$ \\
ALP & $76.42 \pm 10.2$ & $109.7 \pm 12.36^{\#}$ & $74.8 \pm 13.27$ & $73.3 \pm 12.80$ & $71.5 \pm 15.21$ \\
Total protein (g/dL) & $6.23 \pm 0.12$ & $2.31 \pm 0.27$ & $6.12 \pm 0.15$ & $6.24 \pm 0.10$ & $6.21 \pm 0.15$ \\
Blood urea nitrogen & $18.25 \pm 0.03$ & $32.16 \pm 0.02^{\#}$ & $28.12 \pm 0.02$ & $28.75 \pm 0.04$ & $19.43 \pm 0.02$ \\
(mg/dL) & $0.60 \pm 0.002$ & $0.61 \pm 0.002$ & $0.62 \pm 0.002$ & $0.55 \pm 0.002$ & $0.50 \pm 0.004$ \\
Creatinine (mg/dL) & $112.2 \pm 0.37$ & $131.4 \pm 0.40^{\#}$ & $115.1 \pm 0.37$ & $117.7 \pm 0.23$ & $119.4 \pm 0.40$ \\
Glucose $(\mathrm{mg} / \mathrm{dL})$ & $47.20 \pm 0.04$ & $50.02 \pm 0.05$ & $47.18 \pm 0.03$ & $45.19 \pm 0.04$ & $43.16 \pm 0.04$ \\
Cholesterol $(\mathrm{mg} / \mathrm{dL})$ & & & & \\
\hline
\end{tabular}

Standard error of mean $=$ standard deviation $(\mathrm{SD}) / \sqrt{ }$ total subject. Results are analyzed by the $t$-test and one-way ANOVA and confirmed by Dunnett's multiple comparison test. "Significant difference at $p<0.05$, when compared with the control group.

value was found in the highest dose of rutheniumfluvastatin complex-treated animals $\quad(p<0.01)$ (Figure 14(a) C-E) relative to carcinogen control animals.

\subsubsection{Ruthenium-Fluvastatin Complex Promotes Apoptosis in} Mammary Tissue. The TUNNEL assay was carried out to assess the outcome of apoptosis with ruthenium-fluvastatin therapy in mammary carcinogenesis (Figure 14(b)). Apoptosis prompts the nuclear DNA to be fragmented into different segments that create DNA strand breaks that could be identified by the brown marks produced by DAB chromogen. Normal control cells undergoing cell death have been displayed in (Figure 14(b) A). In the carcinogen control group, the TUNEL-labeled cells enduring apoptosis were very limited (Figure 14(b) B), while the TUNEL-labeled cells of ruthenium-fluvastatin-treated animals dramatically increased (Figure 14(b) C-E). Typically, 3 to 5 apoptotic cells were found in an environment of approximately 700 cells throughout the carcinogen control group, which increased to $10-14$ cells per 700 cells in the $100 \mathrm{mg} / \mathrm{kg}$ of the complex-administered animals. AI specifies the apoptotic index and appears in Table 8. Animals obtaining $100 \mathrm{mg} / \mathrm{kg}$ of the drug, when compared with the carcinogen control group, represented a marked increase in apoptosis. The $R$ value represents the relationship between cell proliferation and apoptosis. Cell proliferation and TUNEL evaluation suggest that the new improvements in the tumor's microenvironment could be followed by a parallel rise in cell proliferation and a minimization of cell death. The $R$ value hits a plateau in the carcinogen control group; however, it gradually decreases with the complex's increasing concentration. Through mentioning both of these hypotheses, we can conclude that the complex activates apoptosis and ultimately decreases cell proliferation in a dose-dependent manner.

\section{Discussion}

Current anticancer drugs obtained from metal complexes focus entirely on activating cell apoptosis and offer substantial improvements in pharmacological studies [64]. This change was spectacularly motivated by the discovery of platinum-based antitumor drugs, but various obstacles such 


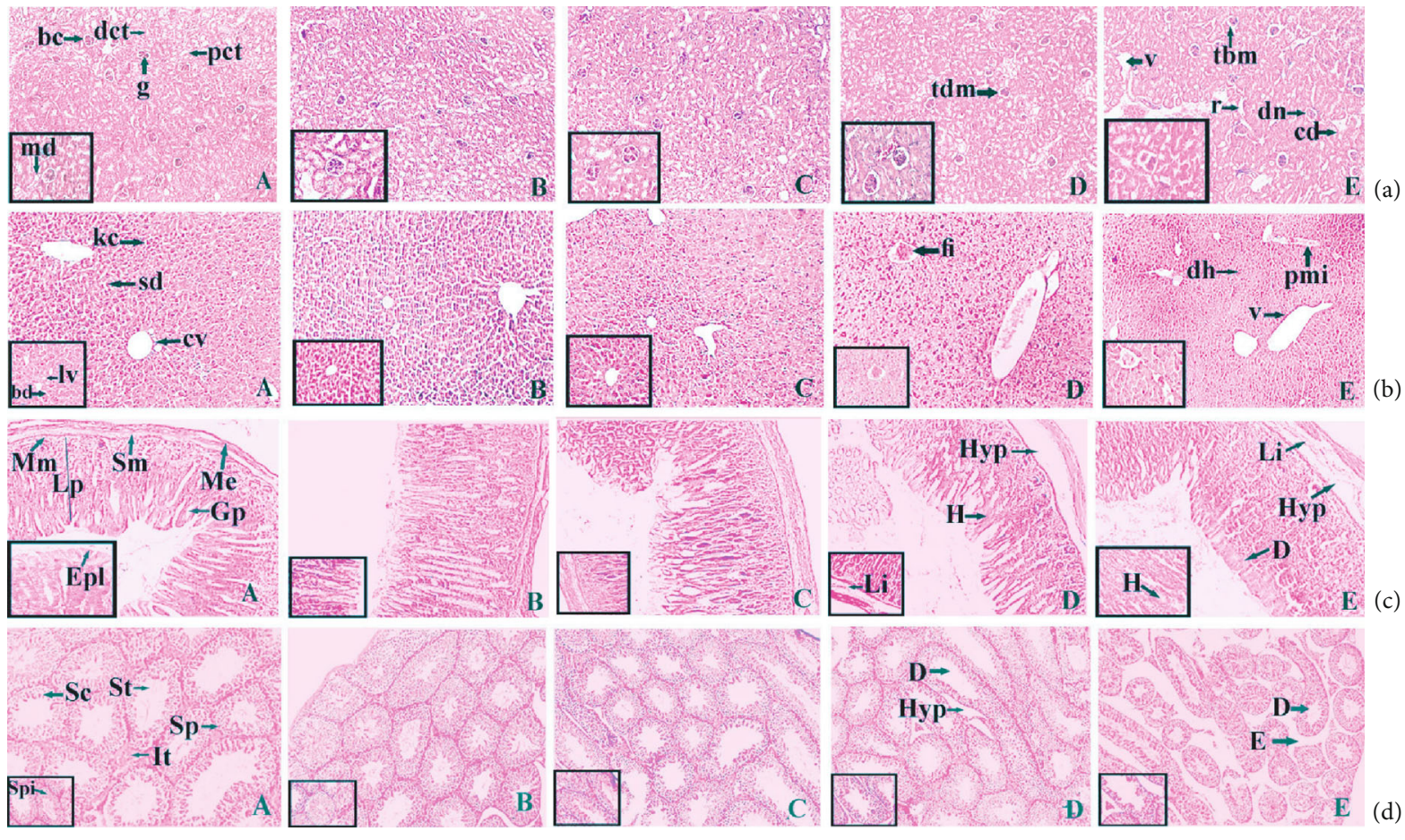

Figure 11: (a) Histopathological representation of the kidney of Balb/c mice: (A) normal tissue showing the glomerulus (g), Bowman's capsule (bc), macula densa (md), proximal convoluted tubule (pct), and distal convoluted tubule (dct); (B) kidney tissue exposed to $25 \mathrm{mg} / \mathrm{kg}$ complex; (C) kidney tissue exposed to $50 \mathrm{mg} / \mathrm{kg}$ complex; and (D) kidney tissue exposed to $100 \mathrm{mg} / \mathrm{kg}$ complex and (E) exposed to $200 \mathrm{mg} / \mathrm{kg}$ complex showing thickening of the capsular membrane (tbm), ruptures ( $\mathrm{r}$ ), desquamated nuclei (dn), and vacuolization. (b) Histopathological representation of the liver of Balb/c mice: (a) normal control showing the central vein (cv), bile duct (bd), sinusoidal dilation (sd), Kupffer cell (kc), and lymph vessel (lv); (B and C) kidney tissue exposed to $25 \mathrm{mg} / \mathrm{kg}$ and $50 \mathrm{mg} / \mathrm{kg}$ of the complex, respectively; and (D and E) kidney tissue exposed to 100 and $200 \mathrm{mg} / \mathrm{kg}$ complex showing the periportal mononuclear infiltrates (pmi), degeneration of hepatocytes (dh), and focal inflammation (fi). (c) Histopathological representation of the stomach of Balb/c mice: (a) normal control showing the muscularis externa (Me), submucosa $(\mathrm{Sm})$, muscularis mucosa (Mm), lamina propria (Lp), gastric pit (Gp), and epithelial lining (Epl); (B and C) stomach tissue exposed to $25 \mathrm{mg} / \mathrm{kg}$ and $50 \mathrm{mg} / \mathrm{kg}$ of the complex, respectively; and (D and E) stomach tissue exposed to 100 and $200 \mathrm{mg} / \mathrm{kg}$ complex showing hemorrhages (H) between the villus, hyperplasia (Hyp), and leukocyte infiltration (Li). (d) Histopathological representation of the testis of Balb/c mice: (a) normal control showing the Sertoli cell (Sc), spermatogonia (Sp), seminiferous tubule (St), and interstitial tissues (It) seen within the tubular lumen; (B and C) testis exposed to $25 \mathrm{mg} / \mathrm{kg}$ and $50 \mathrm{mg} / \mathrm{kg}$ of the complex, respectively; and (D and E) testis exposed to 100 and $200 \mathrm{mg} / \mathrm{kg}$ complex showing edema in interstitial tissue (E), degeneration of the seminiferous tubule (D), and hyperplasia (Hyp). H\&E: 10x magnification (inset: 40x).

as intense side effects, drug resistance, mutation aggregation, and epimutations cause to come up with substitute therapies. In their research paper, Allardyce and Dyson explained that another platinum group metal, ruthenium, exhibits similar propitious biological properties [65] and is further able to establish strong chemical bonds through variable electronegativity thus rendering it capable to interact with a variety of biomolecules [66].

A lot of emerging chemotherapeutics utilize apoptosis as a mechanism to induce cellular death in tumor cells [67]. To prevent apoptosis, a tumor may gain a variety of mutations or alterations. While escaping from programmed cell death is a crucial feature of tumorigenesis, it does not appear to be a common response to all apoptotic stressors. Arguably, some of the apoptotic mechanisms and pathways in tumors stay unchanged, making them ideal candidates for therapeutic targeting [68]. Among other molecules, statins have been found to have apoptosis-inducing properties. The potency of statins as an anticancer therapy has been explored both in monotherapy and in combined regimens with commonly used chemotherapeutics [69]. Several reports have also indicated that statins caused programmed cell death in a subset of tumor-derived cell lines in vitro, indicating that the analogous cancers might be susceptible to statin-specific apoptosis in vivo [70-72]. Thus, the present study focuses on exploring the potential effects of the ruthenium-fluvastatin complex on in vitro and in vivo breast cancer models.

Synuclein- $\gamma$ (SNCG) is a member of the synuclein family that has been associated with both neurodegenerative disorder and cancer [73]. A collection of functional experiments has shown that SNCG's ectopic expression in breast carcinoma facilitates proliferation and migration [34]. SNGC inhibitors have been investigated extensively based on previous studies and offer significant probability as a future drug target [74]. Inspired by this data and extensively exploring this problem, we decided to take benefit of molecular docking analyses to evaluate and explore the novel complex's binding mechanism against SNCG as a target protein. 


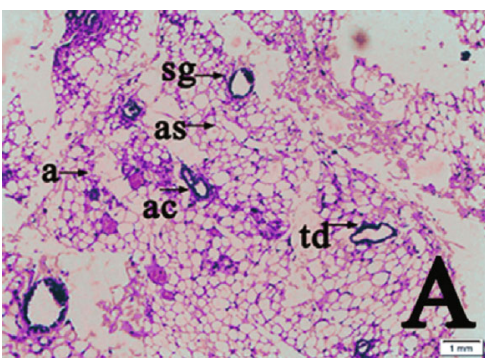

(a)

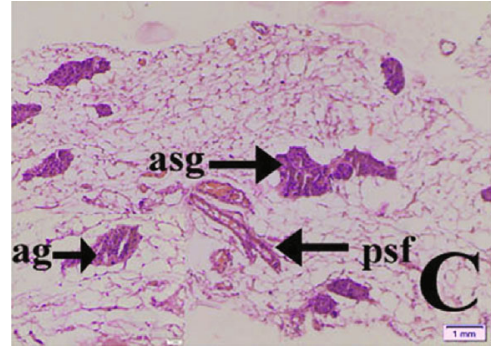

(c)

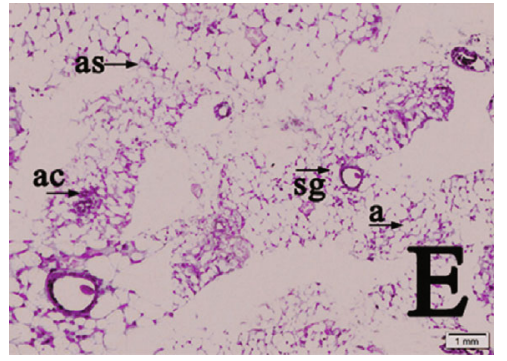

(e)

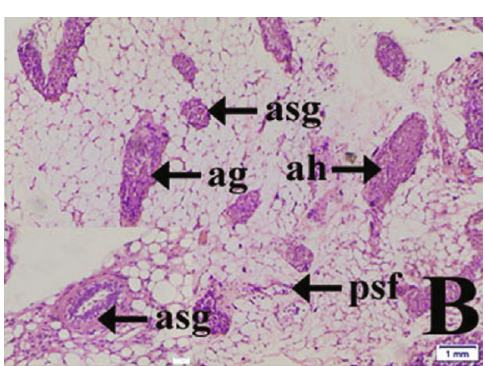

(b)

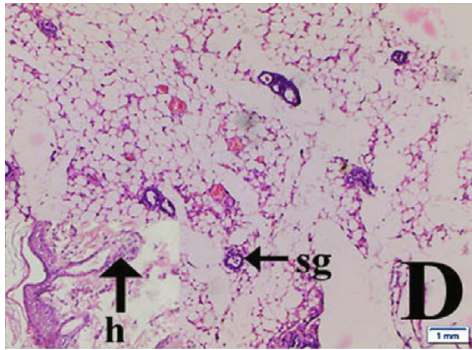

(d)

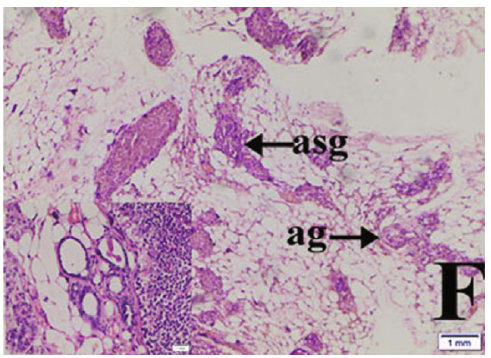

(f)

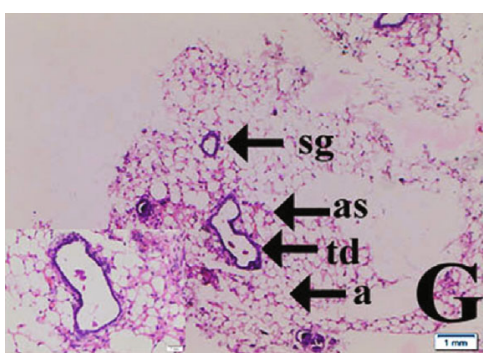

(g)

Figure 12: Continued. 


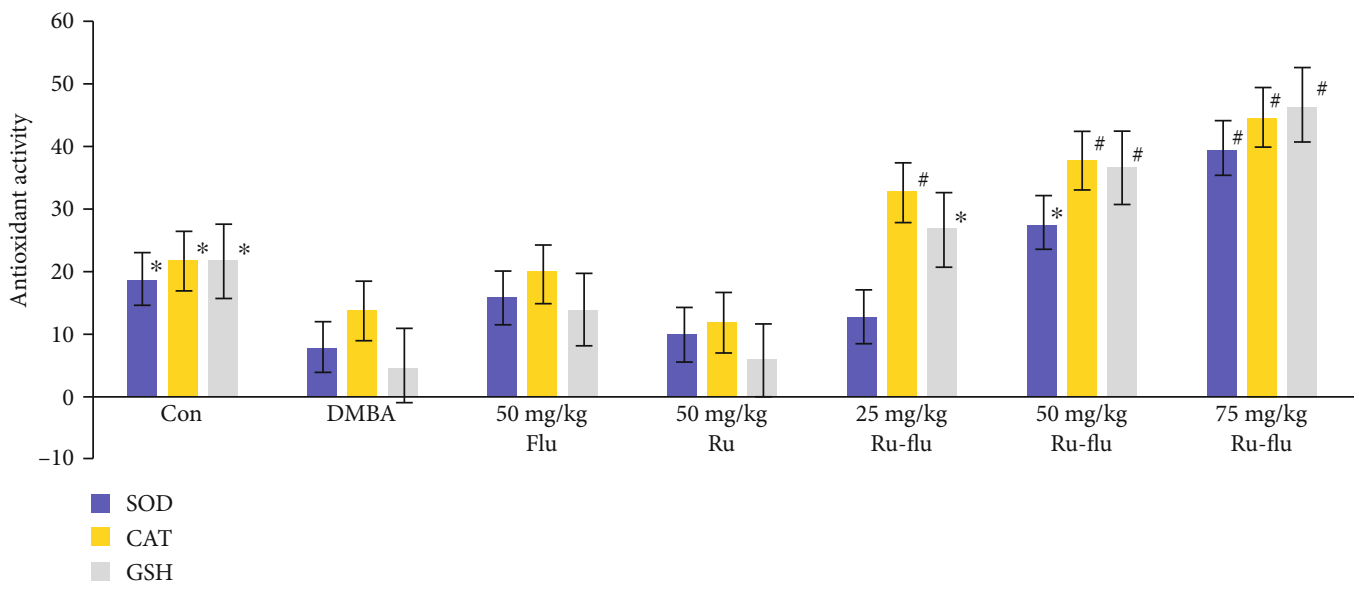

(h)

FIgURE 12: (a) Histological appearance of mammary tissue of normal control showing the terminal duct lobular units (td), alveoli (a), alveolar septa (sg), acinus (ac), and serous gland (sg). (b) DMBA control shows atrophy of glands with periductal stromal fibrosis and fatty tissue (psf), atrophy of glands (ag) with surrounding fatty tissue, atrophy of serous glands (asg) with surrounding stromal fibrosis, and atypical hyperplasia (ah). (c) Mammary tissue of the DMBA-induced group treated with $25 \mathrm{mg} / \mathrm{kg}$ ruthenium-fluvastatin complex showing atrophy of serous glands (asg), atrophy of glands (ag), and periductal stromal fibrosis and fatty tissue (psf). (d) Mammary tissue of the DMBA-induced group treated with $50 \mathrm{mg} / \mathrm{kg}$ ruthenium-fluvastatin complex showing hyperplasia of serous and mucinous glands (h). (e) Mammary tissue of the DMBA-induced group treated with $75 \mathrm{mg} / \mathrm{kg}$ ruthenium-fluvastatin complex having almost normal architecture. (f) Mammary tissue of the DMBA-induced group treated with $50 \mathrm{mg} / \mathrm{kg}$ ruthenium. (g) Mammary tissue of the DMBA-induced group treated with $50 \mathrm{mg} / \mathrm{kg}$ fluvastatin. (h) Effect of the ruthenium-fluvastatin complex on in vivo antioxidant enzymes: SOD (superoxide dismutase), CAT (catalase), and GST (glutathione). ${ }^{*} p<0.05$ as compared to the carcinogen control; ${ }^{*} p<0.01$ as compared to the ruthenium, fluvastatin, and ruthenium-fluvastatin $(25,50$, and $100 \mathrm{mg} / \mathrm{kg})$.
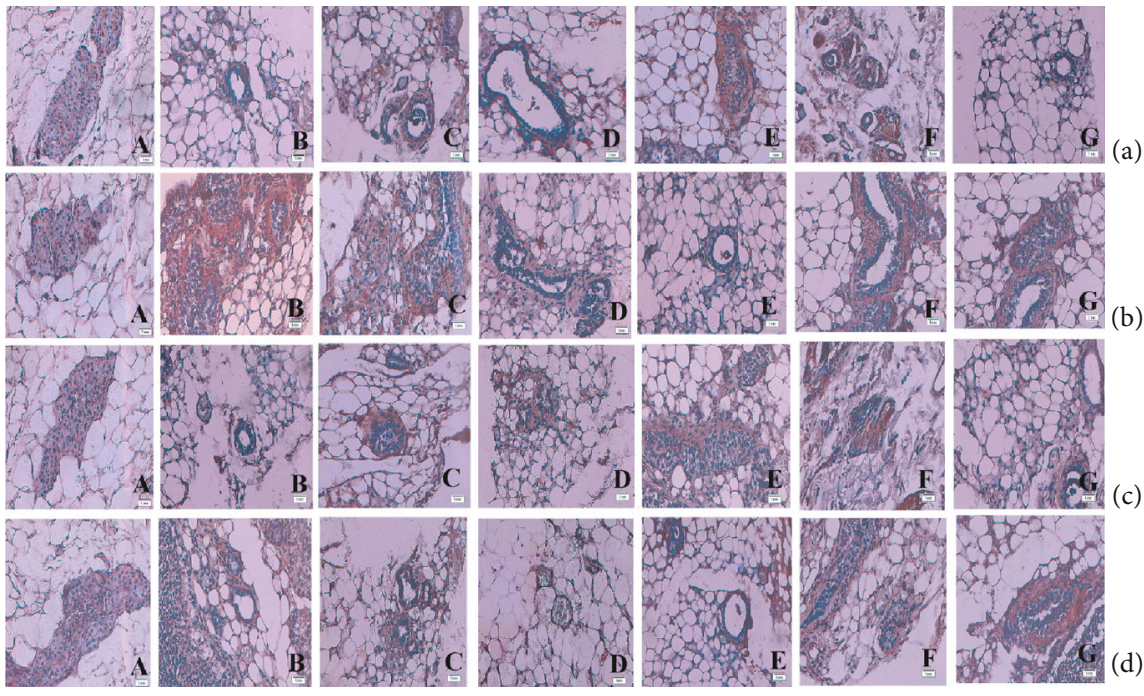

Figure 13: The immunohistochemical analysis of the (a) p53, (b) Bcl2, (c) Bax, and (d) MMP9 expressions in the mammary tissues of different groups of rats: (A) the normal control, (B) carcinogen control, (C) $25 \mathrm{mg} / \mathrm{kg}$ complex-treated rats, (D and E) 50 and $100 \mathrm{mg} / \mathrm{kg}$ complex-treated rats, (F) $50 \mathrm{mg} / \mathrm{kg}$ fluvastatin-treated animals, and (G) $50 \mathrm{mg} / \mathrm{kg}$ ruthenium-treated animals. All images at 40x.

Our findings showed that the unrestricted binding energy for the complex was low, thus promoting the binding direction of the compounds in the SNCG binding pocket circling the active site, resulting in enzyme inhibition. Since SNCG is one of the prominent markers in breast carcinoma, our binding studies denote that the novel complex could also modulate the SNCG proteins in breast carcinoma. In fact, our research included the synthesis and characterization of the complex. We utilized different spectroscopic evaluations to evaluate fluvastatin's antioxidant capacity pre- and postcomplex formation. Results confirm that the oxygen group $(=\mathrm{O})$ and hydroxyl group are responsible for the chelation and formation of the ruthenium-fluvastatin complex and that it is crystalline in nature. The analysis of antioxidant activity showed that the mechanism of free radical scavenging of fluvastatin on 
TABLE 7: Effect of ruthenium, fluvastatin, and the rutheniumfluvastatin complex on the expression of $\mathrm{Bax}, \mathrm{Bcl} 2, \mathrm{p} 53$, and MMP9 in breast tissues.

\begin{tabular}{lcccc}
\hline Groups & ${\mathrm{p} 53^{\S}}^{\S} \mathrm{Bcl}^{\S}$ & $\mathrm{Bax}^{\S}$ & $\mathrm{MMP9}^{\S}$ \\
\hline Control & $8.5 \pm 0.2$ & $7.1 \pm 0.7$ & $7.9 \pm 0.3$ & $8.3 \pm 0.1$ \\
DMBA & $3.2 \pm 0.8$ & $15.2 \pm 1.8$ & $3.5 \pm 0.7$ & $19.5 \pm 0.7$ \\
Ru-flu & $6.7 \pm 0.1$ & $12.6 \pm 0.3^{* *}$ & $4.1 \pm 0.8^{* *}$ & $15.5 \pm 0.2$ \\
$25 \mathrm{mg} / \mathrm{kg}$ & & & & \\
Ru-flu & $8.7 \pm 0.2^{* *}$ & $9.6 \pm 0.4^{* *}$ & $5.2 \pm 0.7^{*}$ & $12.7 \pm 0.8^{* *}$ \\
$50 \mathrm{mg} / \mathrm{kg}$ & & & & \\
Ru-flu & $9.3 \pm 0.9^{*}$ & $7.2 \pm 0.9^{*}$ & $8.3 \pm 1.6^{*}$ & $10.2 \pm 0.1^{*}$ \\
$75 \mathrm{mg} / \mathrm{kg}$ & & & & \\
Ru 50 mg/kg & $6.4 \pm 0.4$ & $10.2 \pm 0.5$ & $4.5 \pm 0.7$ & $14.7 \pm 0.2$ \\
Flu 50 mg/kg & $5.5 \pm 0.9$ & $11.7 \pm 1.2$ & $4.9 \pm 0.3$ & $16.4 \pm 1.6$ \\
\hline
\end{tabular}

${ }^{9}$ Each score represents the results of 6 slides per rat and 6 rats per group (mean \pm SE, $n=6$ ). Each field was selected randomly for evaluation of percentage of immune-positive cells. ${ }^{*}$ Significant difference between the treated groups and carcinogen control $(p<0.01) .{ }^{* *}$ Significant difference between the treated groups and carcinogen control $(p<0.05)$.

resultant metal complexation is greatly enhanced. Ruthenium thus promotes the modification of fluvastatin's oxidative ability after complexation by enhancing the transfer of electrons from fluvastatin and thus raising its redox potential. The complex's reaction towards CTDNA led to a reduction in the absorption spectra as compared to that of uncombined DNA, thus confirming that the complex binds through the intercalation mode with CT-DNA.

The next research section was devoted to evaluating the impact of the ruthenium-fluvastatin complex on the cancer cell lines MCF-7 and MDA-MB-231. The MTT assay showed that the ruthenium-fluvastatin complex can minimize cellular proliferation and promote apoptosis. One of major significant aspects of anticancer therapies is the modulation of the cell cycle; specifically, the inhibition of phases G1 and G2 plays a key role in the cell cycle cascade [75]. To determine the complex's mechanistic approach to the induction of apoptosis, flow cytometric experiments were employed that made use of annexin V and PI staining procedures. Furthermore, the results revealed that a higher percentage of early apoptotic events were identified on both MCF-7 and MDAMB-231 cancer cells by ruthenium-fluvastatin treatment, resulting in the arrest of the G0/G1 point, amounting to cellular death.

In addition, a cell-oriented reporter analysis was performed to identify the effects of complex treatment on the presence of PI3K-, Akt-, mTOR-, EGFR-, and VEGFassociated signaling trails. The PI3K/Akt/mTOR pathway is a cell signaling cascade associated with growth modulation, proliferation, reproduction, motility, metabolism, and immune response [76, 77]. The mammalian target of rapamycin (mTOR) strongly engages in various tumor progression processes by activating the signaling pathway PI3K/Akt [78]. Alterations are found in nearly all human tumors, especially with breast cancer, of which up to $60 \%$ of tumors represent unique configurations that acti- vate this cascade [79]. Dysregulation of this mechanism covers a wide variety of cancer symptoms including unchecked proliferation, genomic disturbance, and metabolic reconfiguring in tumor cells $[64,80]$. In fact, activation of the PI3K/Akt/mTOR pathway is one of the major causes of current cancer chemotherapy resistance [81]. It is aimed at making the PI3K/Akt/mTOR pathway a critical research target for understanding the development and progression of this disease, and the importance of this pathway as a potential therapeutic approach along with the prognostic and diagnostic value of this pathway in patients with breast cancer is undeniable [82, 83]. Thus, our studies denote that the ruthenium-fluvastatin complex significantly downregulates PI3K, Akt, and mTOR in both MCF-7 and MDA-MB-231 cells.

Apart from these, the growth factor of the epidermis and its receptors (EGFR) in breast cancer are continuously often overexpressed [84]. EGFR is a transmembrane tyrosine kinase receptor that regulates cell proliferation and epithelial cell viability via the $\mathrm{PI} 3 \mathrm{~K} / \mathrm{Akt} / \mathrm{mTOR}$ and protein kinase mitogen-activated (MAPK) signaling cascade [85]. The epidermal growth factor pathway serves as a primary mediator for breast cancer initiation and progression by encouraging the proliferation of cancer cells and their survival and promoting resistance to conventional therapy [86]. In cancer chemotherapeutics, epidermal growth factor receptors and their ligands are thoroughly studied due to their mutation and overexpression in a large segment of primary breast carcinomas [87-89]. Likewise, the growth regulation signaling cascade involving the vascular endothelial growth factor (VEGF) binds to the VEGF receptor 2 (VEGFR2) and activates tumor vasculature [90]. Therefore, the inhibition of the signaling pathways EGFR and VEGF is also a promising technique for cancer chemotherapy [91]. Our western blot findings provide definitive proof that the complex operates in both MCF7 and MDA-MB-231 cells via the EGFR and VEGF pathways by downregulation of their signals.

Apoptosis is a crucial and essential method of ideally programmed cell death that involves eliminating dysfunctional cells in mammalian development and retaining tissue homeostasis. Apoptotic activation has been considered an essential and effective cancer treatment approach [92]. In our current research, the DAPI staining approach used fluorescence microscopy in MCF7 and MDA-MB231 cells to explore modification of nuclear morphology. Treatment with the ruthenium-fluvastatin complex has shown condensed chromatin and scattered nuclei, which specifically demonstrate apoptosis induction in these cells. In breast cancer, in vitro studies have shown that dysregulated caspase activity is involved in chemotherapeutic resistance. One study demonstrated that restoration of caspase-3 expression, in caspase-3-deficient MCF-7 breast cancer cells, can sensitize to doxorubicin and etoposide-induced apoptosis, suggesting caspase-3 deficiency may be a possible mechanism for chemoresistance $[93,94]$. Our study is at par with previous literature denoting an increase in the caspase- 3 activity after drug treatment indicating that the complex is capable of 


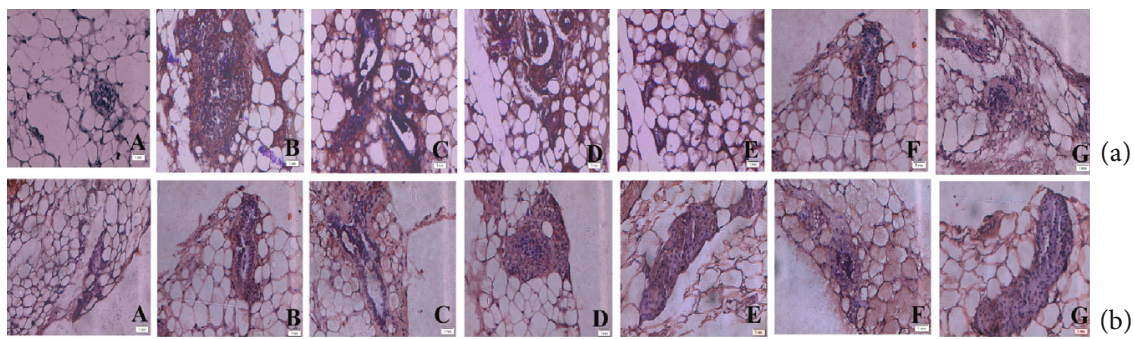

FIgURE 14: (a) The immunohistochemical analysis of expression of Ki-67 of different groups of rats: (A) the normal control, (B) carcinogen control, (C) $25 \mathrm{mg} / \mathrm{kg}$ complex-treated rats, (D and E) 50 and $100 \mathrm{mg} / \mathrm{kg}$ complex-treated rats, (F) $50 \mathrm{mg} / \mathrm{kg}$ fluvastatin-treated animals, and (G) $50 \mathrm{mg} / \mathrm{kg}$ ruthenium-treated animals. All images at 40x. (b) TUNEL assay of apoptotic cells: (A) the normal control, (B) carcinogen control, (C) $25 \mathrm{mg} / \mathrm{kg}$ complex-treated rats, (D and E) 50 and $100 \mathrm{mg} / \mathrm{kg}$ complex-treated rats, (F) $50 \mathrm{mg} / \mathrm{kg}$ fluvastatin-treated animals, and $(\mathrm{G}) 50 \mathrm{mg} / \mathrm{kg}$ ruthenium-treated animals. All images at $40 \mathrm{x}$.

TABLE 8: Cell proliferation and apoptosis in the breast.

\begin{tabular}{lccc}
\hline Groups & Ki-67-LI $^{\S}$ & $\mathrm{AI}(\%)^{\S}$ & $R=\mathrm{Ki}-67-\mathrm{LI} / \mathrm{AI}$ \\
\hline Normal control & $21.08 \pm 0.4$ & $0.16 \pm 0.02$ & $131.75 \pm 0.2$ \\
DMBA & $38.9 \pm 1.3$ & $0.07 \pm 0.02$ & $555.714 \pm 0.5$ \\
Ru-flu 25 mg/kg & $26.3 \pm 0.2$ & $0.09 \pm 0.05$ & $292.222 \pm 0.1$ \\
Ru-flu 50 mg/kg & $22.8 \pm 0.1^{* *}$ & $0.14 \pm 0.02^{\# \#}$ & $162.857 \pm 0.2^{\$ \$}$ \\
Ru-flu 75 mg/kg & $19.3 \pm 0.6^{*}$ & $0.16 \pm 0.03^{\#}$ & $120.625 \pm 0.9^{\$}$ \\
Ru 50 mg/kg & $24.8 \pm 0.1$ & $0.07 \pm 0.02$ & $354.245 \pm 0.4$ \\
Flu 50 mg/kg & $27.8 \pm 0.6$ & $0.11 \pm 0.04$ & $252.727 \pm 0.2$ \\
\hline
\end{tabular}

$\mathrm{LI}=$ labeling index; Ki-67-LI = percentage of PCNA-labeled cells/total number of cells counted; $\mathrm{AI}=$ apoptotic index. $R=$ PCNA-LI/AI. AI was calculated as the percentage of TUNEL-positive cells/total number of cells counted. Values represent mean $\pm \mathrm{SE}$. ${ }^{\mathrm{S}} \mathrm{A}$ total number of six slides were evaluated per rat. Each field consisted of approximately 500 cells. * Significant difference between Ki-67-LI of Ru-flu $75 \mathrm{mg} / \mathrm{kg}$ and carcinogen control animals $(p<0.01)$. ${ }^{* *}$ Significant difference between Ki-67-LI of Ru $50 \mathrm{mg} / \mathrm{kg}$, Ru-flu $50 \mathrm{mg} / \mathrm{kg}$, and carcinogen control animals $(p<0.05)$. "Significant difference between AI of Ru-flu $75 \mathrm{mg} / \mathrm{kg}$ and carcinogen control $(p<0.01)$. ${ }^{\# \#}$ Significant difference between AI of Ru $50 \mathrm{mg} / \mathrm{kg}, \mathrm{Ru}-$ flu $50 \mathrm{mg} / \mathrm{kg}$, and carcinogen control animals $(p<0.05)$. ${ }^{\$}$ Significant difference between $R$ of $\mathrm{Ru}$-flu $75 \mathrm{mg} / \mathrm{kg}$ and carcinogen control animals $(p<0.01) .{ }^{\$ \$}$ Significant difference between $\mathrm{R}$ of $\mathrm{Ru} 50 \mathrm{mg} / \mathrm{kg}$, Ru-flu $50 \mathrm{mg} / \mathrm{kg}$, and carcinogen control animals $(p<0.05)$.

modulating the caspase-3 expression owing to the increased amount of apoptotic events.

The global harmonized program for categorizing and marking chemicals involves the reporting of a safe dose for a novel anticancer molecule [95]. Therefore, an acute and subacute toxicological analysis was performed to determine the $\mathrm{LD}_{50}$ value and appropriate doses of the complex. The findings of our in vivo work further indicate that the ruthenium-fluvastatin complex functions through the escalation of the proteins caspase- 3 and p53 and also downregulates the expression of PI3K, Akt, mTOR, EGFR, and VEGF. Recent research is reportedly centered on the role of p53 in regulating the growth of cells induced by intense oncogenic signals or replicative stress [96]. p53 controls the function of large numbers of target genes related to cell cycle capture, DNA repair, senescence, and apoptosis when activated [97]. Contrary to other cells, cancer cells exhibit elevated mutation levels in the p53 gene. p53-dependent p21 upregulation induces misregulation of DNA replication and has been documented in active cancer cells [98]. Upregulation of p53 in tumors has been documented to cause senescence-induced tumor progression [99]. In addition, the activation of the prosurvival and antiapoptotic proteins causes the cancer cells to proliferate and survive. This mechanism facilitates tumor development and the progression of the disease. DNA damage modulates p53-based signals from a molecular point of view, which also contributes to proapoptotic stimuli [100, 101]. Proapoptotic proteins such as Bax disrupt the mitochondrial membranes and promote the release of cytochrome $c$ and other proapoptotic stimuli through the use of antiapoptotic proteins such as $\mathrm{Bcl} 2$ and $\mathrm{BclxL}$ [102]. Our western blot and immunohistochemical results revealed that expression of p53, caspase-3, and Bax was upregulated, while the role of $\mathrm{Bcl} 2$ proteins was downregulated, thus endorsing our hypothesis that the novel complex operates via the intrinsic apoptotic pathway Bax and $\mathrm{Bcl} 2$ supported by $\mathrm{p} 53$.

Consequently, MMP9, which belongs to a class of zincdependent endopeptidases, was downregulated with ruthenium-fluvastatin treatment. Some of the most frequently observed MMPs is MMP9, which plays a significant role in breast cancer tumor colonization, metastasis, and epithelial-to-mesenchymal transition [103]. Investigators studied the signatures of MMP9 in healthy and cancer breast tissue with various molecular subtypes [104] which showed a marked increase in the expression of MMP9 in cancer tissues relative to ordinary ones [105]. Additionally, it was discovered that MMP9 was differentially expressed within different molecular subtypes of breast cancer [104].

New findings suggest that two common features of tumors are alteration of the redox equilibrium and abolition of redox signals that are closely correlated with malignancy and drug resistance [106]. Therefore, it can be predicted that the upregulation of SOD, GSH, and CAT will contribute to a rise in $\mathrm{H}_{2} \mathrm{O}_{2}$ levels in the mitochondria, which is a major signaling molecule and a "reactive oxygen species" [107]. Several experiments have shown that mitochondrial $\mathrm{H}_{2} \mathrm{O}_{2}$ is a strong and efficient inducer of the apoptotic cycle [108]. Treatment with the ruthenium-fluvastatin complex substantially improved the production of SOD, CAT, and GSH in 


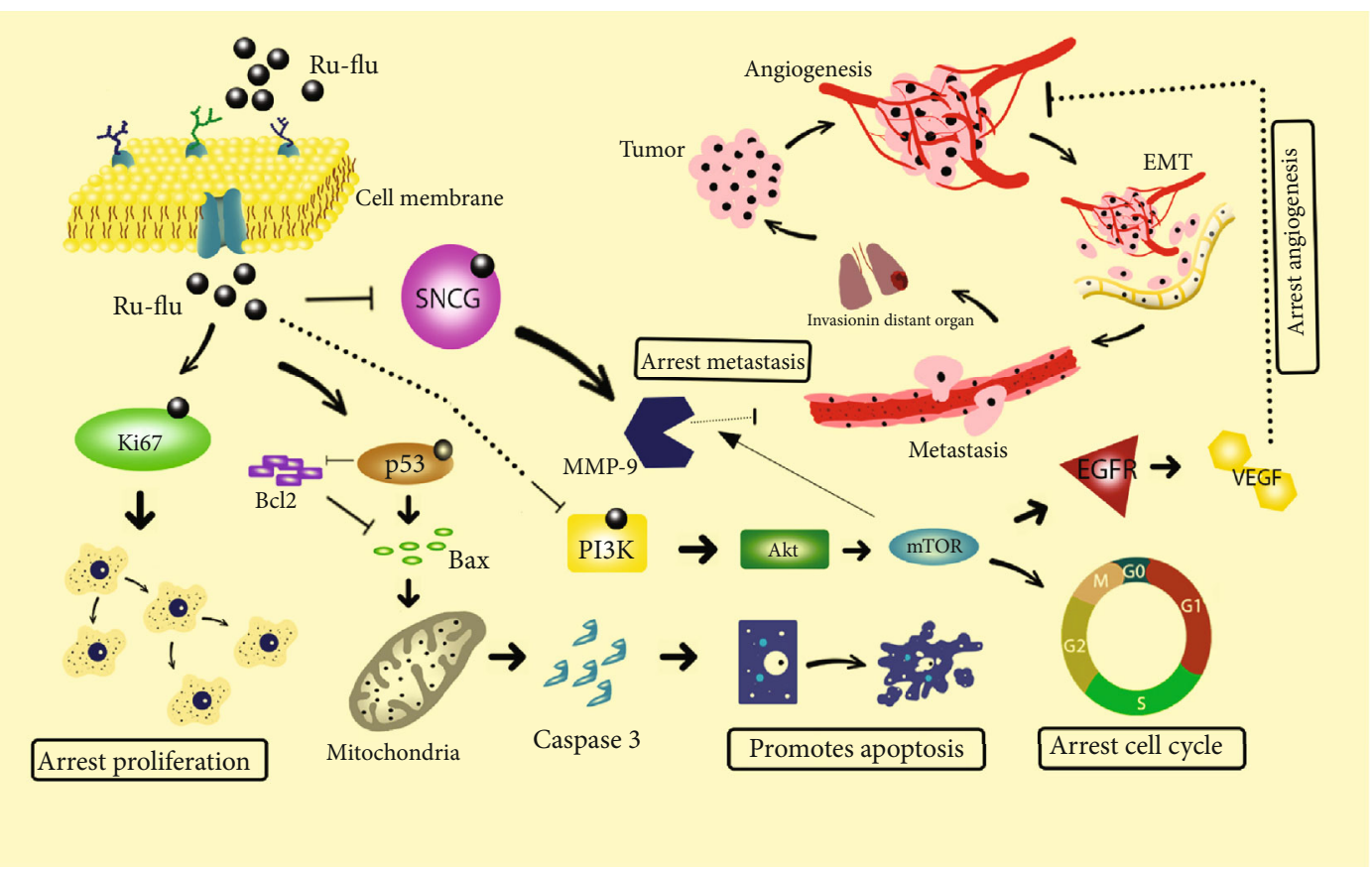

FIGURE 15: Probable molecular mechanistic pathway of the ruthenium-fluvastatin complex in the induction of apoptosis in breast cancer.

breast cancer, possibly through enabling ROS to induce apoptotic events.

Uncontrolled proliferation is a signature of tumors and can be analyzed using a variety of methods, including the counting of mitotic figures in stained tissue samples, the inclusion of labeled nucleotides in DNA, and the cytometric flow measurement of the percentage in the $S$ stage of a cell cycle [109]. Dowsett determined that an immunohistochemical test of the Ki-67 antigen was one of the most important approaches for quantifying proliferation [110]. Ki-67 is predominant in all cancer cells, and its role as a proliferation predictor is of great importance. The proliferation biomarker Ki-67 has also been regarded as a diagnostic biomarker for breast cancer in many studies $[111,112]$. Our analysis shows that the carcinogen control animals displayed a rise in the number of cells labeled with Ki-67 by decreasing AI, suggesting cell proliferation in the breast tissue. On the other hand, after treatment with the ruthenium-fluvastatin complex, a decrease in cells labeled with $\mathrm{Ki}-67$ and consequent rise in AI were observed.

In conclusion, the ruthenium-fluvastatin complex is accountable for p53 interfering apoptosis in breast carcinoma, facilitated by the intrinsic apoptotic path provoked by $\mathrm{Bcl} 2$ and $\mathrm{Bax}$ and simultaneously regulating the $\mathrm{PI} 3 \mathrm{~K} / \mathrm{Akt} / \mathrm{mTOR}$ pathway in conjunction with MMP9regulated invasive tumor pathways (Figure 15). Moreover, the complex reveals antiangiogenic functions by decreasing the EGFR and VEGF biomarkers as well. At the same time, the complex showed a high activity of its free radical scavenging potential in breast carcinoma cells caused by the release of reactive oxygen species extracted from mitochondrial through p53 regulation. The attenuation of Ki-67 coupled with stimulation of p53 further increases apoptosis attained by limiting cell proliferation. The observations offer ample proof that low doses of ruthenium-fluvastatin chemotherapy could interrupt, suspend, or delay breast carcinoma development by observing that the biomarkers correlated with the inhibition of apoptotic processes in breast carcinoma.

\section{Conclusions}

The current study concluded that the novel rutheniumfluvastatin complex is capable of downregulating SNCG expression associated with breast carcinoma cell line regulation by inhibiting cell proliferation and inducing apoptosis by triggering the cascade of PI3K/Akt/mTOR/VEGF/MMP9. In conjunction, the complex was able to alter p53 expressions to interfere with apoptosis in breast carcinoma, induced by the intrinsic apoptotic pathway facilitated by Bcl2 and Bax and associated with MMP9-regulated tumor pathways at the same time regulating the PI3K/Akt/mTOR/VEGF pathway. Our evidence found that chemotherapy with ruthenium-fluvastatin can inhibit, reverse, or impede the advancement of breast carcinoma by altering intrinsic apoptosis as well as the antiangiogenic sequence, thus assuming the potential future role of a potential contender in cancer therapy.

\section{Data Availability}

The information used to validate the results of this study is included within the paper.

\section{Disclosure}

The earlier presentation of the manuscript has been submitted as a preprint version. 


\section{Conflicts of Interest}

The authors declare that they have no competing interests.

\section{Acknowledgments}

The authors would like to thank the Department of Oncology, Nanjing First Hospital Nanjing Medical University, for their unending support. This work was supported by the National Natural Science Foundation of China (81702619) and Health Science and Technology Development Foundation of Nanjing (JQX18004).

\section{References}

[1] E. Bidoli, S. Virdone, M. Hamdi-Cherif et al., "Worldwide age at onset of female breast cancer: a 25-year population-based cancer registry study," Scientific Reports, vol. 9, no. 1, article 14111, 2019.

[2] L. Fan, P. E. Goss, and K. Strasser-Weippl, "Current status and future projections of breast cancer in Asia," Breast Care, vol. 10, no. 6, pp. 372-378, 2015.

[3] P. Wang, C. Xu, and C. Yu, "Age-period-cohort analysis on the cancer mortality in rural China: 1990-2010," International Journal for Equity in Health, vol. 13, no. 1, pp. 1-12, 2014.

[4] J. Stebbing, S. Slater, and M. Slevin, Breast cancer (metastatic), no. article 0811, 2007BMJ Clin Evid, 2007.

[5] V. Andresen and B. T. Gjertsen, "Drug repurposing for the treatment of acute myeloid leukemia," Frontiers in Medicine, vol. 4, p. 211, 2017.

[6] J. Foucquier and M. Guedj, "Analysis of drug combinations: current methodological landscape," Pharmacology Research \& Perspectives, vol. 3, no. 3, article e00149, 2015.

[7] J. J. Hernandez, M. Pryszlak, L. Smith et al., "Giving drugs a second chance: overcoming regulatory and financial hurdles in repurposing approved drugs as cancer therapeutics," Frontiers in Oncology, vol. 7, p. 273, 2017.

[8] D. Y. Lu, T. R. Lu, N. S. Yarla et al., "Drug combination in clinical cancer treatments," Reviews on Recent Clinical Trials, vol. 12, no. 3, pp. 202-211, 2017.

[9] R. B. Mokhtari, T. S. Homayouni, N. Baluch et al., "Combination therapy in combating cancer," Oncotarget, vol. 8, no. 23, pp. 38022-38043, 2017.

[10] C. Y. Wang, P. Y. Liu, and J. K. Liao, "Pleiotropic effects of statin therapy: molecular mechanisms and clinical results," Trends in Molecular Medicine, vol. 14, no. 1, pp. 37-44, 2008.

[11] Y. Ahmadi, A. Ghorbanihaghjo, and H. Argani, "The balance between induction and inhibition of mevalonate pathway regulates cancer suppression by statins: a review of molecular mechanisms," Chemico-Biological Interactions, vol. 273, pp. 273-285, 2017.

[12] J. A. Cauley, A. McTiernan, R. J. Rodabough et al., "Statin use and breast cancer: prospective results from the Women's Health Initiative," Journal of the National Cancer Institute, vol. 98, no. 10, pp. 700-707, 2006.

[13] T. P. Ahern, L. Pedersen, M. Tarp et al., "Statin prescriptions and breast cancer recurrence risk: a Danish nationwide prospective cohort study," Journal of the National Cancer Institute, vol. 103, no. 19, pp. 1461-1468, 2011.
[14] M.-F. Demierre, P. D. R. Higgins, S. B. Gruber, E. Hawk, and S. M. Lippman, "Statins and cancer prevention," Nature Reviews Cancer, vol. 5, no. 12, pp. 930-942, 2005.

[15] A. S. Kumar, C. C. Benz, V. Shim, C. A. Minami, D. H. Moore, and L. J. Esserman, "Estrogen receptor-negative breast cancer is less likely to arise among lipophilic statin users," Cancer Epidemiology, Biomarkers \& Prevention, vol. 17, no. 5, pp. 1028-1033, 2008.

[16] K. Hindler, C. S. Cleeland, E. Rivera, and C. D. Collard, "The role of statins in cancer therapy," The Oncologist, vol. 11, no. 3, pp. 306-315, 2006.

[17] F. Lakha, E. Theodoratou, S. M. Farrington et al., "Statin use and association with colorectal cancer survival and risk: case control study with prescription data linkage," BMC Cancer, vol. 12, no. 1, p. 487, 2012.

[18] H. F. Chiu, S. C. Ho, C. C. Chang, T. N. Wu, and C. Y. Yang, "Statins are associated with a reduced risk of gastric cancer: a population-based case-control study," The American Journal of Gastroenterology, vol. 106, no. 12, pp. 2098-2103, 2011.

[19] S. Vinayak and A. W. Kurian, "Statins may reduce breast cancer risk, particularly hormone receptor-negative disease," Current Breast Cancer Reports, vol. 1, no. 3, pp. 148-156, 2009.

[20] H. B. Serag, M. L. Johnson, C. Hachem, and R. O. Morgana, "Statins are associated with a reduced risk of hepatocellular carcinoma in a large cohort of patients with diabetes," Gastroenterology, vol. 136, no. 5, pp. 1601-1608, 2009.

[21] E. A. Platz, M. F. Leitzmann, K. Visvanathan et al., "Statin drugs and risk of advanced prostate cancer," Journal of the National Cancer Institute, vol. 98, no. 24, pp. 1819-1825, 2006.

[22] V. Khurana, H. R. Bejjanki, G. Caldito, and M. W. Owens, "Statins reduce the risk of lung cancer in humans: a large case-control study of US veterans," Chest, vol. 131, no. 5, pp. 1282-1288, 2007.

[23] M. C. Bradley, C. M. Hughes, M. M. Cantwell, and L. J. Murray, "Statins and pancreatic cancer risk: a nested case-control study," Cancer Causes \& Control, vol. 21, no. 12, pp. 20932100, 2010.

[24] A. Sławińska-Brych, B. Zdzisińska, and M. Kandefer-Szerszeń, "Fluvastatin inhibits growth and alters the malignant phenotype of the C6 glioma cell line," Pharmacological Reports, vol. 66, no. 1, pp. 121-129, 2014.

[25] A. K. Kanugula, V. M. Dhople, U. Völker, R. Ummanni, and S. Kotamraju, "Fluvastatin mediated breast cancer cell death: a proteomic approach to identify differentially regulated proteins in MDA-MB-231 cells," PLoS One, vol. 9, no. 9, article e108890, 2014.

[26] W. Zhang, J. Wu, L. Zhou, H. Y. Xie, and S. S. Zheng, "Fluvastatin, a lipophilic statin, induces apoptosis in human hepatocellular carcinoma cells through mitochondria-operated pathway," Indian Journal of Experimental Biology, vol. 48, no. 12, pp. 1167-1174, 2010.

[27] H. Gbelcová, M. Leníček, J. Zelenka et al., "Differences in antitumor effects of various statins on human pancreatic cancer," International Journal of Cancer, vol. 122, no. 6, pp. 1214-1221, 2008.

[28] A. Bergamo and G. Sava, "Ruthenium anticancer compounds: myths and realities of the emerging metal-based drugs," Dalton Transactions, vol. 40, no. 31, pp. 7817-7823, 2011.

[29] E. Alessio, "Thirty years of the drug candidate NAMI-A and the myths in the field of ruthenium anticancer compounds: a 
personal perspective," European Journal of Inorganic Chemistry, vol. 12, pp. 1549-1560, 2017.

[30] C. A. Vock, W. H. Ang, C. Scolaro et al., "Development of ruthenium antitumor drugs that overcome multidrug resistance mechanisms," Journal of Medicinal Chemistry, vol. 50, no. 9, pp. 2166-2175, 2007.

[31] R. H. Berndsen, A. Weiss, U. K. Abdul et al., "Combination of ruthenium(II)-arene complex $\left[\mathrm{Ru}\left(\eta^{6}-p\right.\right.$-cymene $\left.) \mathrm{Cl}_{2}(\mathrm{pta})\right]$ (RAPTA-C) and the epidermal growth factor receptor inhibitor erlotinib results in efficient angiostatic and antitumor activity," Scientific Reports, vol. 7, no. 1, p. 43005, 2017.

[32] E. Alessio and L. Messori, "NAMI-A and KP1019/1339, two iconic ruthenium anticancer drug candidates face-to-face: a case story in medicinal inorganic chemistry," Molecules, vol. 24, no. 10, p. 1995, 2019.

[33] J. Zhang, X.-h. Liu, C. Li et al., "SNCG promotes the progression and metastasis of high-grade serous ovarian cancer via targeting the PI3K/AKT signaling pathway," Journal of Experimental \& Clinical Cancer Research, vol. 39, no. 1, p. 79, 2020.

[34] T. Jia, Y. E. Liu, J. Liu, and Y. E. Shi, "Stimulation of breast cancer invasion and metastasis by synuclein gamma," Cancer Research, vol. 59, no. 3, pp. 742-747, 1999.

[35] W. Bruening, B. I. Giasson, A. J. P. Klein-Szanto, V. M.-Y. Lee, J. Q. Trojanowski, and A. K. Godwin, "Synucleins are expressed in the majority of breast and ovarian carcinomas and in preneoplastic lesions of the ovary," Cancer, vol. 88, no. 9, pp. 2154-2163, 2000.

[36] Y. Jiang, Y. E. Liu, A. Lu et al., "Stimulation of estrogen receptor signaling by gamma synuclein," Cancer Research, vol. 63, no. 14, pp. 3899-3903, 2003.

[37] S. Inaba, C. Li, Y. E. Shi, D. Q. Song, J. D. Jiang, and J. Liu, "Synuclein gamma inhibits the mitotic checkpoint function and promotes chromosomal instability of breast cancer cells," Breast Cancer Research and Treatment, vol. 94, no. 1, pp. 2535, 2005.

[38] F. Parmar, C. Patel, H. Highland, H. Pandya, and L. B. George, "Antiproliferative efficacy of kaempferol on cultured Daudi cells: an in silico and in vitro study," Advances in Biology, vol. 2016, Article ID 9521756, 10 pages, 2016.

[39] S. Zhang, K. Kumar, X. Jiang, A. Wallqvist, and J. Reifman, "DOVIS: an implementation for high-throughput virtual screening using AutoDock," BMC Bioinformatics, vol. 9, no. 1, p. 126, 2008.

[40] M. Parton, M. Dowsett, and I. Smith, "Studies of apoptosis in breast cancer," BMJ, vol. 322, no. 7301, pp. 1528-1532, 2001.

[41] R. S. Ray, S. Roy, S. Ghosh, M. Kumar, and M. Chatterjee, "Suppression of cell proliferation, DNA protein cross-links, and induction of apoptosis by vanadium in chemical rat mammary carcinogenesis," Biochimica et Biophysica Acta, vol. 1675, no. 1-3, pp. 165-173, 2004.

[42] C. Binder, D. Marx, L. Binder, A. Schauer, and W. Hiddemann, "Expression of Bax in relation to Bcl-2 and other predictive parameters in breast cancer," Annals of Oncology, vol. 7, no. 2, pp. 129-133, 1996.

[43] S. Krajewski, A. D. Thor, S. M. Edgerton, Moore DH 2nd, M. Krajewska, and J. C. Reed, "Analysis of Bax and Bcl-2 expression in p53-immunopositive breast cancers," Clinical Cancer Research, vol. 3, no. 2, pp. 199-208, 1997.

[44] M. Xin and X. Deng, "Nicotine inactivation of the proapoptotic function of Bax through phosphorylation," The Journal of Biological Chemistry, vol. 280, no. 11, pp. 10781-10789, 2005.
[45] A. Bayramoglu, H. V. Gunes, M. Metintas, I. Değirmenci, F. Mutlu, and F. Alataş, "The association of MMP-9 enzyme activity, MMP-9 C1562T polymorphism, and MMP-2 and -9 and TIMP-1, - 2, -3, and -4 gene expression in lung cancer," Genetic Testing and Molecular Biomarkers, vol. 13, no. 5, pp. 671-678, 2009.

[46] R. S. Ray, B. Ghosh, A. Rana, and M. Chatterjee, "Suppression of cell proliferation, induction of apoptosis and cell cycle arrest: chemopreventive activity of vanadiumin vivo andin vitro," International Journal of Cancer, vol. 120, no. 1, pp. 13-23, 2007.

[47] C. Anbuselvam, K. Vijayavel, and M. P. Balasubramanian, "Protective effect of Operculina turpethum against 7,12dimethyl benz(a)anthracene induced oxidative stress with reference to breast cancer in experimental rats," ChemicoBiological Interactions, vol. 168, no. 3, pp. 229-236, 2007.

[48] C. A. Davison, S. M. Durbin, M. R. Thau et al., "Antioxidant enzymes mediate survival of breast cancer cells deprived of extracellular matrix," Cancer Research, vol. 73, no. 12, pp. 3704-3715, 2013.

[49] R. Padmavathi, P. Senthilnathan, D. Chodon, and D. Sakthisekaran, "Therapeutic effect of paclitaxel and propolis on lipid peroxidation and antioxidant system in 7,12 dimethyl benz $(a)$ anthracene-induced breast cancer in female Sprague Dawley rats," Life Sciences, vol. 78, no. 24, pp. 2820 2825, 2006.

[50] B. Vurusaner, G. Poli, and H. Basaga, "Tumor suppressor genes and ROS: complex networks of interactions," Free Radic Biologie et Médecine, vol. 52, no. 1, pp. 7-18, 2012.

[51] G. L. Semenza, "Hypoxia-inducible factors: coupling glucose metabolism and redox regulation with induction of the breast cancer stem cell phenotype," The EMBO Journal, vol. 36, no. 3, pp. 252-259, 2017.

[52] Y. Y. Lim and E. P. L. Quah, "Antioxidant properties of different cultivars of Portulaca oleracea," Food Chemistry, vol. 103, no. 3, pp. 734-740, 2007.

[53] I. F. Benzie and J. J. Strain, "The ferric reducing ability of plasma (FRAP) as a measure of "antioxidant power": the FRAP assay," Analytical Biochemistry, vol. 239, no. 1, pp. 70-76, 1996.

[54] S. P. Griffin and R. Bhagooli, "Measuring antioxidant potential in corals using the FRAP assay," Journal of Experimental Marine Biology and Ecology, vol. 302, no. 2, pp. 201-211, 2004.

[55] J. C. Pennycooke, S. E. Cox, and C. Stushnoff, "Relationship of cold acclimation, total phenolic content and antioxidant capacity with chilling tolerance in petunia (Petunia $\times$ hybrida)," Environmental and Experimental Botany, vol. 53, no. 2, pp. 225-232, 2005.

[56] G. Dehghan, J. E. N. Dolatabadi, A. Jouyban, K. A. Zeynali, S. M. Ahmadi, and S. Kashanian, "Spectroscopic studies on the interaction of quercetin-terbium(III) complex with calf thymus DNA," DNA and Cell Biology, vol. 30, no. 3, pp. 195-201, 2011.

[57] H. Li, Q. Wang, L. Dong et al., "Morusin suppresses breast cancer cell growth in vitro and in vivo through C/EBP $\beta$ and PPAR $\gamma$ mediated lipoapoptosis," Journal of Experimental \& Clinical Cancer Research, vol. 34, no. 1, p. 137, 2015.

[58] X. H. Deng, H. Y. Song, Y. F. Zhou, G. Y. Yuan, and F. J. Zheng, "Effects of quercetin on the proliferation of breast cancer cells and expression of survivin in vitro," Experimental and Therapeutic Medicine, vol. 6, no. 5, pp. 1155-1158, 2013. 
[59] S. Roy, S. Majumdar, A. K. Singh et al., "Synthesis, characterization, antioxidant status, and toxicity study of vanadiumrutin complex in Balb/c mice," Biological Trace Element Research, vol. 166, no. 2, pp. 183-200, 2015.

[60] B. B. P. Sinha, G. A. Peterson, G. C. Li, and R. R. Whitney, "Nuclear charge distributions of isotone pairs. I. P31 and S32," Physical Review C, vol. 6, no. 5, pp. 1657-1663, 1972.

[61] S. Awasthi, P. Kakkar, P. N. Viswanathan, and R. Bharadwaj, "Effect of anaesthetic ether on lipid peroxidation and superoxide dismutase isozymes of young and adult rat brain," Indian Journal of Experimental Biology, vol. 27, no. 7, pp. 647-649, 1989.

[62] J. T. Rotruck, A. L. Pope, H. E. Ganther, A. B. Swanson, D. G. Hafeman, and W. G. Hoekstra, "Selenium: biochemical role as a component of glutathione peroxidase," Science, vol. 179, no. 4073, pp. 588-590, 1973.

[63] R. S. Ray, B. Ghosh, A. Rana, and M. Chatterjee, "Suppression of cell proliferation, induction of apoptosis and cell cycle arrest: chemopreventive activity of vanadiums in vivo and in vitro," International Journal of Cancer, vol. 120, no. 1, pp. 13-23, 2007.

[64] D. Hanahan and R. A. Weinberg, "Hallmarks of cancer: the next generation," Cell, vol. 144, no. 5, pp. 646-674, 2011.

[65] C. S. Allardyce and P. J. Dyson, "Ruthenium in medicine: current clinical uses and future prospect," Platinum Metals Review, vol. 45, pp. 62-69, 2001.

[66] R. Santamaria, C. Irace, G. D’Ericco, D. Montesarchio, and L. Paduano, "Perspectives and potential application of ruthenium based nano-carriers for cancer therapy," Journal of Pharmaceutics and Drug Development, vol. 1, no. 2, pp. 1-4, 2013.

[67] R. S. Y. Wong, “Apoptosis in cancer: from pathogenesis to treatment," Journal of Experimental \& Clinical Cancer Research, vol. 30, no. 1, p. 87, 2011.

[68] A. F. Hassanabad, "Current perspectives on statins as potential anti-cancer therapeutics: clinical outcomes and underlying molecular mechanisms," Translational Lung Cancer Research, vol. 8, no. 5, pp. 692-699, 2019.

[69] P. Gazzerro, M. C. Proto, G. Gangemi et al., "Pharmacological actions of statins: a critical appraisal in the management of cancer," Pharmacological Reviews, vol. 64, no. 1, pp. 102146, 2012.

[70] M. Paškevičiūtè and V. Petrikaite, "Differences of statin activity in 2D and 3D pancreatic cancer cell cultures," Drug Design, Development and Therapy, vol. 11, pp. 3273-3280, 2017.

[71] W. W.-L. Wong, J. W. Clendening, A. Martirosyan et al., "Determinants of sensitivity to lovastatin-induced apoptosis in multiple myeloma," Molecular Cancer Therapeutics, vol. 6, no. 6, pp. 1886-1897, 2007.

[72] C. Vaklavas, Y. S. Chatzizisis, and A. M. Tsimberidou, "Common cardiovascular medications in cancer therapeutics," Pharmacology \& Therapeutics, vol. 130, no. 2, pp. 177-190, 2011.

[73] J. M. George, "The synucleins," in Genome Biology, vol. 3, no. 1, article reviews3002, 2002BMC, 2002.

[74] V. K. Singh, Y. Zhou, J. A. Marsh et al., "Synuclein- $\gamma$ targeting peptide inhibitor that enhances sensitivity of breast cancer cells to antimicrotubule drugs," Cancer Research, vol. 67, no. 2, pp. 626-633, 2007.

[75] T. Muthurajan, P. Rammanohar, N. P. Rajendran, S. Sethuraman, and U. M. Krishnan, "Evaluation of a querce- tin-gadolinium complex as an efficient positive contrast enhancer for magnetic resonance imaging," RSC Advances, vol. 5, no. 106, pp. 86967-86979, 2015.

[76] A. G. Zotano, I. A. Mayerm, and C. L. Arteaga, "PI3K/AKT/mTOR: role in breast cancer progression, drug resistance, and treatment," Cancer Metastasis Reviews, vol. 35, no. 4, pp. 515-524, 2016.

[77] D. A. Fruman, H. Chiu, B. D. Hopkins, S. Bagrodia, L. C. Cantley, and R. T. Abraham, "The PI3K pathway in human disease," Cell, vol. 170, no. 4, pp. 605-635, 2017.

[78] M. D. Laplante and M. Sabatini, "mTOR signaling in growth control and disease," Cell, vol. 149, no. 2, pp. 274-293, 2012.

[79] J. A. Engelman, "Targeting PI3K signalling in cancer: opportunities, challenges and limitations," Nature Reviews. Cancer, vol. 9, no. 8, pp. 550-562, 2009.

[80] E. C. Lien, C. C. Dibble, and A. Toker, "PI3K signaling in cancer: beyond AKT," Current Opinion in Cell Biology, vol. 45, pp. 62-71, 2017.

[81] M. Martini, M. C. D. Santis, L. Braccini, F. Gulluni, and E. Hirsch, "PI3K/AKT signaling pathway and cancer: an updated review," Annals of Medicine, vol. 46, no. 6, pp. 372-383, 2014.

[82] D. A. Fruman and C. Romme, "PI3K and cancer: Lessons, challenges and opportunities," Nature Reviews Drug Discovery, vol. 13, no. 2, pp. 140-156, 2014.

[83] N. M. Davis, M. Sokolosky, K. Stadelman et al., "Deregulation of the EGFR/PI3K/PTEN/Akt/mTORC1 pathway in breast cancer: possibilities for therapeutic intervention," Oncotarget, vol. 5, no. 13, pp. 4603-4650, 2014.

[84] S. Balakrishnan, S. Mukherjee, S. Das et al., "Gold nanoparticles-conjugated quercetin induces apoptosis via inhibition of EGFR/PI3K/Akt-mediated pathway in breast cancer cell lines (MCF-7 and MDA-MB-231)," Cell Biochemistry and Function, vol. 35, no. 4, pp. 217-231, 2017.

[85] T. Mitsudomi and Y. Yatabe, "Epidermal growth factor receptor in relation to tumor development: EGFR gene and cancer," The FEBS Journal, vol. 277, no. 2, pp. 301-308, 2010.

[86] L. Huang, C. C. Wong, G. G. Mackenzie et al., "Phosphoaspirin (MDC-22) inhibits breast cancer in preclinical animal models: an effect mediated by EGFR inhibition, p53 acetylation and oxidative stress," BMC Cancer, vol. 14, no. 1, p. 141, 2014.

[87] T. D. Schladt, K. Schneider, H. Schild, and W. Tremel, "Synthesis and bio-functionalization of magnetic nanoparticles for medical diagnosis and treatment," Dalton Transactions, vol. 40, no. 24, pp. 6315-6343, 2011.

[88] Y. Ding, J. Liu, H. Wang, G. Shen, and R. Yu, “A piezoelectric immunosensor for the detection of $\alpha$-fetoprotein using an interface of gold/hydroxyapatite hybrid nanomaterial," Biomaterials, vol. 28, no. 12, pp. 2147-2154, 2007.

[89] R. A. Sperling, P. R. Gil, F. Zhang, M. Zanella, and W. J. Parak, "Biological applications of gold nanoparticles," Chemical Society Reviews, vol. 37, no. 9, pp. 1896-1908, 2008.

[90] N. Ferrara and K. Alitalo, "Clinical applications of angiogenic growth factors and their inhibitors," Nature Medicine, vol. 5, no. 12, pp. 1359-1364, 1999.

[91] B. N. P. Kumar, N. Puvvada, S. Rajput et al., "Targeting of EGFR, VEGFR2, and Akt by engineered dual drug encapsulated mesoporous silica-gold nanoclusters sensitizes tamoxifen-resistant breast cancer," Molecular Pharmaceutics, vol. 15, no. 7, pp. 2698-2713, 2018. 
[92] M. Hassan, H. Watari, A. Abu Almaaty, Y. Ohba, and N. Sakuragi, "Apoptosis and molecular targeting therapy in cancer," BioMed Research International, vol. 2014, Article ID 150845, 1 pages, 2014.

[93] X.-H. Yang, T. L. Sladek, X. Liu, B. R. Butler, C. J. Froelich, and A. D. Thor, "Reconstitution of caspase 3 sensitizes MCF-7 breast cancer cells to doxorubicin-and etoposideinduced apoptosis," Cancer Research, vol. 61, no. 1, pp. 348-354, 2001.

[94] E. Devarajan, A. A. Sahin, J. S. Chen et al., "Down-regulation of caspase 3 in breast cancer: a possible mechanism for chemoresistance," Oncogene, vol. 21, no. 57, pp. 8843-8851, 2002.

[95] M. Hajrezaie, P. Hassandarvish, S. Z. Moghadamtousi et al., "Chemopreventive evaluation of a Schiff base derived copper (II) complex against azoxymethane-induced colorectal cancer in rats," PLoS One, vol. 9, no. 3, article e91246, 2014.

[96] E. R. Kastenhuber and S. W. Lowe, "Putting p53 in context," Cell, vol. 170, no. 6, pp. 1062-1078, 2017.

[97] M. Fischer, "Census and evaluation of p53 target genes," Oncogene, vol. 36, no. 28, pp. 3943-3956, 2017.

[98] K. Hientz, A. Mohr, D. B. Guha, and T. Efferth, "The role of p53 in cancer drug resistance and targeted chemotherapy," Oncotarget, vol. 8, no. 5, pp. 8921-8946, 2017.

[99] A. Ventura, D. G. Kirsch, M. E. McLaughlin et al., "Restoration of p53 function leads to tumour regression in vivo," Nature, vol. 445, no. 7128, pp. 661-665, 2007.

[100] T. Miyashita and J. C. Reed, "Tumor-suppressor P 53 is a direct transcriptional activator of the human Bax gene," Cell, vol. 80, pp. 293-299, 1995.

[101] P. Jiang, W. J. Du, K. Heese, and M. Wu, "The bad guy cooperates with good cop p53: Bad is transcriptionally upregulated by $\mathrm{p} 53$ and forms a Bad/p53 complex at the mitochondria to induce apoptosis," Molecular and Cellular Biology, vol. 26, no. 23, pp. 9071-9082, 2006.

[102] G. H. Nam, K. J. Jo, Y. S. Park, H. W. Kawk, S. Y. Kim, and Y. M. Kim, "In vitro and in vivo induction of p53dependent apoptosis by extract of Euryale ferox Salisb in A549 human Caucasian lung carcinoma cancer cells is mediated through Akt signaling pathway," Frontiers in Oncology, vol. 9, p. 406, 2019.

[103] M. Balduyck, F. Zerimech, V. Gouyer et al., "Specific expression of matrix metalloproteinases 1, 3, 9 and 13 associated with invasiveness of breast cancer cells in vitro," Clinical \& Experimental Metastasis, vol. 18, no. 2, pp. 171-178, 2000.

[104] E. M. Yousef, M. R. Tahirm, Y. St-Pierre, and L. A. Gaboury, "MMP-9 expression varies according to molecular subtypes of breast cancer," BMC Cancer, vol. 14, no. 1, p. 609, 2014.

[105] D. Cao, K. Polyak, M. K. Halushka et al., "Serial analysis of gene expression of lobular carcinoma in situ identifies down regulation of claudin 4 and overexpression of matrix metalloproteinase 9," Breast Cancer Research, vol. 10, no. 5, article R91, 2008.

[106] E. Panieri and M. M. Santoro, "ROS homeostasis and metabolism: a dangerous liason in cancer cells," Cell Death \& Disease, vol. 7, no. 6, article e2253, 2016.

[107] M. Giorgio, M. Trinei, E. Migliaccio, and P. G. Pelicci, "Hydrogen peroxide: a metabolic by-product or a common mediator of ageing signals?," Nature Reviews. Molecular Cell Biology, vol. 8, no. 9, pp. 722-728, 2007.
[108] M. A. Khan, H. C. Chen, X. X. Wan et al., "Regulatory effects of resveratrol on antioxidant enzymes: a mechanism of growth inhibition and apoptosis induction in cancer cells," Molecules and Cells, vol. 35, no. 3, pp. 219-225, 2013.

[109] C. Suciu, A. Muresan, R. Cornea, O. Suciu, A. Dema, and M. Raica, "Semi-automated evaluation of Ki-67 index in invasive ductal carcinoma of the breast," Oncology Letters, vol. 7, no. 1, pp. 107-114, 2014.

[110] M. Dowsett, T. O. Nielsen, R. A'Hern et al., “Assessment of Ki67 in breast cancer: recommendations from the international Ki67 in breast cancer working group," Journal of the National Cancer Institute, vol. 103, no. 22, pp. 1656-1664, 2011.

[111] R. Yerushalmi, R. Woods, P. M. Ravdin, M. M. Hayes, and K. A. Gelmon, "Ki67 in breast cancer: prognostic and predictive potential," The Lancet Oncology, vol. 11, no. 2, pp. 174$183,2010$.

[112] E. de Azambuja, F. Cardoso, G. de Castro et al., "Ki-67 as prognostic marker in early breast cancer: a meta-analysis of published studies involving 12,155 patients," British Journal of Cancer, vol. 96, no. 10, pp. 1504-1513, 2007. 